\title{
Validação de padrões de web services transacionais
}

\author{
Paulo Roberto de Araújo França Nunes
}

\author{
DISSERTAÇÃO APRESENTADA \\ AO \\ Instituto De Matemática e Estatística \\ DA \\ Universidade DE SÃo PAUlo \\ PARA \\ OBTEnÇÃo DO Título \\ DE \\ Mestre em CiÊnCIAS
}

\author{
Programa: Ciência da Computação \\ Orientador: Profa. Dra. Ana Cristina Vieira de Melo
}

Durante o desenvolvimento deste trabalho o autor recebeu apoio financeiro da Serasa Experian 



\section{Validação de padrões de web services transacionais}

Esta dissertação contém as correções e alterações sugeridas pela Comissão Julgadora durante a defesa realizada por Paulo Roberto de Araújo França Nunes em 03/06/2011. O original encontra-se disponível no Instituto de Matemática

e Estatística da Universidade de São Paulo.

Comissão Julgadora:

- Profa. Dra. Ana Cristina Vieira de Melo (orientadora) - IME-USP

- Prof. Dr. Francisco Carlos da Rocha Reverbel - IME-USP

- Profa. Dra. Eliane Martins - Unicamp 


\section{Agradecimentos}

Durante todo o período em que estive desenvolvendo este trabalho, pude contar com auxílio, apoio, incentivo, enfim, todo tipo de contribuição. Sem dúvida, por mais simples que pareça, cada gesto de alguma forma ajudou a concluir esta pesquisa.

A lista de agradecimento é grande. Inicio agradecendo à Serasa Experian, pela apoio necessário para conduzir a pesquisa. À Eliana Otoni, pelo apoio dado durante todo o programa de bolsa. Aos membros do time de arquitetura que forneceram contribuições e sugestões no decorrer do estudo. À Ana Milani, gerente da equipe de Teste e Homologação, que sempre incentivou e acreditou na pesquisa, desde o seu início. Ao Helio Mariano, gerente da equipe de Análise de Negócios, que também incentivou a pesquisa desde o início. Ao Carlos Cândido, Gustavo Tadao, Glauco Reis e aos demais integrantes do Centro SOA. E a todos que de alguma forma contribuíram com o trabalho.

Agradeço também à Universidade de São Paulo. À professora orientadora Ana Cristina, por suas valiosas dicas. À Simone Hanazumi, colega de mestrado, que também contribuiu para a realização da pesquisa. Também quero agradecer ao Paulo Silveira por suas contribuições.

E tudo isso, sem o apoio fundamental da família, não seria possível. Assim, agradeço à minha amada esposa Michele Lima, pelo suporte e incentivo. Também aos meus pais Antonio e Maria e ao meu irmão Junior, pelo incentivo e pela paciência.

Agradeço principalmente ao Pai. "Porque és a minha ajuda, canto de alegria à sombra das tuas asas" (S1 63:7). 


\section{Resumo}

A velocidade das mudanças e a necessidade de informações disponíveis em vários meios têm feito com que os sistemas atuais se integrem cada vez mais. Neste cenário, arquiteturas orientadas a serviços e Web Services ganham evidência. Por utilizarem padrões já bem difundidos, por exemplo XML (extended markup language), Web Services se destacam pela interoperabilidade e dinamismo, disponibilizados através da Internet e utilizado em ambientes heterogêneos. Contudo, isso afeta significativamente atributos não funcionais, por exemplo, confiabilidade, disponibilidade, entre outros. Para Web Services, além de todos os problemas existentes no paradigma de programação distribuída, temos ainda o problema de que erros em um determinado serviço não devem ser propagados para os demais. Dentre as diversas formas de se contornar o problema, existe a definição de padrões transacionais que visam delinear regras específicas para a comunicação entre os serviços. O objetivo do trabalho é identificar casos de testes que permitam validar a adequação, tanto do serviço quanto da aplicação de padrões definidos, de modo a garantir uma maior confiabilidade do sistema como um todo. Para isso, é avaliada a aplicabilidade de técnicas de pertubação e mutação de dados com relação ao padrão estabelecido. Como resultado, obtém-se um subconjunto das técnicas que possuem potencial de identificação de falhas nesse cenário.

Palavras-chave: Web Services, Confiabilidade, Testes, SOA. 


\section{Abstract}

Software technology has become essential since it is available in most places. Powered by Internet, nowadays, information quickly flows throw systems. Web Services provide a standard way to meet these objectives, as they use common comunication pattern like XML and HTTP. The use of Web Services brings many benefits. On the other hand, it also brings some issues about reliablity, availability and other non funcional problems. Transactional patterns are an alternative to outline such problems. This study aims to find a effective way to certificate the correct use of those patterns by applying perturbation and mutation testing techniques. As work result, it is expected to determine which of techniques are applicable.

Keywords: Web Services, Reliablility, Testing, SOA. 


\section{Sumário}

$\begin{array}{ll}\text { Lista de Figuras } & \text { ix }\end{array}$

Lista de Tabelas $\quad$ xi

1 Introdução $\quad 1$

1.1 Web Services e suas Características . . . . . . . . . . . . . . . . . . 2

1.2 Motivação . . . . . . . . . . . . . . . . . . . . 3

1.3 Iniciativas para solução dos problemas . . . . . . . . . . . . . . . 6

1.3 .1 Definição de padrões . . . . . . . . . . . . . . . . . . . . . 6

1.3.2 Testes de Web Services . . . . . . . . . . . . . . . . . . 8

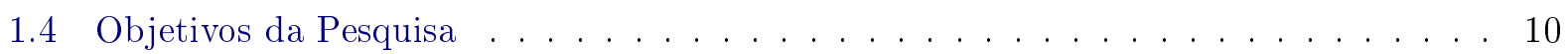

1.5 Organização do Trabalho . . . . . . . . . . . . . . . . . . . . . 10

2 Web Services $\quad 11$

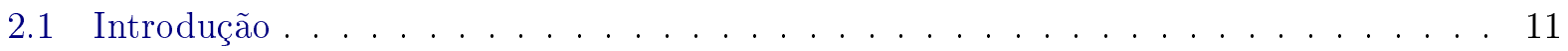

2.2 SOA - Arquitetura Orientada a Serviços . . . . . . . . . . . . . . . . . . . . . . . . . . . . . . .

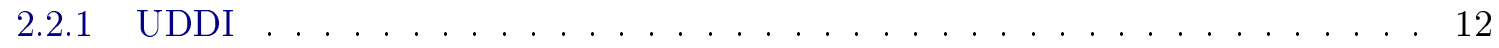

2.2 .2 Modelagem de Serviços e WS-BPEL . . . . . . . . . . . . . . . . . 13

2.3 Conceitos e Definições . . . . . . . . . . . . . . . . . . . . . 16

2.3.1 Web Service como Tecnologia . . . . . . . . . . . . . . . . 17

2.3 .2 Web Service como Solução de Negócios . . . . . . . . . . . . . . . . . 18

2.3 .3 Interoperabilidade . . . . . . . . . . . . . . . . . . . . . 18

2.3 .4 Tipos de Serviços . . . . . . . . . . . . . . . . . . . 18

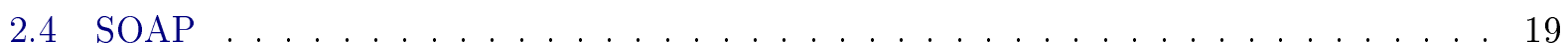

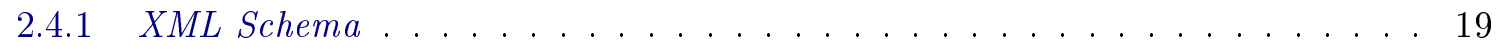

2.4 .2 Mensagens SOAP e Estilo de codificação SOAP . . . . . . . . . . . . . . 20

2.4 .3 Mensagem de falha SOAP . . . . . . . . . . . . . . . . 21

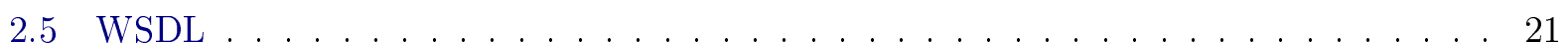

2.6 Aplicação Exemplo . . . . . . . . . . . . . . . . . . . . . . . . . 22

2.7 Qualidade de Web Services. . . . . . . . . . . . . . . . . . 25

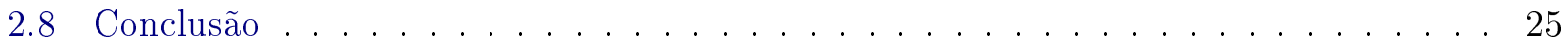

3 Teste de Web Services $\quad 27$

3.1 Introdução . . . . . . . . . . . . . . . . . . . . . . 27

3.2 Testes de Software . . . . . . . . . . . . . . . . . . . . 27 
3.2 .1 Verificação e Validação . . . . . . . . . . . . . . . . . . . . 27

3.2 .2 Objetivos de Testes . . . . . . . . . . . . . . . . . . . . 28

3.2 .3 Casos de Testes . . . . . . . . . . . . . . . . . . . . . . . . . 29

3.2 .4 Processo de Teste . . . . . . . . . . . . . . . . . . . . . 30

3.2 .5 Técnicas de Testes . . . . . . . . . . . . . . . . . . 31

3.2 .6 Execução dos testes . . . . . . . . . . . . . . . . . . 33

3.2 .7 Critérios de Testes . . . . . . . . . . . . . . . . . . . 33

3.3 Testes aplicados a Web Services . . . . . . . . . . . . . . . . . . 34

3.3.1 Exemplo de teste para Web Services . . . . . . . . . . . . . 35

3.3.2 Critérios para testes de Web Services . . . . . . . . . . . . . . 37

3.3.3 Confiabilidade de Web Services . . . . . . . . . . . . . . . . 37

3.3.4 Ferramentas para auxiliar testes de Web Services . . . . . . . . . . . . 38

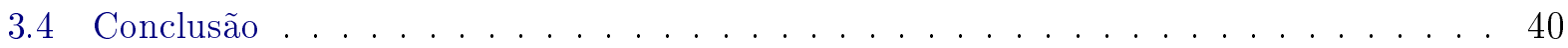

4 Testes de confiabilidade de Web Services Transacionais 43

4.1 Introdução . . . . . . . . . . . . . . . . . . . . . . . 4 43

4.2 Web Services Transacionais . . . . . . . . . . . . . . . . . 43

4.3 Web Services Transacionais Compostos . . . . . . . . . . . . . . . . . . 45

4.4 Padrões de transações . . . . . . . . . . . . . . . . . . . . . . . . 46

4.4 .1 Dependências e Condições para Transições . . . . . . . . . . . . . . . . . 46

4.4 .2 Padrões de Fluxos de Controle e Transações . . . . . . . . . . . . . . . . . . . . 49

4.5 Uma Sistemática para Testes de Confiabilidade de Web Services Transacionais Compostos baseada em Padrões de Transação . . . . . . . . . . . . . . . . . . . 51

4.5.1 Validação de Web Services Transacionais isolados . . . . . . . . . . . . . 53

4.5.2 Validação de pré-condições e sequência . . . . . . . . . . . . . . . 55

4.5 .3 Violação de sequência . . . . . . . . . . . . . . . . . . 57

4.5.4 Violação de pré-condições . . . . . . . . . . . . . . . . . . . . 58

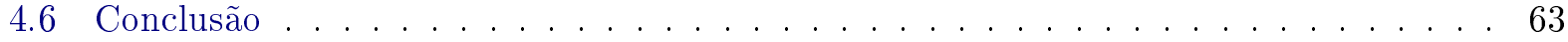

5 Estudo de Caso - Sistema de Viagens $\quad 65$

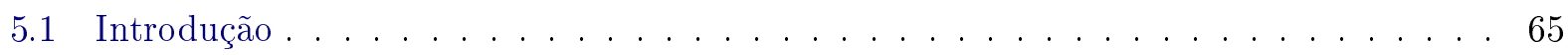

5.2 Sistema de Viagens . . . . . . . . . . . . . . . . . . . . 65

5.3 Ambiente de execução . . . . . . . . . . . . . . . . . . . 70

5.4 Técnicas e Geração Automática de casos de testes . . . . . . . . . . . . . . . . . 71

5.4 .1 Testes realizados para Serviços Isolados e para a Sequência . . . . . . . . . . 71

5.4 .2 Validação de pré-condições e sequência . . . . . . . . . . . . . . . 71

5.4 .3 Violação de pré-condições . . . . . . . . . . . . . . . . . . . . 74

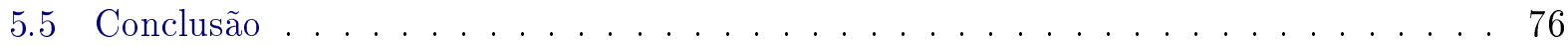

6 Considerações Finais $\quad 77$

6.1 A ferramenta GenAutoWs, padrões e critérios . . . . . . . . . . . . . 77

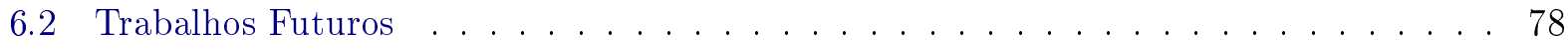

$\begin{array}{ll}\text { Referências Bibliográficas } & \mathbf{7 9}\end{array}$ 


\section{Lista de Figuras}

1.1 Modelo de Arquitetura Orientada a Serviços . . . . . . . . . . . . . . . . . . . 2

1.2 Sistema de Viagens Composto por Web Services . . . . . . . . . . . . . . . . 4

1.3 Árvore de Falhas do Sistema . . . . . . . . . . . . . . . . . . . . . 5

1.4 Composição de Sistemas disponíveis através de Web Services . . . . . . . . . . . . . . 5

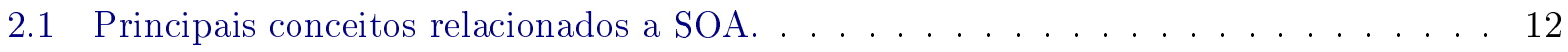

2.2 Arquitetura de um Web Service . . . . . . . . . . . . . . . . . . . . . . 17

2.3 Tipos de Web Services . . . . . . . . . . . . . . . . . . . . . . 19

2.4 Estrutura de uma mensagem SOAP . . . . . . . . . . . . . . . . . . . . . . 19

2.5 Comparação entre os estilos de codificação e os tipos de mensagens . . . . . . . . . . 21

2.6 Estrutura conceitual da descrição de um serviço (WSDL) . . . . . . . . . . . . . . 22

3.1 Origem do Defeito . . . . . . . . . . . . . . . . . . . . 28

3.2 Custo relativo de correção de defeitos . . . . . . . . . . . . . . . . . . . . 29

3.3 Visualização de classes de equivalência . . . . . . . . . . . . . . . . . . . . 32

3.4 Visualização de Valores de Fronteiras . . . . . . . . . . . . . . . . . . . . . 32

3.5 Taxa de identificação de defeitos . . . . . . . . . . . . . . . . . . 35

3.6 Criação de Novo Projeto WSDL . . . . . . . . . . . . . . . . . . . . . . 41

3.7 Tela de entrada GenAutoWS com projeto aberto . . . . . . . . . . . . . . . . . . 41

3.8 Menu de contexto para geração automática de casos de teste . . . . . . . . . . . . . 42

3.9 Lista de casos de teste gerados automaticamente . . . . . . . . . . . . . . . . 42

4.1 Transição de Ativação . . . . . . . . . . . . . . . . . . . . . . . . . . . . 47

4.2 Transição de Alternativa . . . . . . . . . . . . . . . . . . . . . . . 48

4.3 Transição de Aborto . . . . . . . . . . . . . . . . . . . . . . . . . . 48

4.4 Transição de Compensação . . . . . . . . . . . . . . . . . . . . . . . . . . . 49

4.5 Transição de Cancelamento . . . . . . . . . . . . . . . . . . . . . . . . . 49

4.6 Exemplo de fluxo inconsistente . . . . . . . . . . . . . . . . 51

4.7 Validações em uma dada sequência . . . . . . . . . . . . . . . . . 58

4.8 Violação de pré-condição de ativação . . . . . . . . . . . . . . . . . . . 60

4.9 Violação de pré-condição de alternativa . . . . . . . . . . . . . . . . . . 60

4.10 Violação de pré-condição de compensaçãa . . . . . . . . . . . . . . . . . . 61

4.11 Violação de pré-condição de aborto . . . . . . . . . . . . . . . . . . . . 61

4.12 Violação de pré-condição de cancelamento . . . . . . . . . . . . . . . . . . 62

5.1 Processo BPEL do sistema de viagens $\ldots \ldots \ldots \ldots$ 


\section{Lista de Tabelas}

3.1 Casos de testes para o sistema de agendamento de entrega . . . . . . . . . . . 35

3.2 Perturbação de Dados . . . . . . . . . . . . . . . . . . . . . . 38

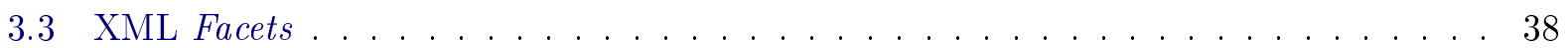

3.4 Perturbação de relacionamento (comunicação de dados) $\ldots \ldots$. . . . . . . . . . 39

3.5 Mutação de Dados - operadores . . . . . . . . . . . . . . . . . . . . 39

3.6 Dados de testes derivados a partir de técnicas de perturbação e mutação . . . . . . . 40

4.1 Perturbação de Dados com base em Valores Limite - Aplicação para testes isolados

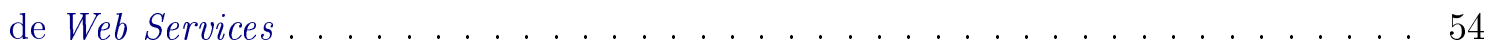

4.2 Perturbação de Dados com base em Facetas XML - Aplicação para testes isolados de

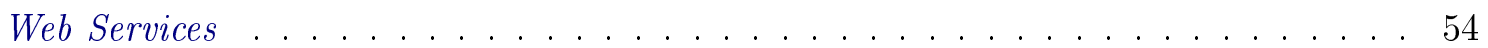

4.3 Validação de pré-condições e sequência - Perturbação de Comunicação . . . . . . . . 54

4.4 Mutação de Dados - Aplicação para testes isolados de Web Services . . . . . . . . . . 55

4.5 Validação de pré-condições e sequência - Perturbação de Dados primitivos . . . . . . 55

4.6 Validação de pré-condições e sequência - Perturbação de Dados com base em restrições 56

4.7 Validação de pré-condições e sequência - Perturbação de Comunicação . . . . . . . . 56

4.8 Validação de pré-condições e sequência - Mutação de Dados . . . . . . . . . . . . 57

4.9 Violação de pré-condições - Condição de ativação - Perturbação de Dados . . . . . . 59

4.10 Violação de pré-condições - Condição de ativação - Perturbação de Dados com base

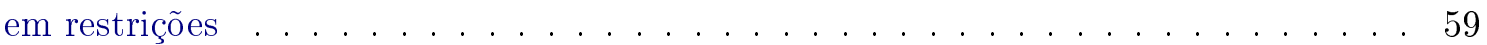

4.11 Violação de pré-condições - Condição de ativação - Perturbação de Comunicação . . 59

4.12 Violação de pré-condições - Condição de ativação - Mutação de Dados . . . . . . . . 59

4.13 Violação de pré-condições - Condição de cancelamento - Perturbação de Dados . . 61

4.14 Violação de pré-condições - Condição de cancelamento - Perturbação de Dados com base em restrições . . . . . . . . . . . . . . . . . . . . . . . . . . 62 62

4.15 Violação de pré-condições - Condição de cancelamento - Perturbação de Comunicação 62

4.16 Violação de pré-condições - Condição de cancelamento - Mutação de Dados . . . . . 62

4.17 Tabela de cobertura dos casos de testes apresentados por Silveira e Melo . . . . . . . 64

5.1 Mapeamento de informações das listagens 5.1 e $5.2 \ldots \ldots$. . . . . . . . . . 67

5.2 Mapeamento de informações das listagens 5.1 e $5.3 \ldots \ldots$. . . . . . . . . . . 68

5.3 Mapeamento de informações das listagens $5.1,5.4,5.5$ e 5.6 . . . . . . . . . . . 69

5.4 Mapeamento de informações das listagens $5.1,5.7$ e $5.8 \ldots \ldots$. . . . . . . . . . 69

5.5 Mapeamento de informações obtidas nas respostas de cada serviço $\quad \ldots$. . . . . . . 70 
5.6 Testes Isolados - Lista de Testes Executados com base em perturbação de valores para os Web Services do processo . . . . . . . . . . . . . . . . . . 72

5.7 Testes de Validação de Sequência e Pré-condições - Lista de Testes Executados com base em perturbação de valores para os Web Services do processo . . . . . . . . . . 73

5.8 Testes de Violação de Pré-condições - Lista de Testes Executados com base em perturbação de valores para os Web Services do processo . . . . . . . . . . . . . 75 


\section{Lista de Listagens}

2.1 Estrutura para definição de Process . . . . . . . . . . . . . . . . . . . 13

2.2 Estrutura para definição de Partner . . . . . . . . . . . . . . . . . . . 13

2.3 Estrutura para definição de Variables . . . . . . . . . . . . . . . . . . 13

2.4 Estrutura para definição de Assign . . . . . . . . . . . . . . . . . . . . . . 14

2.5 Estrutura para definição de Invoke . . . . . . . . . . . . . . . . . . . . . . . 14

2.6 Estrutura para definição de Receive . . . . . . . . . . . . . . . . . . . . . . . . . 14

2.7 Estrutura para definição de Reply . . . . . . . . . . . . . . . . . . . . . . . 14

2.8 Estrutura para definição de Throw . . . . . . . . . . . . . . . . . . . . . 14

2.9 Estrutura para definição de Wait . . . . . . . . . . . . . . . . . . 15

2.10 Estrutura para definição de Empty . . . . . . . . . . . . . . . . . . . 15

2.11 Estrutura para definição de If . . . . . . . . . . . . . . . . . . . 15

2.12 Estrutura para definição de Switch . . . . . . . . . . . . . . . . . . 15

2.13 Estrutura para definição de While . . . . . . . . . . . . . . . . 15

2.14 Estrutura para definição de Pick . . . . . . . . . . . . . . . . . . . . 15

2.15 Estrutura para definição de Sequence . . . . . . . . . . . . . . . . 16

2.16 Estrutura para definição de Flow . . . . . . . . . . . . . . . . . . . . . 16

2.17 Estrutura para definição de FaultHandlers . . . . . . . . . . . . . . . 16

2.18 Exemplo de um XML Schema . . . . . . . . . . . . . . . . . . . . 20

2.19 Exemplo de requisição SOAP . . . . . . . . . . . . . . . . . . 22

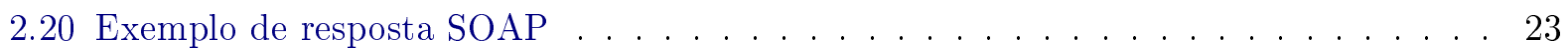

2.21 Descrição WSDL para consulta a recomendações de Snowboarding . . . . . . . . . . . 23

2.22 Elemento $<$ service $>$ alternativo para múltiplos locais . . . . . . . . . . . . . . . 25

3.1 Requisição realizada no caso de teste $1 \ldots \ldots \ldots \ldots \ldots$

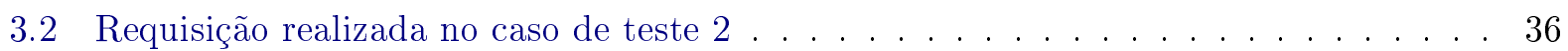

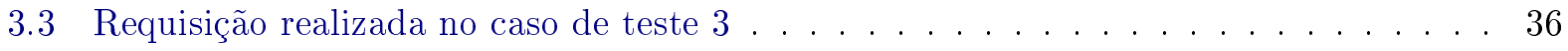

3.4 Requisição realizada no caso de teste $4 \ldots \ldots \ldots$. . . . . . . . . . . 36

3.5 Requisição realizada no caso de teste $5 \ldots \ldots \ldots \ldots \ldots \ldots$

5.1 Dados de entrada para confirmação dos serviços . . . . . . . . . . . . . . . . 65

5.2 Dados de entrada para o serviço de reserva aérea . . . . . . . . . . . . . 67

5.3 Dados de entrada para o serviço de reserva aérea . . . . . . . . . . . . . . . 67

5.4 Dados de resposta do serviço de reserva hoteleira . . . . . . . . . . . . . 68

5.5 Dados de resposta do serviço de reserva aérea . . . . . . . . . . . . . . . . 68

5.6 Dados de entrada para o serviço de pagamento . . . . . . . . . . . 68

5.7 Dados de entrada para o serviço de pagamento . . . . . . . . . . . . . . . . . 69

5.8 Dados de resposta do serviço de pagamento . . . . . . . . . . . . . . . . 69 
5.9 Dados de resposta do serviço de pagamento . . . . . . . . . . . . . . . . . 69

5.10 Dados de entrada para confirmação dos serviços . . . . . . . . . . . . . . . . 70

5.11 Falha apresentada após execução de inversão de data . . . . . . . . . . . . . . 71 


\section{Capítulo 1}

\section{Introdução}

A integração entre aplicativos está cada vez mais presente. Com a necessidade de informações disponíveis e com a chegada de novas demandas, arquiteturas orientadas a serviços, onde diversas funções agrupadas são disponibilizadas através de sistema operacional e uma linguagem de programação [67], ganham evidência, juntamente com os Web Services, softwares projetados para prover interoperabilidade máquina à máquina através de uma rede [98].

Web Services, também chamados de Serviços Web, são um meio de requisição de informações através de uma rede e cuja resposta é solicitada e informada através de XML (extended markup language) [98]. Na internet, os Web Services utilizam protocolos padrão de modo que as informações estejam disponíveis. Atualmente, representam uma tecnologia baseada em componentes e com grande utilização para implementação de soluções e sistemas [42].

O conceito de tornar disponíveis diversos serviços permite a criação de um cenário, no qual a Internet exerce um papel de repositório de dados, informações e serviços, visto que um serviço cujo acesso é permitido através da Rede Mundial pode ser utilizado de qualquer parte do planeta, desde que esteja disponível na rede [37]. Tal ambiente apresenta melhor interoperabilidade, maior dinamismo e flexibilidade, principalmente se compararmos a outras plataformas, como o Common Object Request Broker Architecture (Corba) [3]. Contudo, isso afeta significativamente atributos não funcionais, por exemplo confiabilidade, disponibilidade, segurança, entre outros [49, 26, 21].

Para que o serviço seja utilizado, é necessário disponibilizar as suas especificações. Dados de entrada e a definição da informação que será retornada em determinadas condições são exemplos de tais especificações. Isso faz com que Web Services estejam expostos em um crescente número de sistemas altamente complexos, disponíveis a grandes distâncias e a qualquer hora do dia. Em alguns cenários com maior criticidade, a confiança no Web Service passa a ser um fator importante [21].

A confiabilidade de um sistema é entendida como sendo a probabilidade de se funcionar de acordo com o especificado durante um período determinado [88]. Atualmente, uma das suas principais características é o fato de que sua comunicação é feita em um ambiente com baixa confiabilidade[36], como a Internet, cujos protocolos de comunicação nem sempre provêm as garantias necessárias de funcionamento correto, por exemplo certeza de entrega. De fato, isso é uma barreira que impede que empresas invistam em aplicativos críticos que dependam de integração com Web Services[21].

Com objetivo de resolver essa limitação, a comunidade acadêmica e até mesmo a indústria têm despendido um grande esforço para elaborar modelos voltados para Qualidade de Serviço, especificamente a Web Services [59], além de estudar alternativas para o problema, buscando aumentar a confiabilidade nos serviços oferecidos por eles [34]. A abordagem varia desde a definição de padrões até mesmo à elaboração de testes que garantam uma cobertura adequada.

Inúmeros padrões têm sido criados com o objetivo de estabelecer maneiras claras de execução dos Serviços Web. A execução é correta se ela atinge o objetivo, ou falha se de alguma forma os requisitos não são cumpridos. Quando uma série de execuções ocorre de acordo com um padrão pré-estabelecido, é mais previsível o comportamento dos serviços compostos [14].

A WSBPEL (Business Process Execution Language), também chamada BPEL, é uma linguagem 
que permite a padronização, definida por OASIS, para a modelagem de processos e execução, além de determinar como os diferentes serviços se conectam[72]. Foi criada para que fosse permitida a orquestração de Web Services. Com base em modelos projetados com BPEL, é possível determinar padrões de comportamento e composição de serviços, bem como implementar sistemas tolerantes a falhas [34].

Uma outra maneira de se obter um serviço confiável é através da execução de testes que garantam o bom funcionamento do conjunto de serviços. Quando uma bateria de testes é realizada, tem como objetivo fundamental avaliar se o serviço responde de acordo com requisitos, quer sejam funcionais ou não funcionais. Algumas empresas e institutos fornecem este tipo de análise, garantindo ao fornecedor do serviço um certificado de qualidade [6].

Ainda assim, a realização dos testes é uma tarefa cara e difícil, mais especificamente para Web Services, devido às suas peculiaridades [33]. Técnicas de testes aplicadas a outros paradigmas, tais como Orientação a Objetos e procedimental, são em geral também aplicadas a Web Services. Contudo, existem diversas características específicas que permitem explorar melhor tais técnicas [11].

Dentre os desafios atuais está a tarefa de tornar mais eficiente a atividade de testes de Web Services, com a finalidade principal de aumentar a confiabilidade. Testes não funcionais têm vasto suporte de ferramentas [33, 11, 89]. O mesmo não ocorre para avaliação funcional [33].

\subsection{Web Services e suas Características}

Aplicações Web conquistaram destaque no mundo da tecnologia da informação e se tornaram um dos principais meios de comunicação entre fornecedores e seus clientes. Com o avanço da tecnologia, as aplicações se tornaram mais complexas e dinâmicas, fazendo com que negócios eletrônicos entrem em uma nova fase do desenvolvimento de sistemas [105].

Web Services representam interoperabilidade e baixo acoplamento. Isso permite flexibilidade na composição e na orquestração de serviços, desde que esteja em uma plataforma adequada [89] e que a arquitetura modele a interação entre eles [34].

Em uma Arquitetura Orientada a Serviços (SOA, do inglês Service-Oriented Architecture) existe um Provedor de Serviço, disponível através de um protocolo de comunicação, Requisitor de Serviços (também chamado de cliente ou consumidor do serviço) que utiliza o serviço e um Repositório de Serviços, exibidos na Figura 1.1[76]. O repositório contém a lista de serviços disponíveis e também suas respectivas descrições de uso, geralmente alimentados pelos diversos provedores existentes.

\section{Repositório de Serviços}
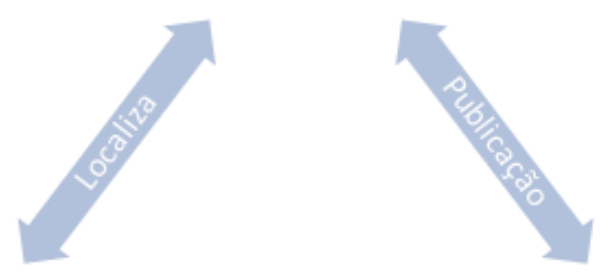

\section{Requisitor de Serviços}

\section{Provedor de Serviços}

Figura 1.1 Modelo de Arquitetura Orientada a Serviços 
O Provedor cria uma descrição WSDL (Web Services Description Language) do serviço [97], detalhando a interface: as operações realizadas por ele, as entradas e saídas, bem como suas restrições.

Depois de criada, a descrição é disponibilizada no repositório para que os clientes possam utilizar o serviço. Existem diversos desses repositórios disponíveis na Internet, cuja principal finalidade é prover informações necessárias sobre os diversos serviços publicados, como local de acesso, descrição geral. Muitos desses repositórios oferecem alguns critérios de busca (por exemplo, por categoria), visando facilitar o acesso pelos clientes.

Para efetivar a comunicação Cliente-Provedor, cada cliente implementa um tipo de aplicação fronteira, a qual é responsável pela troca de mensagens entre a aplicação cliente e o serviço disponível, seguindo as especificações descritas de como enviar e receber as informações.

Atualmente, o protocolo SOAP (Simple Object Access Protocol) é a tecnologia mais popular para utilização de Web Services [85]. Este protocolo baseia-se na utilização de XML para permitir transmissão de informações através de outros protocolos, por exemplo, HTTP [96]. É formado por um cabeçalho e corpo, onde estão as informações trocadas.

Para a publicação de serviços, consultas dinâmicas e invocações através da Web [76], existe o UDDI (Universal Description, Discovery and Integration), padrão proposto por OASIS [70].

\subsection{Motivação}

Tradicionalmente, sistemas distribuídos devem ter um tratamento robusto de exceções, prevendo assim o maior número possível de problemas, tentando de alguma forma garantir um serviço adequado e tolerante a falhas [39].

Para Web Services, além de todos os problemas existentes no paradigma de programação distribuída, temos ainda o problema de que erros em um determinado serviço não devem ser propagados para os demais. Com isso, a manipulação de falhas deve inicialmente identificar e classificar os possíveis erros que podem ocorrer internamente e durante a comunicação entre os diversos serviços utilizados.

Basicamente, podem-se classificar os problemas em três grandes categorias: Funcional e Comportamental, Operacional e Violação dos Níveis Mínimos Aceitáveis de Serviço (geralmente definidos em SLAs - Service Level Agreements). Dentro dessas categorias, existem alguns subproblemas, como seguem:

1. Funcional e Comportamental

(a) Respostas Inválidas

(b) Erros de processamento

(c) Chamadas impróprias

2. Operacional

(a) Indisponibilidade do meio

(b) Perda de dados

3. Violação dos Níveis Mínimos Aceitáveis de Serviço

(a) Violação do tempo de resposta

(b) Indisponbilidade do serviço

(c) Falhas de segurança

Para entender melhor tais aspectos, considere um sistema online para Viagens, composto por diversos Web Services, conforme visto na Figura 1.2.

O cliente especifica qual localidade deseja ir e em quais os hotéis quer se hospedar. O Sistema então inicia simultaneamente a reserva do voo e do hotel. Depois, é solicitado ao cliente o pagamento. Uma vez finalizada esta etapa, os documentos da viagem são enviados ao cliente. 


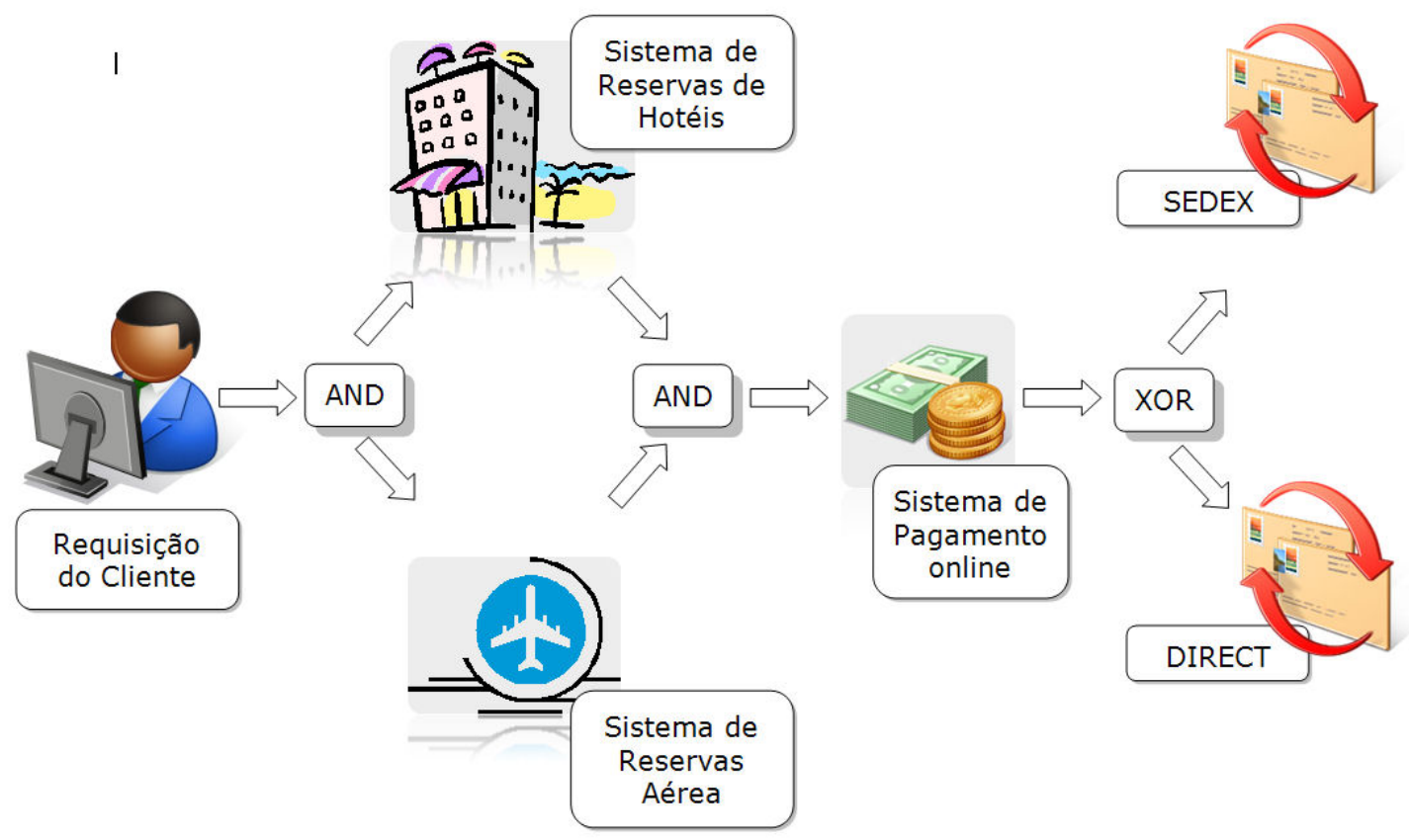

Figura 1.2Sistema de Viagens Composto por Web Services

Na Figura 1.3 podemos analisar os problemas relacionados à implementação do sistema exemplificado. As folhas da árvore, representadas no diagrama por círculos, denotam um problema fim ou que não pode ser explorado/detalhado. Os problemas representados por retângulos são causados em detrimento da combinação de outros eventos [53]. Por exemplo, um Dado Inválido ocorre devido a um erro no processamento ou a um dado incompleto enviado ao sistema. A propagação do erro ocorre das folhas até o ramo mais alto da árvore.

Para garantir a confiabilidade do sistema e para tratar adequadamente as possíveis condições de falha, diversos pontos do sistema podem ser analisados em uma primeira etapa individualmente, e, numa segunda etapa, em conjunto, de modo que seja evitado que a execução prossiga em um estado defeituoso $[65,88,39]$. Nesse sistema, são considerados pontos críticos as comunicações feitas entre os serviços, por exemplo, entre a requisição do cliente e o sistema hoteleiro. São recorrentes os problemas de indisponibilidade do serviço, ou inconsistência de dados, que podem se dar através da degradação do meio, ou até mesmo do tratamento inadequado do processo. Existe apenas um ponto de redundância que é serviço de entrega. Em uma outra modelagem seria possível escolher entre diversos serviços de hotéis, serviços de empresas aéreas como também de pagamento online.

Entre as diversas modelagens possíveis para o problema, uma especificação de estado seguro é: ou todos têm as informações corretas da viagem ou ninguém as tem. Por exemplo, ao requisitar uma viagem, a comunicação com o serviço bancário falha logo após a confirmação das reservas de voo e de hospedagem. É um estado inseguro, pois as reservas não podem estar confirmadas caso o cliente não tenha efetuado seu pagamento.

De uma maneira geral, o problema é semelhante à situação de composição de produtos (Figura 1.4). Um conjunto de informações providas por diversos produtos é combinado e apresentado ao cliente na forma de consolidação. Cada produto é responsável pela sua respectiva cobrança. Supondo que o cliente apenas consiga acessar a consolidação caso todas as informações estejam disponíveis, são considerados estados seguros do sistema: consolidação disponível ao cliente e todos os subprodutos registraram cobrança ou consolidação indisponível ao cliente e nenhum produto registrou cobrança.

Diversos esforços têm sido empenhados na solução dos problemas, tanto do ponto de vista técnico quanto do ponto de vista de negócio [61]. Embora muitos desses problemas ainda estejam 


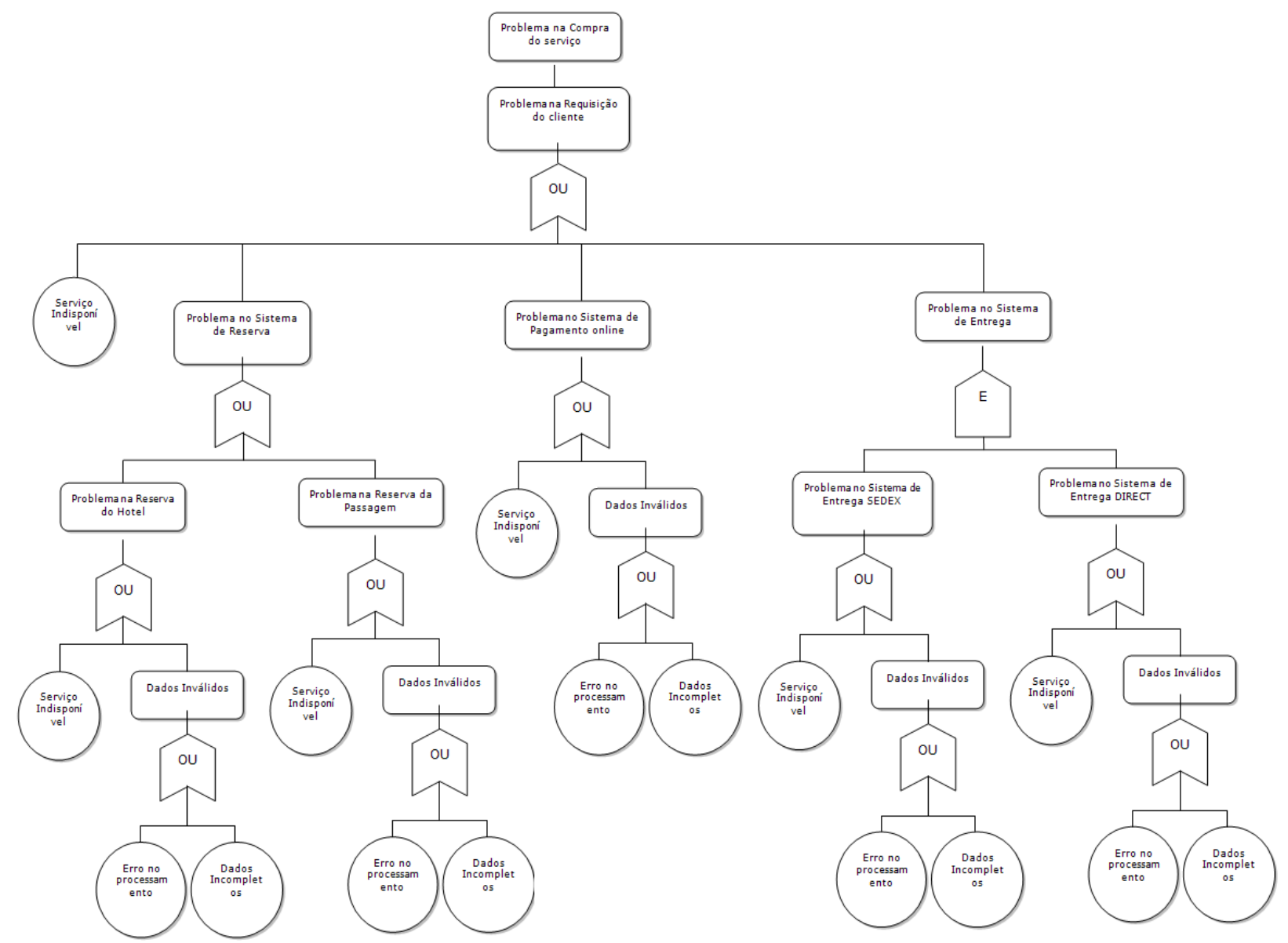

Figura 1.3Árvore de Falhas do Sistema

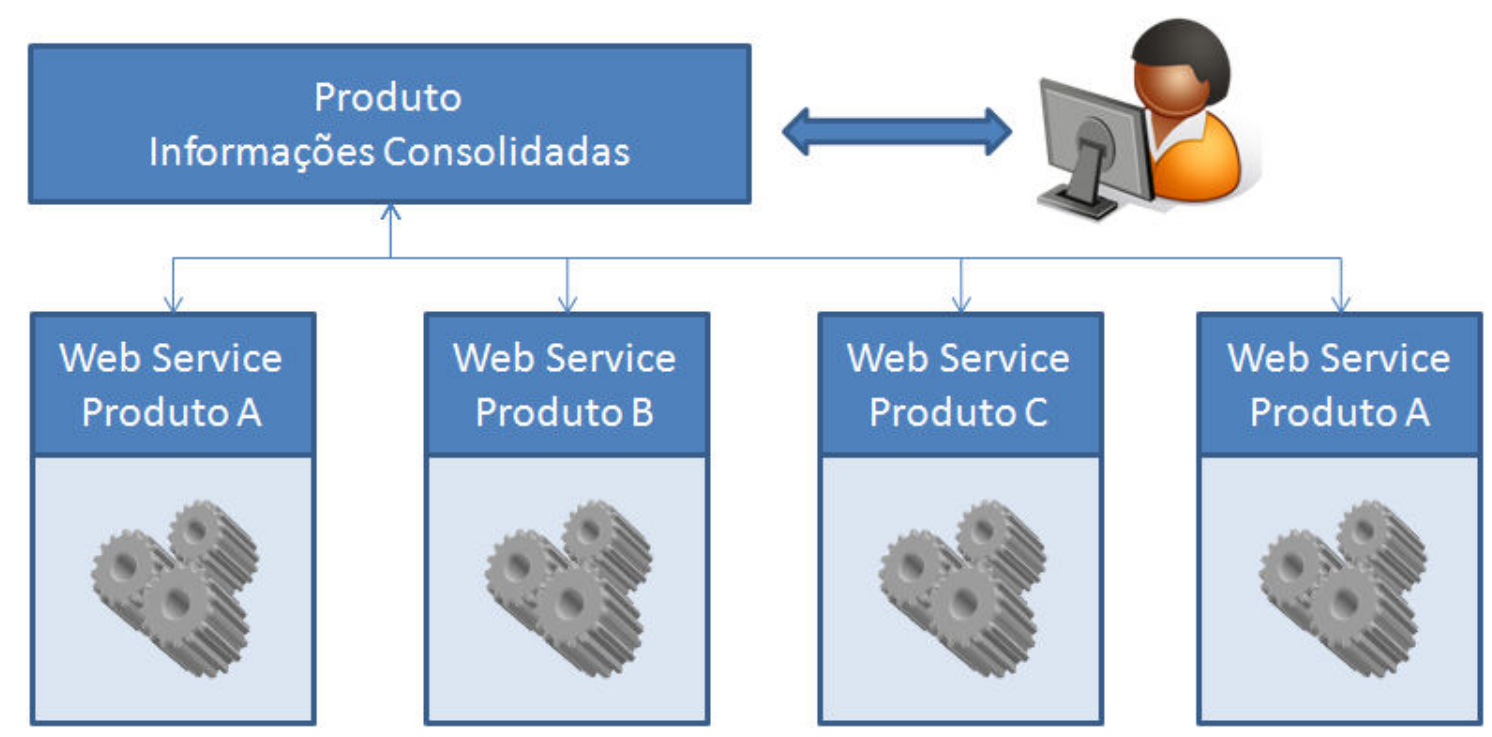

Figura 1.4Composição de Sistemas disponiveis através deWeb Services 
em aberto, para alguns deles já foram encontradas soluções, porém, que não resolvem todos os aspectos.

Garantir a confiabilidade de Web Services não é uma tarefa simples devido principalmente à dificuldade de se prever o comportamento de composições de serviços. A definição de padrões transacionais que combinam fluxo de utilização de serviços e suas respectivas transações pode contribuir para uma composição confiável [14].

Estabelecer critérios de teste que permitam avaliar se um serviço atende ou não tais padrões passa a ter papel fundamental quando se pretende determinar seu nível de confiabilidade. Essa informação é valiosa, principalmente para se definir com mais precisão o SLA do Web Service.

\subsection{Iniciativas para solução dos problemas}

A importância de se ter disponíveis Web Services confiáveis é amplamente reconhecida nas empresas e na academia [54]. Com isso, muitas pesquisas abordam as questões citadas na seção anterior, fazendo com que o cenário tenha uma mudança significativa [19].

Dentre as iniciativas, podem-se destacar as que buscam garantir a qualidade através de definição de padrões. Podem-se destacar também as que verificam se a qualidade existe ou não, por meio da realização de testes [39].

\subsubsection{Definição de padrões}

A padronização da comunicação entre os serviços contribui com a interoperabilidade, facilitando a execução das respectivas funções. Interoperabilidade é a capacidade de múltiplos componentes funcionarem em conjunto, trocando informações num processo bem definido [63]. Para que trabalhem corretamente, a definição de padrões de comunicação e de funcionamento é necessária.

Em sua pesquisa, Saha descreve uma técnica que consiste em garantir uma maior confiabilidade nos dados transmitidos [85]. Para isso, é assumido que os dados trocados entre os serviços compõem a parte mais sensível da transação e por isso devem ser corretos. Baseado em algoritmos de tolerância a falhas [84] utiliza-se principalmente a redundância de dados - dividida em três níveis. Para cada requisição utiliza-se um nível diferente. Ao final das requisições, a aplicação verifica a integridade dos dados recebidos e então decide pela utilização ou não da informação.

A técnica se baseia num votador, o que reduz muito o problema de respostas inválidas, uma vez que para diversas situações, decidir se uma informação é ou não válida é a maior incógnita [85]. O problema de perda de dados também é reduzido, bem como o de indisponibilidade do serviço requerido (que por muitas vezes é momentâneo). Porém, há alguns problemas. O primeiro é com relação ao aumento de tráfego de informações na rede e ao aumento do tempo de resposta. Dependendo da aplicação, isto pode ser um agravante. Para a maioria das aplicações não chega a ser significativo. Além disso, a abordagem não resolve problemas de longa indisponibilidade de serviços, tanto por consequência da aplicação, quanto por consequência do meio. Com relação ao método em si, o estudo não cita como devem ser tratados os casos em que o votador decide se os dados não são confiáveis. Assim, o problema passa a ser da aplicação, que neste caso deveria tratar a falha para entrar num possível estado seguro.

Um outro trabalho de Saha enfatiza principalmente a disponibilidade do serviço [84]. É tomada como base uma série de trabalhos semelhantes, mas que não oferecem portabilidade, característica muito destacada na Internet. Com isso, o objetivo foi elaborar um modelo confiável e flexível. Para resolver a questão da disponibilidade, novamente é utilizada redundância, porém, de serviço, pois, a redundância aumenta disponibilidade [85, 84]. São criadas unidades de processamento do serviço requisitado que conversam entre si. Foi desenvolvido um algoritmo que organiza as diversas etapas de processamento, mantendo check-points e, de acordo com a necessidade, uma determinada réplica pode fazer papel de primário, mas em outra etapa fazer papel de reserva.

A demonstração de corretude do algoritmo e, por consequência do modelo, além da realização de testes, confirmaram o que o autor esperava com relação a um bom desempenho operacional, 
sendo que o tempo de resposta e de processamento tiveram leve aumento quando comparados com métodos convencionais [84]. O problema de indisponibilidade de meio, embora ainda não resolvido por completo, pode ser atenuado com esta proposta através da disponibilização das réplicas em meios e locais variados. Mas, dependendo de como é feita tal disponibilização, pode-se começar a afetar os tempos de resposta, entrando no problema de Violação de SLA. Problemas relacionados à segurança não foram mencionados (não faziam parte do escopo do trabalho). Além disso, a abordagem não oferece garantia das respostas da requisição, nem apresenta meios de contorno para tais problemas. Ainda assim, o modelo atende bem o que se propôs a cobrir.

Outras pesquisas têm como objetivo a garantia de entrega [71, 69, 45]. Esforços têm sido empregados na padronização visando tal objetivo. Uma maneira de se obter isso é através de uma especificação que ofereça formas de controlar determinado nível de qualidade de serviço. É definida uma especificação para o uso de confirmação de entrega e, com isso, as aplicações podem detectar erros e iniciar o tratamento e as devidas correções, por exemplo retransmissão. Além disso, existe preocupação com a envio de grupos de mensagens, tornando possível receber não somente a confirmação de entrega, como também perceber se ela foi realizada na ordem esperada.

Os problemas de Respostas Inválidas, Erros de processamento e Chamadas impróprias são facilmente identificados, permitindo seu tratamento [75]. As questões de seguranças também são levadas em consideração, pois o nível aceitável é controlado em tempo de especificação, tornando assim a segurança dos dados independente da segurança do meio. A questão ainda é com relação à indisponibilidade. Existe sim um meio de detectar a indisponibilidade, mas não fornece uma maneira de contorná-la, que fica a cargo de quem utiliza o serviço.

Devido à grande dinamicidade dos sistemas envolvidos, é complexo fazer a detecção e o tratamento de todos os tipos de falhas. Tendo isso como objetivo, Erradi et al. sugerem a criação de um framework, MASC (Manageable and Adaptive Service Composition), baseado principalmente em políticas capazes de reger o gerenciamento de falhas [36]. Através do XML, são modelados eventos que disparam rotinas que colocam o sistema novamente num estado seguro. Com isso, foi criado um padrão que intercepta as operações normalmente executadas, adicionando assim uma camada de política na arquitetura. Essa camada intermediária passa a ter papel fundamental na detecção e manipulação de falhas, além de ser responsável por direcionar a funções que tratem o problema de maneira segura para o sistema.

A proposta do trabalho é a criação de políticas para gerenciar os tipos mais comuns de falhas. Essa abordagem cria uma separação bastante evidente entre a camada de aplicação e a camada de negócio (a não existência dessa separação é um problema enfrentado não só em Web Services, mas em toda a engenharia de software [80]). Esta solução seria muito mais completa se, por exemplo, definisse políticas relacionadas a transações. A criação de checkpoints atribuídos às políticas poderiam definir de maneira mais clara a relação de dependências entre os serviços, determinando que se o serviço foi executado até um ponto específico, pode-se avançar para um outro processo.

Em sua pesquisa, Arjan explica a necessidade de credenciais como forma de garantia da qualidade do serviço [6]. Tais credenciais facilitam a integração e a relação de confiança entre os diversos serviços integrados. De fato, a confiança é um pré-requisito para qualquer tipo de comércio [6]. Ao utilizar um determinado serviço oferecido, é necessário ter alguns parâmetros para discernir sobre os níveis de confiabilidade, o que poderão fazer com que o serviço seja ou não solicitado.

Existem três níveis de confiança, que podem ser atribuídos em especial a Web Services:

- Autenticação - Garante autenticidade de quem fornece o serviço. Geralmente, Entidades Certificadoras realizam uma série de procedimentos para validar sua segurança;

- Desempenho - Garante, através de diretivas de desempenho operacional, números satisfatórios de performance na utilização do serviço. Diversas Autoridades fornecem tal certificado, como órgãos de padrões internacionais (Ex: ISO - International Organization for Standardization, SEI - Software Engineering Institute), órgãos nacionais (Ex: BOVAG - Dutch Federation of Entrepreneurs in Mobility Sector) e Autoridades Governamentais (Ex: Forças Armadas dos Estados Unidos); 
- Geral - para os casos não atendidos pelos dois níveis anteriores.

A informação relacionada à Certificação é lida através do arquivo descritivo do serviço (WSDL), com possibilidade de ser verificada sob demanda (ao requerer o serviço, a credencial é validada).

A abordagem é bem diferente das demais. A relação passa a ser de confiança nos números e dados fornecidos pelos órgãos responsáveis. Quando existem diversas opções, pode ser um fator de escolha de qual serviço utilizar, uma vez que a qualidade do serviço oferecido auxilia na decisão [40]. Essa abordagem permite que o conjunto de serviços seja mais confiável. Contudo, não elimina a necessidade de adaptação das aplicações para serem tolerantes a falhas, nem as auxilia na modelagem de solução dos problemas de confiabilidade. Um exemplo disso é que um sistema que utiliza dois serviços certificados não necessariamente é confiável ou seguro.

Bhiri et al. apresentam a criação de um padrão que leva em consideração o fluxo do sistema como um todo, sem perder as garantias oferecidas pelos métodos transacionais [14]. Foram levantados os diversos fatores que devem ser levados em consideração ao serem analisadas as dependências entre o solicitante e o requisitado: Dependência de Ativação e Condição de Ativação; Dependência Alternativa e Condição Alternativa; Dependência de Aborto e Condição de Aborto; Dependência de Compensação e Condição de Compensação e; Dependência de Cancelamento e Condição de Cancelamento. Com base nesses itens, foram identificadas definições de fluxo de controle e fluxos de transações para assim definir os padrões próprios para tais transações.

Wen et al. também enfocam a análise de transações para Web Services, mas com a utilização de BPEL (Business Process Execution Language). Foi desenvolvida uma ferramenta para validação de propriedades transacionais em composições de Web Services[100].

Das soluções estudadas, as que mais obtiveram sucesso eram as que envolviam especificações voltadas à modelagem de transações. Outras soluções acabam auxiliando mais os desenvolvedores na tarefa de aumentar a confiabilidade de Serviços Web diante de problemas como indisponibilidade, perda de dados e segurança.

\subsubsection{Testes de Web Services}

A realização de testes representa um papel fundamental na avaliação do sistema como um todo. Apesar de todos os estudos que têm sido conduzidos na busca por Web Services com qualidade cada vez mais notáveis, é necessário atestar que alguns requisitos de fato tenham sido implementados [52].

Muito tem-se pesquisado sobre isso [19, 63, 35], avaliando sob o aspecto das fases em que são realizados os testes (teste de unidade, de integração, regressivo, entre outros), ou a respeito das técnicas aplicadas (baseada em especificação, baseado em modelo, interoperabilidade, etc.), buscando, sobre tudo, confiabilidade [39].

Li et al. apresentam um método de geração de casos de testes a partir da combinação de características do WSDL e do conhecimento do usuário [51]. No trabalho, é apresentada uma ferramenta chamada WSTD-Gen que aplica o método definido. A ferramenta possibilita o usuário personalizar tipos de dados e, com isso, selecionar uma determinada regra para cada tipo.

Offut e Xu propõem uma abordagem na qual são capturadas mensagens SOAP durante a comunicação entre serviços e, a partir delas, são gerados casos de testes através da inserção de falhas na mensagem [73]. Esses casos de testes avaliam o comportamento do serviço na presença de mensagens inválidas. Na pesquisa, Offut e Xu apresentam 3 tipos de pertubação de mensagens:

- DVP - Data Value Pertubation: alteração nos valores de dados da mensagem SOAP;

- RCP - Remote Procedures Calls Communication Pertubations: alteração nos parâmetros e argumentos da chamada de rotinas remotas;

- DCP - Data Communication Pertubations: visa testar mensagens que possuem regras e restrições de uso de banco de dados. 
Avaliando também o comportamento de serviços perante um dado inválido, Laranjeiro et al. apresentam uma ferramenta, chamada wsrbench ${ }^{1}$, para avaliar a robustez de um dado Web Service [50]. A ferramenta permite configurar mensagens SOAP com chamadas inválidas, além de apresentar resultados detalhados dos testes realizados. Os autores apresentam na pesquisa a consolidação da avaliação de testes realizados em 100 Web Services disponíveis na internet, cujos resultados mostraram a existência de diversos problemas nos serviços testados.

Na pesquisa de Paradkar et al., é utilizada geração de caso de testes a partir de modelos [77]. A proposta apresenta um método para gerar dados de testes com base em modelos de falhas, com o intuito de usá-los para avaliar Web Serives semânticos, os quais são definidos através de entradas, saídas, pré-condições e efeitos - IOPE (Input, Output, Preconditions and Effects).

Semelhante ao trabalho de Paradkar et al., mas, sem a geração de dados para testes, a pesquisa de Heckel e Lohmann propõe um desenvolvimento baseado em contrato para Web Services, que são utilizados futuramente para realização de testes [43]. O desenvolvimento com base em contrato (DbC - Design by Contract) define condições para o acesso do serviço e condições que devem prevalecer após sua execução. Isso viabiliza a geração automática de casos de testes, uma vez que os contratos são definidos antes mesmo do desenvolvimento do serviço ser iniciado.

Wang et al. propõem uma priorização de casos de testes para realização de testes regressivos [24]. Foram desenvolvidas critérios de priorização de testes com base em modelo BPEL e na descrição do serviço WSDL, tendo como perspectiva testes de regressão. De acordo com a cobertura de um determinado conjunto de casos de teste, a prioridade é maior.

Tsai et al. apresentam também uma abordagem baseada em contrato, propondo uma extensão do WSDL, com o objetivo de facilitar os testes [94]. A descrição do serviço estendida passa a ter informações de dependência de entrada e saída, sequência de invocação, funcionalidade hierárquica, entre outros. Isso permite a criação de um conjunto de casos de testes que avalia se determinados itens do contrato foram ou não seguidos.

Já Bertolino e Polini [13] apresentam uma pesquisa, cuja a abordagem é identificar problemas de comportamento de serviço antes mesmo de registrá-los. No trabalho, a extensão do registro UDDI permite a verificação de alguns padrões (que os autores chamam de audition), definidos através de Diagramas de Máquinas de Estados. A ordem de invocações entre os diferentes serviços é analisada e possíveis problemas de interoperabilidade são apresentados.

Pentafronimos et al. exploram características específicas de Web Services utilizados em e-Government para definir um modelo para testar a interoperabilidade das soluções [79]. São sugeridos passos que guiam a definição de casos de testes. Num ambiente amplamente heterogêneo, mas com fortes tendências de utilização de padrões, o método proposto pelos autores permite a criação de casos de testes independentes de plataforma, completos e flexíveis.

Wombacher et al. definem um processo para análise de uma especificação BPEL e transformação em autômato finito determinístico [102]. Embora o objetivo principal do trabalho seja a facilitação da descoberta de serviços em catálogos, é possível avaliar cenários para testes, desde que sejam realizadas adaptações, tais como considerar variáveis e condições transacionais.

Ainda na linha de testes de interoperabilidade, Ramsokul e Sowmya apresentam um framework que verifica a adequação de implementação de protocolos de Web Service com as respectivas especificações [82]. Com a utilização de um Autômato Hierárquico assíncrono estendido (ASEHA - Asynchronous Extended Hierarchical Automata), utilizado para modelar aspectos funcionais do protocolo, é possível avaliar diversas características transacionais, por exemplo, atomicidade. O Framework captura mensagens SOAP enviadas pelos serviços e confronta a implementação com a sua especificação.

A necessidade por testes é evidente. Para Web Services, apresentam-se novos desafios e demandam estudo mais aprofundados, em particular em questões relacionadas à aplicação de padrões. Com isso, o foco deste trabalho será os testes de interoperabilidade. No Capítulo 3 são apresentados com mais detalhes Testes de Software e de Web Services, bem como os conceitos envolvidos.

\footnotetext{
${ }^{1}$ Disponível em http://wsrbench.dei.uc.pt
} 


\subsection{Objetivos da Pesquisa}

O objetivo do trabalho é identificar requisitos de testes que permitam validar a adequação tanto do serviço quanto da aplicação de padrões definidos de modo a garantir uma maior confiabilidade do sistema como um todo.

Para isso, é necessário estudar os principais problemas de confiabilidade com Web Services e analisar algumas soluções já existentes. Para a identificação de casos de testes, padrões transacionais [14] fornecem um conjunto de características específicas de sua implementação que podem ser exploradas, ilustrando-se situações de composição com BPEL.

Ao final da pesquisa, será possível aplicar os testes identificados e avaliar se um dado serviço atende ou não os padrões transacionais. Será utilizada a ferramenta GenAutoWS[89] com o intuito de gerar automaticamente casos de testes, além de determinar se os casos de testes gerados são suficientes para cobrir os critérios identificados.

Em resumo, pretende-se atender os seguintes objetivos:

- explorar características de Web Services e seus padrões transacionais;

- determinar sistemática para testar Web Services Transacionais

- determinar se os testes realizados com o auxílio da GenAutoWS são suficientes para cobrir os critérios identificados.

\subsection{Organização do Trabalho}

Para a realização da pesquisa, propõe-se a seguinte estrutura:

1. Trabalhos Relacionados

Confiabilidade e soluções de problemas

Técnicas utilizadas em testes de Web Services

2. Web Services e suas características

3. Testes aplicados a Software em geral e especificamente a Web Services

4. Padrões Transacionais

Características dos padrões transacionais

Sistemática para testes de Web Services

5. Estudo de caso

Apresentação do problema

Testes aplicados e resultados obtidos

Análise dos resultados

6. Conclusão 


\section{Capítulo 2}

\section{Web Services}

\subsection{Introdução}

Negócios eletrônicos têm utilizado frequentemente aplicações $W e b$ para apoiar a comunicação entre fornecedores e seus clientes. Para o uso de tais aplicações, pouco importa se elas estão centralizadas ou possuem processamento distribuído. Com isso, os requisitos têm se tornado cada vez mais complexos e dinâmicos.

O desenvolvimento de negócios eletrônicos entra em uma nova fase, à medida em que as funcionalidades são projetadas com características consideradas flexíveis. Modelos tradicionais demonstram certa dificuldade em acompanhar a dinâmica [1]. Faz-se necessária a adoção de padrões e protocolos de comunicação que permitam atender tal demanda, facilitando o desenvolvimento de aplicações que interajam com distintas plataformas e linguagens [35]. Com características de destaque, por exemplo interoperabilidade e modelos de baixo acoplamento, Web Services se tornaram notáveis dentre as diversas abordagens de desenvolvimento de sistemas e uma alternativa para tais questões, representando um avanço significativo nos negócios do futuro [87, 8].

A mais comum implementação de SOA(Service Oriented Architecture), Web Services têm como principal vantagem a capacidade de prover integração entre aplicações e sistemas heterogêneos, devido a sua interface independente de plataforma [29]. Neste capítulo será apresentada SOA, sua definição e conceitos relacionados. Serão apresentados também os conceitos de Web Services, bem como alguns tipos que podem assumir e as tecnologias aplicáveis. Por fim será apresentado um exemplo para ilustrar a utilização.

\subsection{SOA - Arquitetura Orientada a Serviços}

Arquitetura orientada a serviços (Service Oriented Architecture - SOA) é uma concepção de projeto de sistemas que visa coordenar o relacionamento entre componentes de serviços, oferecendo suporte dinâmico à pesquisa e ao uso [23]. Tem atraído o interesse de muitos pesquisadores e de muitas empresas [10]. A forma com que foi projetada possibilita maior agilidade e qualidade nas soluções de negócio.

Uma arquitetura típica consiste da interação de três papeis: Provedor; Consumidor e; Registro. Envolve também três atividades: descrição e publicação; busca e localização e; ligação. A publicação e descrição feitas são referentes aos métodos disponíveis para utilização. A operação de busca permite a quem está interessado pelo serviço identificá-lo. A ligação é quando o consumidor de fato se comunica com o serviço e faz uso dele.

Uma análise mais profunda permite avaliar outros conceitos envolvidos na definição de SOA.

A Figura 2.1 ilustra os principais conceitos relacionados a SOA [10]. Um Serviço é um Recurso disponível na rede. É implementado por um Sistema, capaz de executar uma operação que atente a alguma Requisição de Serviço.

Um Serviço pode ser caracterizado por uma ou mais Descrições de Serviço, armazenada no Registro de Serviços. As várias descrições de serviço podem prover visões diferentes do mesmo serviço. 
Isso é útil quando um Provedor deseja oferecer a diferentes Consumidores alguma visão especializada de um Serviço. Descrições de serviço são geralmente compostas da especificação sintática e semântica das habilidades do serviço. Essa Especificação é projetada e implementada pelo Desenvolvedor. A descrição do serviço pode conter Informações Adicionais, podendo ser coletada mesmo durante a execução do serviço. Tais informações dizem respeito ao comportamento do serviço enquanto é executado.

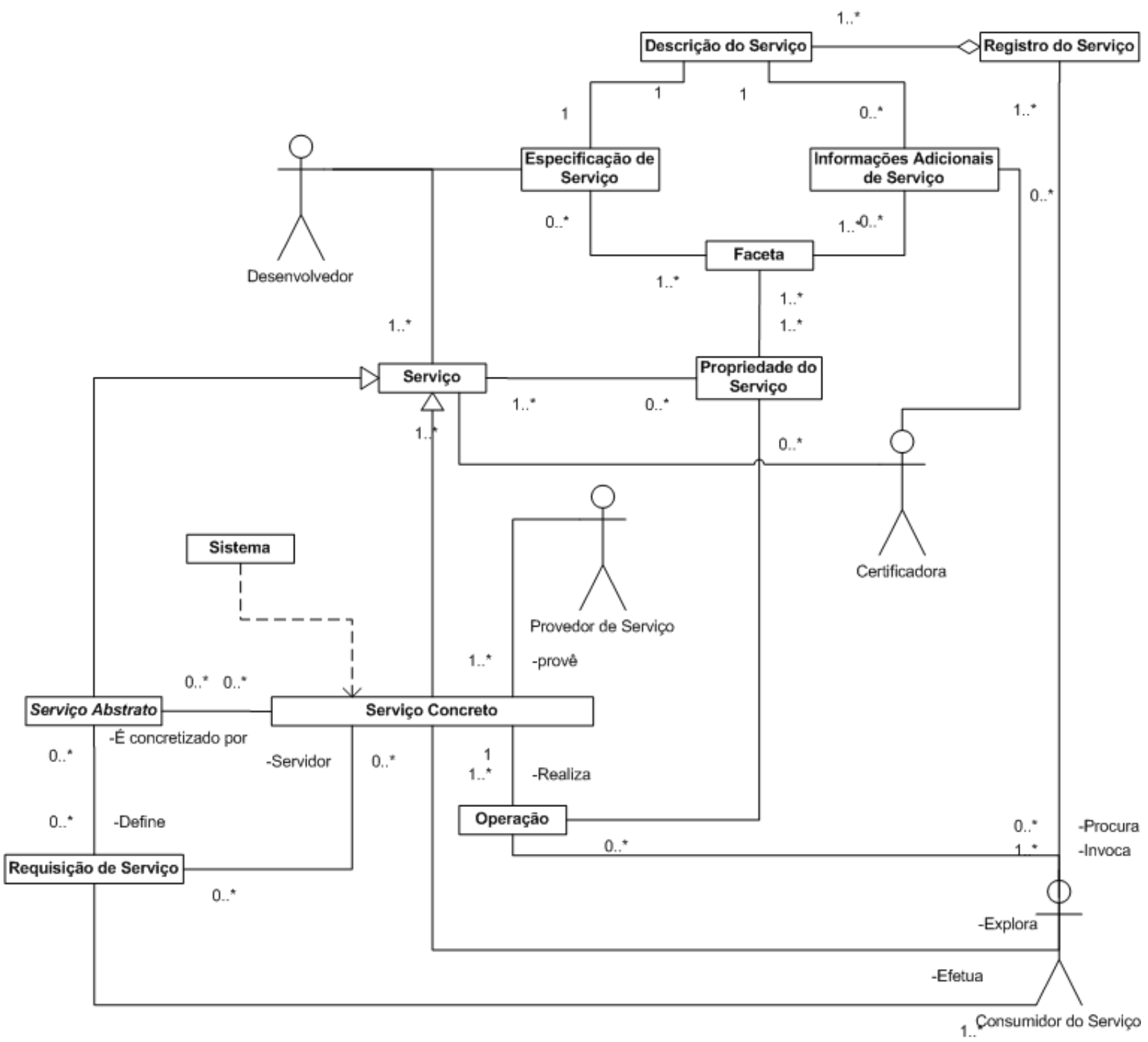

Figura 2.1 Principais conceitos relacionados a $S O A$.

A SOA está muito mais ligada ao negócio, que requer contextos envolvidos e modelagem com o mesmo nível de definição. Um conjunto de serviços disponíveis, por exemplo, de setor financeiro, fazem sentido no contexto de negócios: calcular juros e risco, estabelecer valor e avaliar decisões são exemplos de serviços neste cenário. Assim, fica mais evidente que o objetivo principal é a melhoria do negócio, através de agilidade do desenvolvimento, qualidade do produto e redução de custo.

\subsubsection{UDDI}

Mantida pelo grupo de padrões OASIS (Organization for de Advancement of Structured Information Standards) [70], UDDI é uma especificação técnica para a criação de um serviço de registro que cataloga e organiza Web Services. O Registro (ou Registry), implementação do UDDI, contém um banco de dados de estruturas padrões, definidas em sua especificação. O UDDI é considerado 
pelo OASIS o elemento centra da arquitetura de Web Services[73].

UDDI funciona de maneira semelhante a um catálogo telefônico. Os provedores de serviço adicionam e excluem informações a respeito dos serviços, enquanto os consumidores realizam consultas, obtendo o WSDL para utilizá-los [22]. O serviço UDDI disponibiliza páginas brancas (informações sobre empresas provedoras de serviço), páginas amarelas (classificação por categoria de negócios dos serviços) e páginas verdes (detalhes técnicos sobre os serviços).

\subsubsection{Modelagem de Serviços e WS-BPEL}

Faz parte do processo de modelagem definir como se relacionam os diversos serviços e como o fluxo de execução é realizado. Com a finalidade de padronizar a notação para a execução de processos de negócios, a linguagem WS-BPEL (Web Services Business Process Execution Language), também chamada BPEL, foi criada pela OASIS (Organization for the Advancement of Structured Information Standards) [72], descrevendo a composição dos Web Services e do relacionamento entre eles. Isso permite implementar funcionalidades complexas. A primeira versão foi desenvolvida em 2002 pela IBM, BEA e Microsoft. Em 2003, a OASIS recebeu uma versão para padronização e em 2007 lançou oficialmente a versão 2.0 com o nome de WS-BPEL 2.0.

BPEL permite a utilização de determinados tipos de construções como estruturas de repetição, estruturas condicionais, variáveis e atribuições, podendo se definir um processo como síncrono ou assíncrono. Em sua estrutura, BPEL é composto pelos elementos $<$ process $>,<$ partnerLinks $>,<$ message $>,<$ variables $>,<$ assign $>,<$ invoke $>,<$ receive $>,<$ reply $>,<$ throw $>,<$ wait $>$, $<$ empty $>,<$ sequence $>,<$ flow $\rangle<$ switch $>,<$ while $>,<$ pick $>$, $<$ eventHandlers $>$, entre outros.

O elemento process é a raiz da estrutura. Dentro deste elemento, é necessário haver pelo menos uma atividade, tendo a estrutura apresentada na Listagem 2.1.

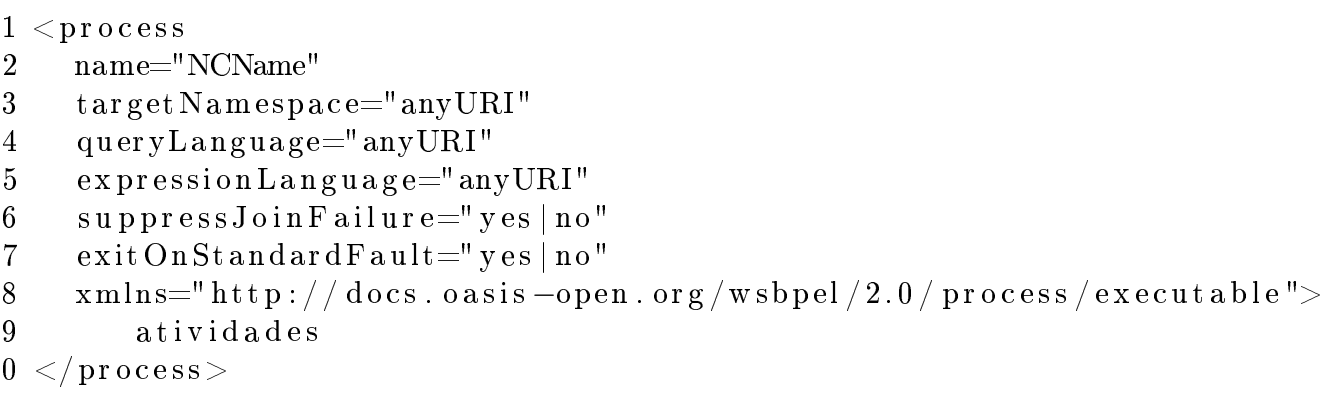

Listagem 2.1Estrutura para definição de Process

O relacionamento entre Web Services e parceiros (partners) é descrito por um elemento específico, chamado partnerLink (Listagem 2.2). Cada parceiro relacionado no processo BPEL deve ter sua descrição de serviço (WSDL). Cada partnerLink possui um atributo partnerLinkType que lhe caracteriza. Deve possuir um nome exclusivo para identificar o parceiro.

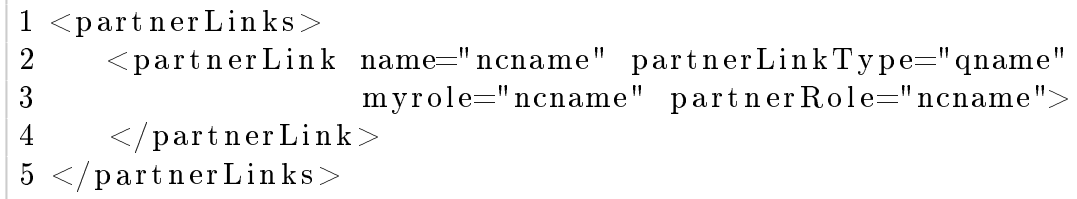

Listagem 2.2 Estrutura para definição de Partner

Outros elementos são projetados para a manipulação de dados. O elemento variable é diretamente ligado com uma mensagem do WSDL. As várias mensagens contidas são mapeadas para seu respectivo elemento variable, agrupados no elemento variables (Listagem 2.3).

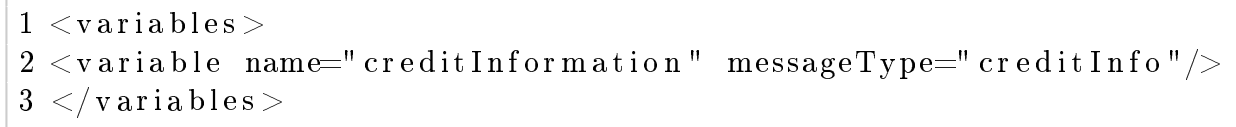

Listagem 2.3Estrutura para definição de Variables 
De acordo com o processo, pode se fazer necessário realizar uma atividade de cópia de variáveis, permitida através da atividade assign, conforme Listagem 2.4. É permitido também que sejam realizadas cópias de outros elementos para uma variável, por exemplo, a partir de um partnerLink.

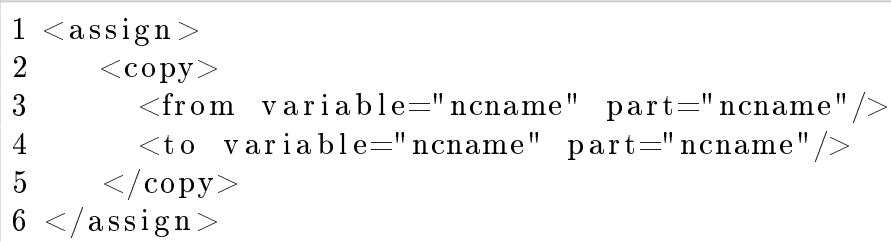

Listagem 2.4Estrutura para definição de Assign

A comunicação entre Web Services acontece por meio de envios, recebimentos e respostas de mensagens. Uma invocação pode ocorrer através de uma chamada a um Web Service dentre os listados como parceiro. A chamada através da atividade Invoke pode ser síncrona ou assíncrona. Para uma chamada assíncrona, é necessário especificar a variável de entrada, mas a de saída não. Já uma chamada síncrona, é preciso especificar ambas. A estrutura deste elemento é apresentada na Listagem 2.5.

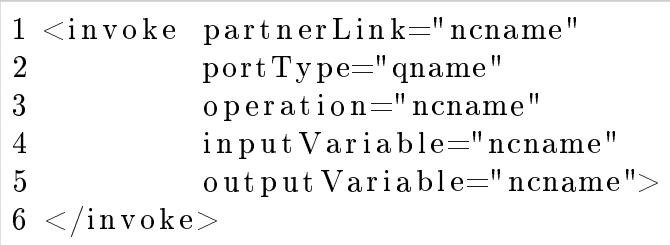

Listagem 2.5 Estrutura para definição de Invoke

A atividade de recebimento (receive) determina a operação que será invocada, o tipo de porta e o parceiro (Listagem 2.6). O início de um processo pode ocorrer de diversas formas, sendo uma delas através do atributo createInstance, quando com valor yes. O processo não deve conter duas atividades do tipo receive com os mesmos parceiros, tipo de porta e operação.

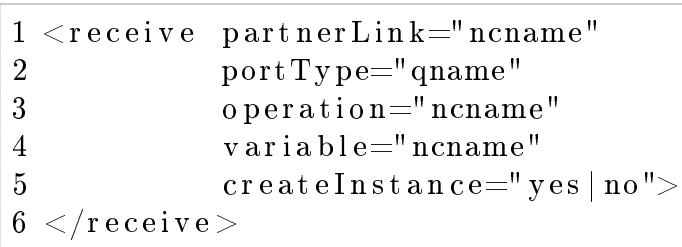

Listagem 2.6Estrutura para definição de Receive

A atividade de resposta (reply) é utilizada para retornar uma mensagem após a ocorrência de uma atividade receive. É utilizada para interações síncronas, possibilitando transferir informações utilizando o campo variável. A Listagem 2.7 mostra a estrutura da atividade reply.

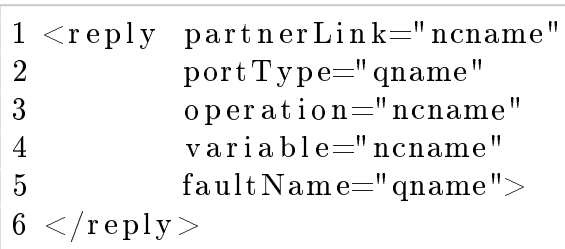

Listagem 2.7Estrutura para definição de Reply

Para os casos em que o processo identifica alguma falha, a atividade Throw (Listagem 2.8) permite notificar os parceiros sobre o ocorrido, para que tomem as medidas necessárias.

$1<$ throw faultName="qname" faultVariable="ncname" $/>$

\section{Listagem 2.8Estrutura para definição de Throw}

A atividade Wait permite congelar o processo durante uma fatia de tempo, ou até que um determinado horário aconteça, chamado limite (deadline). 
$1<$ wait (for="duration-expr" | until="deadline-expr") />

Listagem 2.9Estrutura para definição de Wait

Por fim, pode-se definir também uma atividade vazia que não realiza nenhuma ação. Ela é útil para situações de tratamento de exceção e que não é necessária ação para intervenção. Neste caso, utiliza-se a atividade empty (Listagem 2.10).

$1<$ empty $/>$

\section{Listagem 2.10Estrutura para definição de Empty}

Existem ainda outras funcionalidades na linguagem que permitem manipular o fluxo de controle do processo. Por exemplo, pode-se utilizar estruturas tais como If (Listagem 2.11), Switch (Listagem 2.12) ou While (Listagem 2.13).

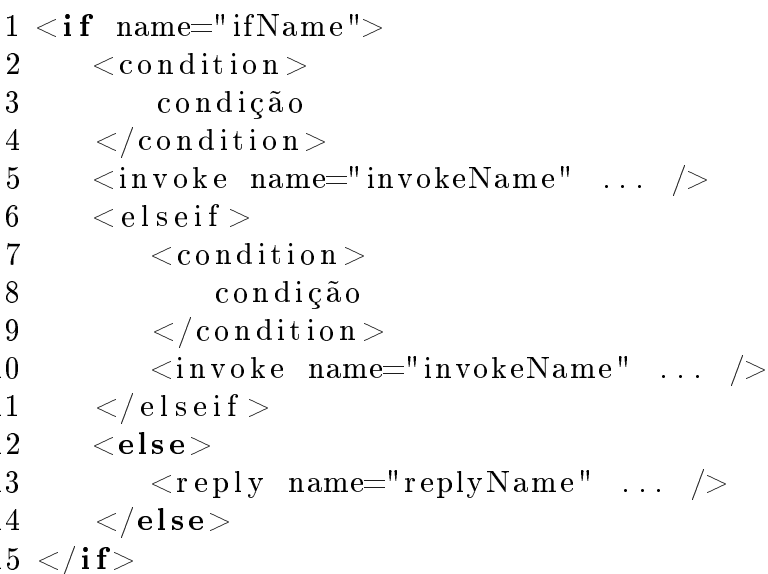

Listagem 2.11Estrutura para definição de If

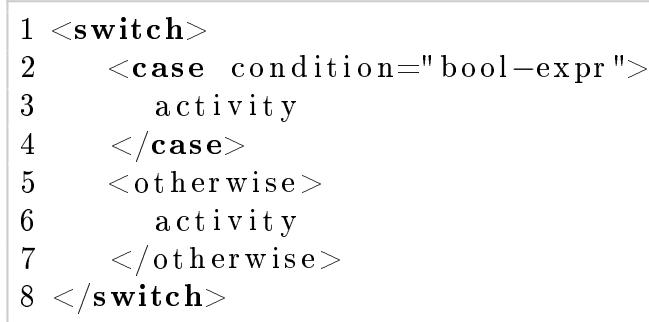

Listagem 2.12 Estrutura para definição de Switch

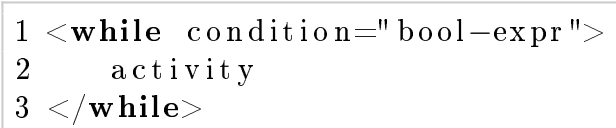

Listagem 2.13Estrutura para definição de While

A atividade pick aguarda pela ocorrência de um evento de recebimento de mensagem. Quando o evento acontece, a atividade associada a ele é executada. Os eventos podem ser a detecção de uma mensagem ou no modo temporizado, conforme é apresentado na Listagem 2.14.

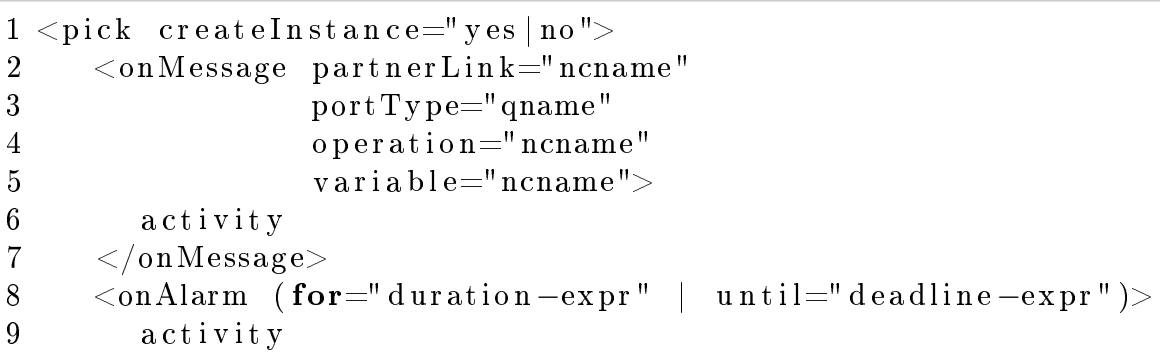


$10<$ /onAlarm $>$

$11</$ pick $>$

Listagem 2.14Estrutura para definição de Pick

Pode-se também determinar se uma ou mais atividade devem ser realizadas em paralelo ou de modo sequencial. A tag de sequência (sequence, visto na Listagem 2.15) indica que as atividades serão realizadas sequencialmente. Já flow (visto na Listagem 2.16) indica que as atividades serão executadas paralelamente.

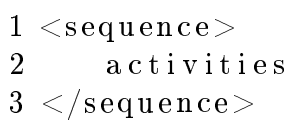

Listagem 2.15Estrutura para definição de Sequence

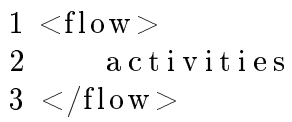

Listagem 2.16Estrutura para definição de Flow

Para a manipulação de exceção, existe um mecanismo oferecido no BPEL. É possível definir um catch ou mais e no máximo um catchAll. A Listagem 2.17 apresenta como é estruturado o comando faultHandlers.

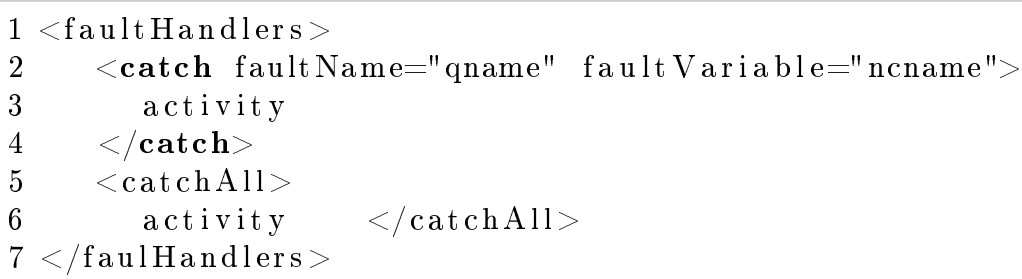

Listagem 2.17Estrutura para definição de FaultHandlers

Esses são os principais comandos do BPEL. Existem outras, mais que não são relevantes para presente trabalho. O próprio site de definição do BPEL apresenta mais detalhes sobre a utilização de cada um [72]

\subsection{Conceitos e Definições}

Existem duas linhas de pesquisa relacionadas a Web Services. O estilo de arquitetura chamado REST (Representational State Transfer), que define um conjunto de princípios para representação de Web Services e a arquitetura que dê suporte a eles [38]. É escopo do trabalho apenas a arquitetura convencional de Web Services(REST não é considerado no escopo desta pesquisa).

Existe um certo consenso sobre a definição para Web Services. Algumas dessas definições são mais técnicas e formais; outras, no entanto, são mais simples e menos abstratas. Todas essas definições ajudam a entender outros conceitos que estão relacionados à aplicação da tecnologia.

O World Wide Web Consortium (W3C), define da seguinte forma um serviço web:

"É um sistema de software projetado para dar suporte à interoperabilidade entre máquinas sobre a rede de aplicações web, mas utilizam uma arquitetura específica. Possui uma interface descrita em um formato processado por computadores chamada WSDL. Sistemas interagem com Web Services de maneira estipulada pela sua descrição usando mensagens SOAP, tipicamente enviando-as sobre HTTP com uma serialização baseada em XML, juntamente com outros padrões Web relacionados"[98]. 
Outra definição bastante referenciada é dada por Curbera [28]. Segundo o autor, o serviço web é uma aplicação disponível através de uma rede e que é capaz de interagir utilizando protocolos web de comunicação sobre interfaces bem definidas, e que são descritas por uma linguagem funcional padrão.

Embora mais simples, uma outra definição bastante útil é dada por Rouvellou [62]. Web Services compõem uma tecnologia emergente para a exposição de serviços através da Internet, possibilitando a interação entre aplicações dinamicamente, desde simples troca de informações a complicados processos de negócio.

Essas definições fornecem embasamento para analisar Web Services. Isso permite visualizá-los sob diferentes perspectivas, tanto tecnologicamente quanto relacionados a negócios.

\subsubsection{Web Service como Tecnologia}

O termo "Serviço" é responsável pelo aspecto tecnológico de Web Services[21]. Pode-se avaliar um serviço, especificamente em sistemas orientados a objetos, como sendo um método, um processo, ou simplesmente uma comunicação. Esses métodos, ou "serviços" são operações que a aplicação realiza para atingir um objetivo de negócio.

Web Services são definidos como sendo parte de uma tecnologia de middleware, com o claro objetivo de padronizar a comunicação entre diversos componentes/aplicações, distribuídos sobre uma rede. Mesmo em ambientes com aplicações heterogêneas, Web Services provêm organização e integração de negócio, com objetivo de atender às exigências e metas comerciais. Sua arquitetura é formada por uma camada de mensagens, e uma camada para transporte, como visto na figura 2.2. Na camada de mensagem estão o próprio serviço, a descrição de sua interface e o empacotamento. Na camada de transporte estão os protocolos que serão utilizados.

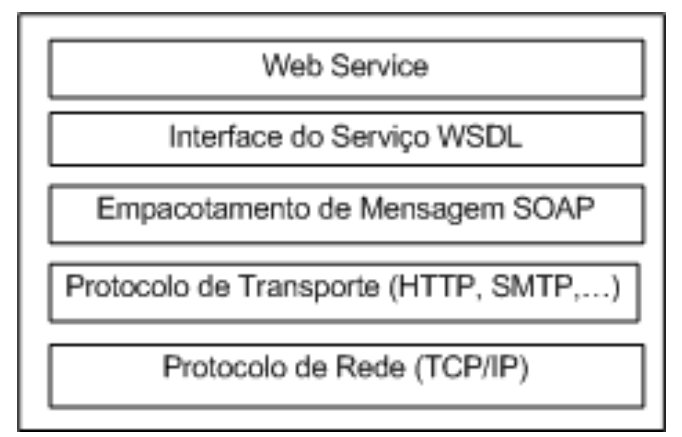

Figura 2.2Arquitetura de um Web Service

Existem alguns padrões que auxiliam a utilização e o desenvolvimento de tais serviços [4]. Baseados em mensagens XML, podem-se listar os mais comuns: o próprio XML, SOAP e WSDL.

XML, do inglês Extensible Markup Language, é uma linguagem padrão, utilizada para armazenamento de informações, mas também utilizada como interface de comunicação entre sistemas distintos. Desenvolvida com base em SGML (Standard Generalized Markup Language) pela W3C, teve sua primeira versão disponibilizada em 1998. Seus marcadores identificam pedaços de informações, localizados entre um marcador de início e um marcador de fim ( $<$ marcador $>$ e $</$ marcador $>$ ). Muitas especificações são construídas sobre XML com a finalidade de tornar mais flexíveis, possibilitando a aplicação em grande variedade de aplicações, incluindo Web Services.

SOAP, do inglês Simple Object Access Protocol, especifica o formato da mensagem que define um modo uniforme de se transmitir dados XML [20]. Esse padrão permite que uma aplicação invoque uma outra aplicação através da utilização de mensagens XML pela rede.

WSDL, do inglês Web Services Description Language, é utilizado para descrever o serviço disponível no registro de serviços. Contém informações detalhadas que permitem o uso do Web Service [1]. Descrito em XML, o WSDL fornece a localização do Web Service, suas funções e operações, além do formato e tipo de dados [98]. Do ponto de vista de fornecedor, ele informa os serviços oferecidos. Do ponto de vista de consumidor, ele informa os serviços pelos quais se está procurando. 
UDDI, do inglês Universal Description, Discovery and Integration é desenvolvido para publicação e localização de serviço. Ele coleta todos os serviços disponíveis numa rede e centraliza no registro [21]. Com isso, ele funciona como um catálogo, disponibilizando serviços similares em categorias e provendo funções de publicação e busca de provedores e consumidores dos Web Services.

Embora haja uma forte conotação do uso de Web Services através da Internet (até mesmo pelo próprio termo $W E B$ ), não é necessário que um serviço esteja na Web. Existem muitos exemplos de empresas que disponibilizam dentro de suas Intranet's toda a arquitetura necessária para o desenvolvimento e utilização dos serviços. Dependendo dos padrões organizacionais, o cenário pode passar de aplicações heterogêneas para um conjunto homogêneo de sistemas e componentes, o que pode ajudar na direção de algumas soluções específicas, aplicáveis particularmente a cada um desses cenários.

\subsubsection{Web Service como Solução de Negócios}

A demanda de áreas de negócio é cada vez mais exigente, principalmente no que é relacionado ao mundo real de serviços. A camada de middleware é responsável por destacar a possibilidade de se utilizar aplicações diferentes, para negócios diferentes, de forma bastante dinâmica e integrada. Através de interfaces homogêneas e padrões de protocolos e linguagens, Web Services atualmente representam o estado da arte de serviços middleware.

A conotação de negócios dada à arquitetura de serviços se dá principalmente devido a soluções de baixo acoplamento, com relação custo x benefício bastante interessante, provê privacidade e segurança, além de possibilitar uma remodelagem do desenvolvimento de sistemas.

A adoção de tal tecnologia começa a ganhar força no cenário atual de negócios eletrônicos. À medida em que essas frentes avançam, é quase que essencial que as soluções tirem proveito de alguma forma das vantagens oferecidas pela aplicação de Serviços Web, visando sempre melhorar o produto final e a velocidade com que é desenvolvido.

\subsubsection{Interoperabilidade}

Muito se vê sobre as vantagens da implementação da tecnologia de Web Services, principalmente num ambiente orientado a serviços. Dentre os benefícios apresentados está a interoperabilidade. Segundo o glossário do IEEE, interoperabilidade é a habilidade de dois ou mais sistemas ou componentes em trocar informações e utilizá-las [47]. Diversos sistemas são implementados de maneiras bastante particulares de modo que dificultam a interoperabilidade.

Para evitar este problema, são acordados padrões que permitem a comunicação entre componentes específicos sem que as respectivas plataformas, linguagens ou até mesmo características próprias de implementação sejam dificultadas ou inviabilizada [61]. Para Web Services, a interoperabilidade auxilia a aplicação de tais padrões, mesmo para os que não são amplamente utilizados na indústria ou no meio acadêmico [74].

Questões relacionadas a interoperabilidade são estudadas e avaliadas por pesquisadores e por institutos especializados [61, 74, 13, 79].

\subsubsection{Tipos de Serviços}

São inúmeras as formas de se desenvolver soluções baseadas em Web Services, ou até mesmo o próprio serviço [10]. Dependendo da solução, o serviço necessário pode ser mais representativo para a aplicação. Uma composição de serviços, por exemplo, é formada por um conjunto de serviços, mas age como apenas um, para quem o utiliza. Sendo composto ou simples, um serviço pode ser ou não baseado em estado. Além disso, pode ser associado a uma implementação, fazendo dele um serviço concreto, ou representar simplesmente uma ideia de serviço, sendo então um serviço abstrato. A representação desses tipos de serviços ${ }^{1}$ pode ser vista na Figura 2.3.

\footnotetext{
${ }^{1}$ figura adaptada, seguindo o conceito sugerido por Baresi [10]
} 


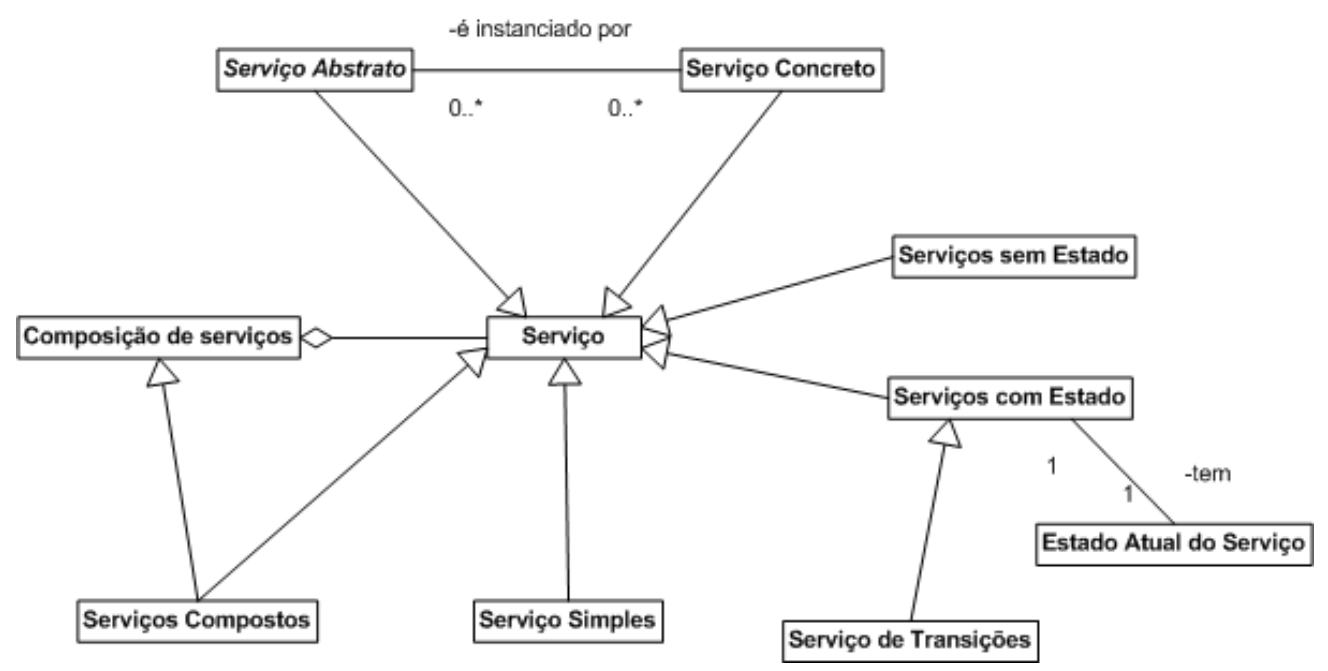

Figura 2.3Tipos de Web Services

\subsection{SOAP}

Como visto anteriormente, SOAP define um formato padrão de transmissão de mensagens entre os serviços. Uma das principais vantagens de SOAP é a distinção entre o formato do dado a ser transmitido e o protocolo responsável pelo transporte.

SOAP é independente do protocolo de transporte. Contudo, utilizam-se com frequência HTTP e HTTPS, ambos sobre TCP/IP [90].

A mensagem SOAP é constituída por um documento XML, cujo elemento raiz, chamado Envelope, contém Header e Body (como descrito na Figura 2.4). Isso o torna portável, podendo ser facilmente interpretado.

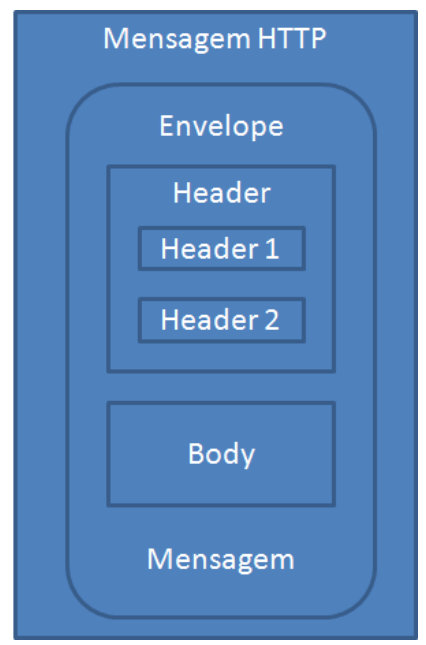

Figura 2.4Estrutura de uma mensagem SOAP

\subsubsection{XML Schema}

Surgido no início de 2001, XML Schema Definition Language (XSDL), descreve a estrutura de um documento XML. Apesar de complexo, provê recursos que permitem determinar como a comunicação pode ser feita [41], sendo usado para garantir a consistência da estrutura dos objetos e mensagens.

Os elementos são declarados através da tag <element>, cujos principais atributos são:

- name: nome do elemento; 
- type: tipo de dados do elemento;

- minOccurs: define a quantidade mínima de vezes que o elemento pode aparecer;

- maxOccurs: define a quantidade máxima de vezes que o elemento pode aparecer ${ }^{2}$.

Para determinar os tipos de dados e assim garantir a integridade, existe um conjunto pré-definido de tipos, podendo ser utilizados tanto com elementos, quanto com atributos. A seguir, os tipos de dados do XML Schema:

- xsd:string - string de caracteres de comprimento ilimitado;

- xsd:boolean - valor booleano (true, false - 1 ou 0);

- xsd:decimal - número decimal;

- xsd:float - ponto flutuante;

- xsd:date - Uma data no calendário gregoriano;

- xsd:dateTime - Um instante específico no calendário gregoriano;

- xsd:integer - Um número inteiro.

A Listagem 2.18 apresenta um exemplo de XML Schema.

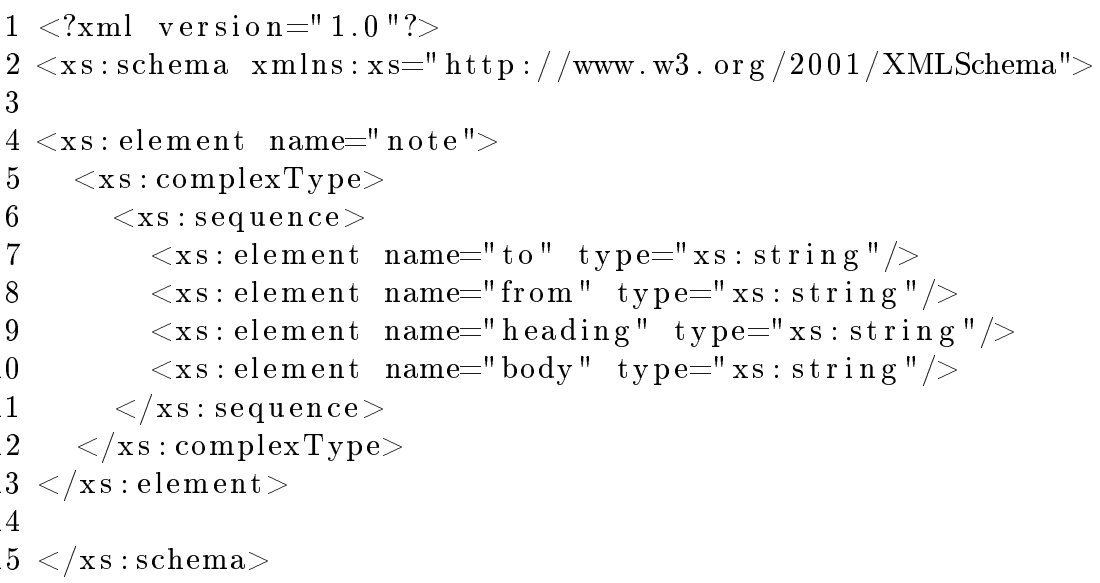

Listagem 2.18Exemplo de um XML Schema

\subsubsection{Mensagens SOAP e Estilo de codificação SOAP}

A flexibilidade SOAP devida à implementação através de XML permite que a forma do documento seja feita de acordo com a necessidade. Dois documentos distintos podem ser definidos com semânticas idênticas, ou seja, embora diferentes, significam a mesma coisa.

Existem dois diferentes tipos de mensagens SOAP: RPC (Remote Procedure Call) e EDI (Electronic Document Interchange). O tipo RPC, chamado também de $R P C$-style, permite a execução direta de uma função, feita de maneira explícita. No tipo EDI, ou Document-style, quem envia a mensagem submete o objeto inteiro, deixando a cargo do servidor decidir qual função será executada. As regras para construção das mensagens estão descritas na especificação SOAP 1.1 e SOAP $1.2^{3}$.

A Codificação determina a forma como os dados são representados [86]. Os dados codificados da mensagem são disponibilizados dentro do corpo (body) e são enviados para outra aplicação.

\footnotetext{
${ }^{2}$ para especificar que a quantidade máxima é ilimitada, utiliza-se como valor unbounded

${ }^{3}$ disponível em http://www.w3.org/standards/techs/soap, acessado maio/2010
} 
Seus estilos podem ser encoded e Literal. No estilo encoded, é utilizada uma codificação predefinida que informa como deve ser mapeada cada tipo de dados do documento. O estilo Literal indica que as regras de codificação foram definidas no próprio XML Schema. A Figura 2.5 apresenta um comparativo de Encoded, Literal, EDI e RPC.

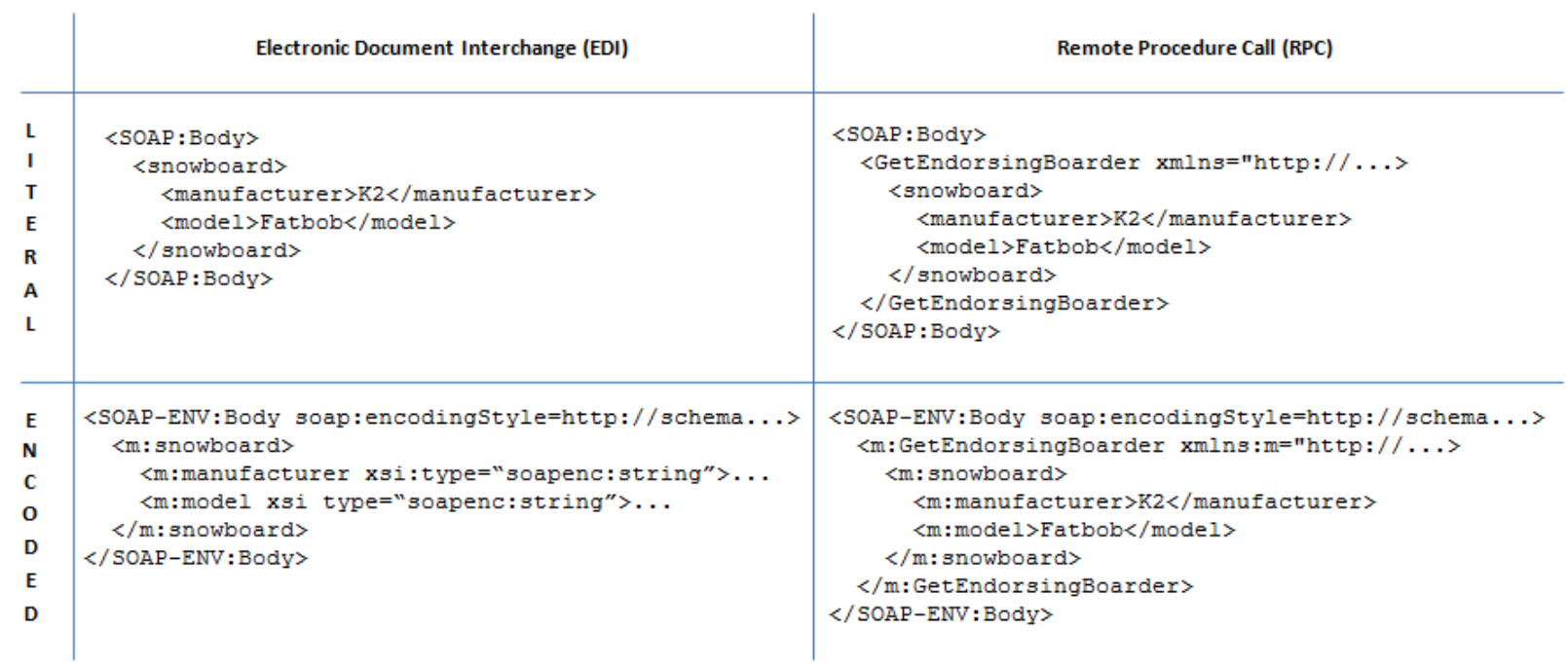

Figura 2.5 Comparação entre os estilos de codificação e os tipos de mensagens

\subsubsection{Mensagem de falha SOAP}

A transmissão das mensagens está sujeita às condições do meio de transmissão e até mesmo às condições de processamento da informação. Na ocorrência de falhas, mensagens SOAP são identificadas com a presença de um elemento $<$ Fault $>$ [96]. Tal elemento aparece como sendo filho do elemento $<$ body $>$, limitado a no máximo uma ocorrência.

O elemento $<$ Fault $>$ contém os seguintes subelementos:

- code: código que identifica a falha;

- reason: texto explicativo sobre a falha;

- detail (opcional): detalhes da falha, específicos da aplicação, por exemplo linha do código;

- node (opcional): informações sobre o elemento da mensagem origem que causou a falha;

- role (opcional): uri que identifica quem estava executando quando a falha aconteceu.

\subsection{WSDL}

Como apresentado anteriormente, WSDL descreve as estruturas e os tipos de dados usados pelo serviço. Ele também provê informações de como mapeá-los nas mensagens, vinculando à implementação [66]. Tal descrição é utilizada tanto pelo provedor quanto pelo consumidor. O consumidor cria a mensagem no formato esperado e utiliza o protocolo indicado, com a finalidade de consumir o serviço. Já o provedor utiliza para entender, classificar e mapear a mensagem para o programa apropriado [66]

A Figura 2.6 representa conceitualmente um documento WSDL. A parte abstrata é composta pelos seguintes elementos: Tipos, contendo as definições que independem de linguagem; elementos de mensagens, que descrevem as entradas e saídas do serviço; elementos de operações, que representam operações específicas, com seus respectivos parâmetros de entrada e saída. Já a parte concreta se refere à implementação para o serviço, formada por dois elementos fundamentais: Interfaces, que 


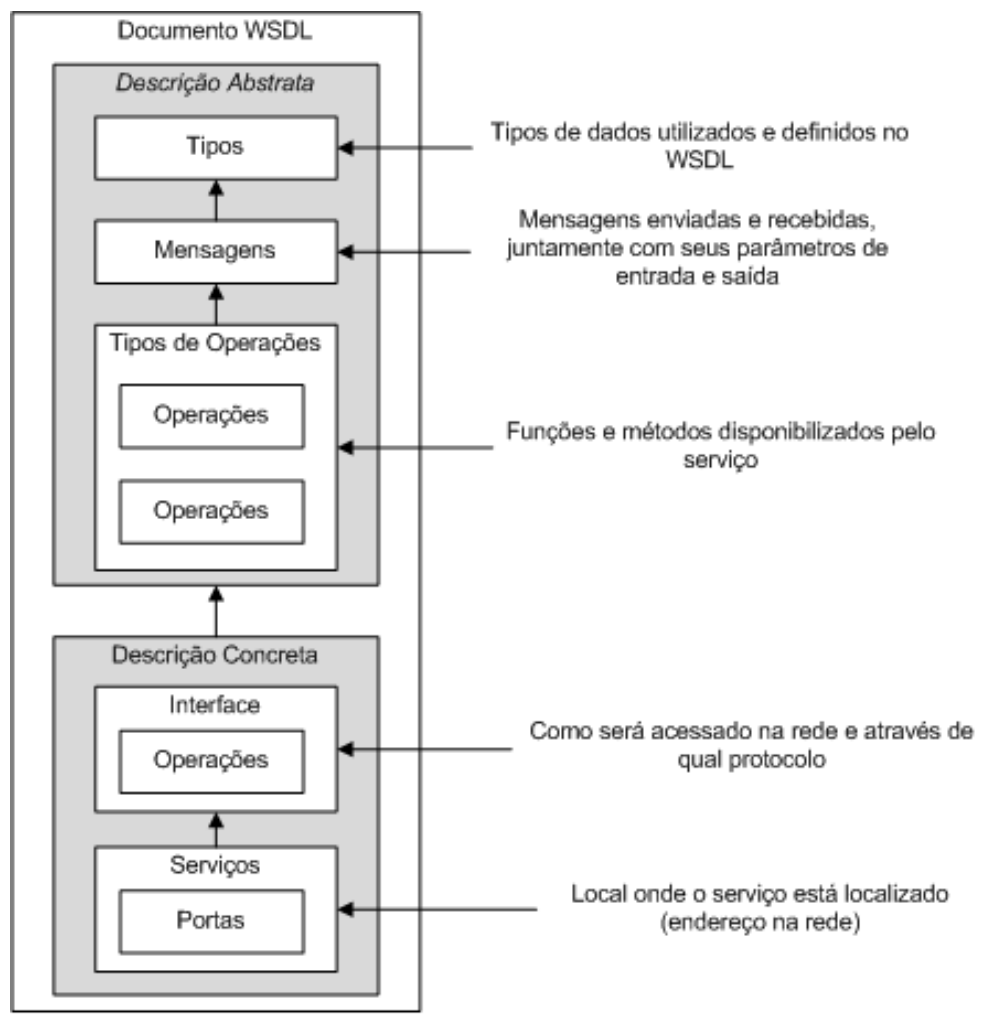

Figura 2.6Estrutura conceitual da descrição de um serviço (WSDL)

definem a ligação entre as operações na descrição abstrata com um protocolo de rede; Serviço, que apresenta o local onde o serviço foi publicado e está disponível [56].

WSDL pode ser usado para especificar interfaces dos Web Services com diversos protocolos. O SOAP é o mais difundido [22].

\subsection{Aplicação Exemplo}

Para ilustrar o uso de Web Services, será apresentado um exemplo ${ }^{4}$. Suponha um cenário no qual existe uma empresa de snowboard, que provê aos fabricantes de snowboard uma base de dados e serviços de consulta por recomendações. Um cliente pode enviar ao servidor uma requisição de informação usando requisição SOAP, visto na Listagem 2.19. Em linguagem natural, a Listagem 2.19 encapsula a questão "qual profissional de snowboard recomenda a K2 FatBob?"

1 POST/EndorsementSearch HTTP/1.1

2 Host: www. snowboard-info.com

3 Content-Type: text $/ \mathrm{xml}$; charset="utf -8 "

4 Content-Length: 261

5 SOAPAction: "http://www. snowboard-info.com/EndorsementSearch"

$6<$ SOAP-ENV: Envelope

7 xmlns:SOAP-ENV="http ://schemas.xmlsoap.org/soap/envelope/"

8 SOAP-ENV: encodingStyle="http://schemas.xmlsoap.org/soap/encoding /">

9 SOAP-ENV: Body>

$10<\mathrm{m}$ : GetEndorsingBoarder xmlns:m="http:// namespaces.snowboard-info.com">

$11<$ manufacturer $>\mathrm{K} 2</$ manufacturer $>$

$12<$ model $>$ Fatbob $</$ model $>$

$13</$ m: GetEndorsingBoarder $>$

$14<$ SOAP-ENV: Body $>$

$15<$ SOAP-ENV: Envelope $>$

\footnotetext{
${ }^{4}$ Exemplo extraído da página da IBM: http://www.ibm.com/developerworks/webservices/library/ws-soap/index. html. Acessado em 14/04/2010.
} 


\section{Listagem 2.19Exemplo de requisição SOAP}

Como resposta, o servidor envia uma mensagem SOAP 1.1 para a requisição realizada (Listagem 2.20). Em outras palavras, ele informa que "Chris Englesmann" recomenda. WSDL provê uma padronização para especificação de serviços capaz de unir tipos de requisição com os requisitos necessários para processá-las.

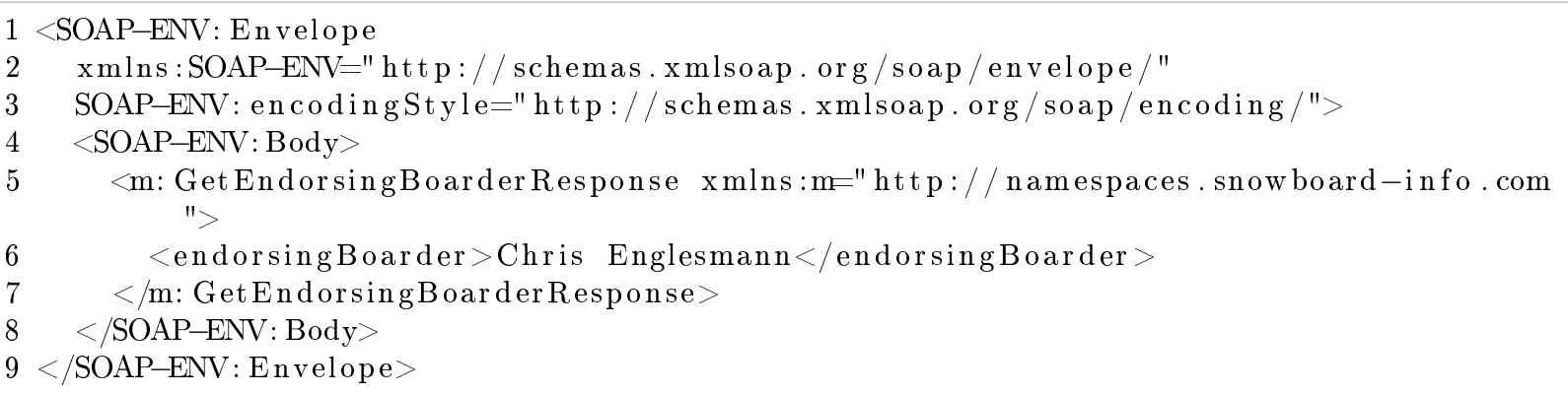

Listagem 2.20Exemplo de resposta SOAP

A fim de obter todos os portais de snowboard e também as discussões relacionadas ao sistema, é necessário definir portas de comunicação no WSDL. Mais detalhes podem ser vistos na Listagem 2.21 .

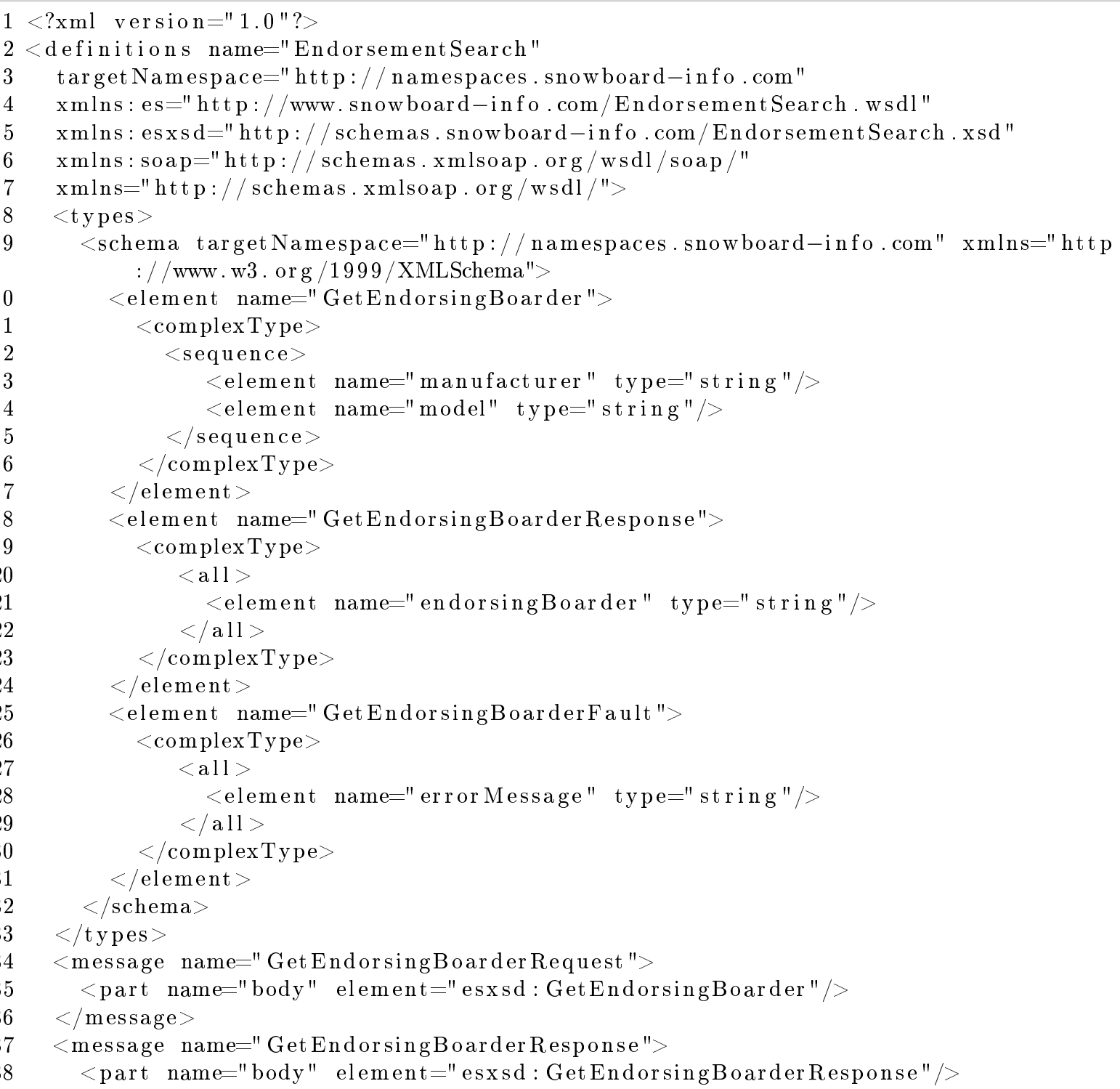


$</$ message $>$

$<$ portType name="GetEndorsingBoarderPortType" $>$

$<$ operation name="GetEndorsingBoarder" $>$

$<$ input message="es : GetEndorsingBoarderRequest" $/>$

$<$ output message="es: GetEndorsingBoarderResponse"/>

$<$ fault message="es: GetEndorsingBoarderFault" $/>$

$</$ operation $>$

$</$ portType $>$

$<$ binding name="EndorsementSearchSoapBinding" type="es :

GetEndorsingBoarderPortType">

<soap:binding style="document" transport="http://schemas.xmlsoap.org/soap/ http" />

$<$ operation name="GetEndorsingBoarder" $>$

$<$ soap: operation soapAction="http://www. snowboard-info.com/

EndorsementSearch"/>

$<$ input $>$

$<$ soap:body use="literal" namespace="http://schemas.snowboard-info.com/

EndorsementSearch. $x$ sd" $^{\prime \prime} />$

$</$ input $>$

$<$ output $>$

$<$ soap : body use="literal" namespace="http://schemas.snowboard-info.com/

EndorsementSearch.xsd"/>

$</$ output $>$

$<$ fault $>$

$<$ soap : body use="literal" namespace="http://schemas.snowboard-info.com/ $</$ fault $>$ EndorsementSearch.xsd"/>

$</$ operation $>$

$</$ binding $>$

$<$ service name="EndorsementSearchService" $>$

$<$ documentation $>$ snowboarding - info.com Endorsement Service $<$ /documentation $>$

$<$ port name="GetEndorsingBoarderPort" binding="es: Endorsement SearchSoapBinding">

$<$ soap: address location="http://www.snowboard-info.com/EndorsementSearch"/>

$</$ port $>$

$</$ service $>$

$8</$ definitions $>$

Listagem 2.21Descrição WSDL para consulta a recomendações de Snowboarding

Embora pareça longo, o WSDL é bastante simples. O exemplo não somente utiliza quase todas as facetas de WSDL, mas também usa trechos de XML para fazer a ligação entre o SOAP e o WSDL.

O elemento $<$ message $>$ define o formato de cada transmissão. No exemplo, uma mensagem representa requisição de EndorsingBoarder e a outra, a resposta. Isto mostra que o corpo da mensagem é um elemento particular do schema XML, dentro da seção de tipos. Dividir a transmissão em mensagens depende de uma visão lógica da informação. Por exemplo, se a transmissão é uma chamada remota a uma rotina, a mensagem pode ser dividida em partes, sendo a primeira o nome da rotina e as mensagens seguintes os seus respectivos parâmetros. Há uma relação natural entre a granularidade do tipo de dados com a possibilidade de divisão em subpartes.

O elemento < portType> agrupa mensagens que formam uma operação lógica. No exemplo, pode-se ter uma requisição de EndorsingBoarder, que dispara uma resposta de um EndorsingBoarder, ou, no caso de erro, um EndorsingBoarderFault.

O elemento < binding > provê uma conexão entre o mundo físico e lógico. No caso, ele leva a operação definida através da porta abstrata e a conecta à porta concreta, com a descrição de como é transmitida pelo SOAP. No exemplo, GetEndorsingBoarderPortType é especificado o estilo SOAP do documento. O estilo pode ser RPC ou Document, que define procedimentos de comunicação e até a direção das trocas de mensagens.

A ligação também especifica o protocolo de transporte como sendo HTTP. O elemento $<$ soap:operation $>$ relaciona as mensagens individuais das portas às definições de transmissão SOAP. 
Por ser transmitido via HTTP, é necessário definir o SoapAction, obrigatório quando transmitido por este protocolo. O valor é utilizado nos cabeçalhos das mensagens, com o objetivo de demonstrar a intenção da mensagem.

O último elemento, <service>, define o local físico para a comunicação. Utiliza os tipos de porta e as ligações especificadas anteriormente e, basicamente fornece o endereço Web para um provedor em particular. No exemplo, é onde está o servidor SOAP que provê as consultas de recomendações de snowboarding.

Supondo que, após o lançamento do serviço, inúmeros usuários passem a consumir o recurso. Isso faz surgir a necessidade de se configurar um serviço espelho que funcione como alternativa de acesso. Neste caso, o serviço é exatamente igual, mas provido por outro endereço físico, pelo qual será obtido. No WSDL, basta adicionar outro elemento < service>, como pode ser visto na Listagem 2.22. Os serviços, disponíveis com nomes e endereços distintos, podem ser localizados através do documento WSDL através de buscas, fazendo com que um seja alternativa para o outro.

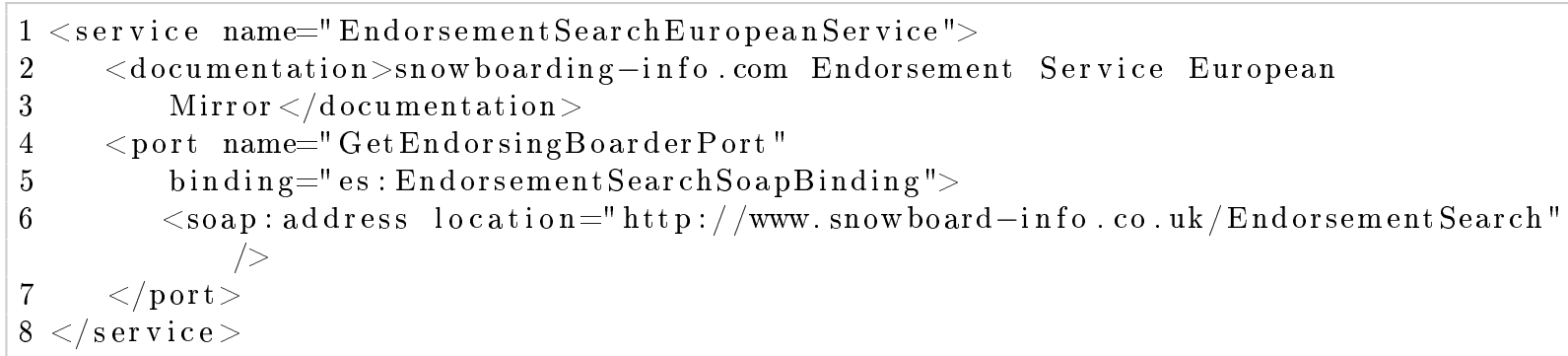

Listagem 2.22Elemento <service $>$ alternativo para múltiplos locais

\subsection{Qualidade de Web Services}

É necessário que o conjunto de testes realize uma cobertura nos principais requisitos, , funcionais e não funcionais, principalmente quando se tratam de Web Services:

- Funcional - avalia se o serviço apresenta respostas adequadas, de acordo com as especificações fornecidas;

- Não Funcional - avalia se:

- a capacidade de atender de maneira eficiente a um dado número de requisições é adequada (desempenho);

- são considerados aspectos de autorização, criptografia e proteção contra ataques (segurança) e;

- há aderência a um determinado conjunto de padrões pré-estabelecidos (interoperabilidade).

Existe uma série de características que devem ser consideradas quando se trata de testes de Web Services: falta de acesso ao código-fonte, alto dinamismo e baixo acoplamento, ambientes heterogêneos, plataformas independentes e ausência de interface com o usuário [73]. Isso, para execução manual de testes, torna a validação da qualidade de Web Services difícil [63].

No Capítulo 3 são exibidas com mais detalhes as particularidades da atividade de testes específicos para Web Services.

\subsection{Conclusão}

Muitos benefícios podem ser obtidos através da utilização de Web Services, possibilitando desenvolvimento rápido e com custos menores. Isso tem dado destaque de principal implementação numa arquitetura orientada a serviços. 
Neste capítulo foram apresentados conceitos de Web Services, suas aplicações e suas características tecnológicas, tais como SOA, WSDL, UDDI, entre outras. Foi apresentado também uma aplicação de exemplo. Por fim, foram apresentados quais aspectos determinam a qualidade de um dado serviço. 


\section{Capítulo 3}

\section{Teste de Web Services}

\subsection{Introdução}

Web Services têm se tornado mais comuns nas soluções adotadas para as aplicações atuais. Em virtude disso, a tarefa de testá-los passou a receber maior atenção [93]. Ainda é um desafio a verificação e validação de SOA devido principalmente ao baixo controle que o sistema integrador tem com os serviços utilizados [78], pois ainda são pouco explorados pela comunidade acadêmica e pela indústria [44].

Bloomberg apresenta um estudo sobre testes para Web Services e o que se espera como tendência [17]. Em seu trabalho, são citados novos cenários de testes que estão prestes a emergir e que consumidores e produtores de Web Services devem se adaptar a essa nova forma de computação.

As metodologias e técnicas atuais de testes, principalmente voltadas para web, exploram suas principais características [68]. Componentes de software podem ser escritos em diversas linguagens, baseados em diversos modelos [5]. Testes de Componentes formam uma das bases para as principais metodologias de testes de aplicações Web.

No presente trabalho, tem-se como foco a análise de confiabilidade de sistemas construídos a partir de Web Services. Este capítulo trata de conceitos fundamentais relacionados à atividade de testes e à aplicação de testes em Web Services isoladamente.

\subsection{Testes de Software}

Teste é uma atividade que faz parte do processo de desenvolvimento de software. Tem por objetivo validar e aumentar a qualidade do sistema através da identificação de erros [80]. A qualidade de software muitas vezes é confundida com a realização de testes. Mas, testes é uma parte crítica da garantia da qualidade e representa a fase de revisão de especificação, do projeto e do próprio software.

O aumento da complexidade dos sistemas e dos custos relacionados a falhas tem motivado a realização de testes. Com a crescente demanda por qualidade, passam a ser essenciais testes cada vez mais eficazes e bem planejados.

\subsubsection{Verificação e Validação}

Durante todo o ciclo de desenvolvimento de software, existe uma série de pontos que são sujeitos a análise. Isso é mais evidente quando o resultado da análise afeta diretamente a qualidade final do produto. Esses pontos podem ser classificados em dois tipos: os que avaliam se o produto está sendo construído corretamente e os que avaliam se o produto de fato corresponde ao especificado.

É exatamente o conceito de Verificação e Validação, ou frequentemente chamado de V\&V, que está atrelado às avaliações de qualidade do software. Durante a etapa de Verificação, busca-se assegurar que as funções do sistema estão sendo desenvolvidas de forma correta. Por outro lado, na 
etapa de Validação, o objetivo é garantir que o software construído atenda aos requisitos do usuário [80].

As atividades de V\&V são ligadas diretamente à disciplina de garantia da qualidade de software (ou SQA, do inglês Software Quality Assurance). Dentre as atividades de V\&V, tem-se: revisão técnica formal, inspeção de código, revisão de documentação, testes de desenvolvimento, testes de usabilidade, testes de desempenho, etc. A realização de testes representa um papel importante dentro de $\mathrm{V} \& \mathrm{~V}$.

No processo de engenharia de software, pode-se classificar as atividades em duas fases: a primeira, de construção, inicia-se com o levantamento de requisitos e termina com a codificação do sistema; a segunda, é a realização dos testes. Durante a primeira, técnicas de verificação são aplicadas. É nesta fase em que se acompanha a construção do produto (verificação de requisitos, verificação da arquitetura e projeto, verificação de aspectos estruturais do código, etc.). Durante a fase de validação, todo o produto já construído passa a ser validado, com o objetivo principal de avaliar se de fato está de acordo com o especificado. A realização de testes pode ocorrer tanto na primeira quanto na segunda fase do processo. São vistas a seguir com mais detalhes as fases do processo de teste.

\subsubsection{Objetivos de Testes}

Verificar e validar um sistema exige a execução de testes. Mesmo com definições de testes bastante consolidadas, empresas e pessoas possuem conceitos variados com relação à definição e objetivos de testes [27]. Tais conceitos estão associados principalmente a questões culturais, as quais passam a direcionar objetivos dos testes.

Com isso, identificar falhas é o objetivo maior da atividade de testes [64]. Encontrá-las, entretanto, não é a tarefa mais simples [80]. Devido a essa dificuldade, definir com exatidão o objetivo dos testes depende mais da estratégia de como serão abordados pontos de verificação e validação.

As falhas têm origem em diversas fases do ciclo de desenvolvimento. A Figura 3.1 mostra a distribuição dos defeitos segundo a origem: 37.6\% Especificação; 25.9\% Design; 36.5\% Construção [80].

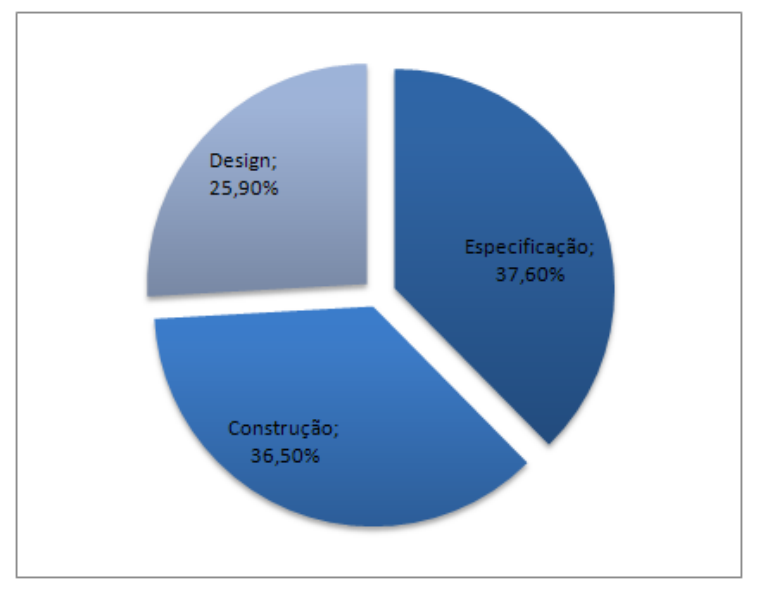

Figura 3.1 Origem do Defeito

Quanto mais tarde se localiza um defeito, mais cara é sua correção [80]. O custo para resolver um defeito pode até mesmo ultrapassar o valor do software, dependendo da fase em que é localizado. A Figura 3.2 mostra o custo relativo da correção de um defeito de acordo com a fase em que ele é identificado.

Diferentes pessoas e organizações têm visões diferentes dos reais objetivos de testes. Beizer descreve quatro níveis de maturidade relacionados ao que se entende como objetivos dos testes [12].

- Nível 0: Não há diferenças entre testes e depuração. O objetivo dos testes é apenas fornecer suporte à depuração; 


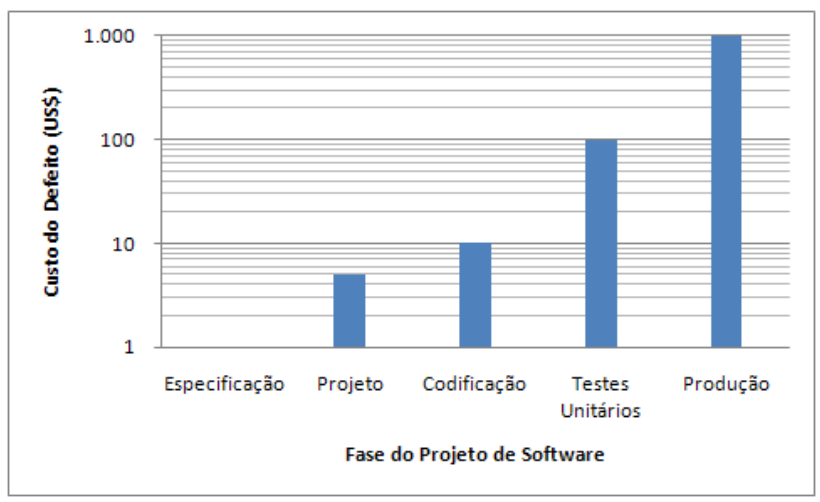

Figura 3.2 Custo relativo de correção de defeitos

- Nível 1: O objetivo do teste é mostrar que o software funciona;

- Nível 2: O objetivo do teste é mostrar que o software NÃO funciona;

- Nível 3: O objetivo do teste não é provar nada, mas reduzir o risco percebido do sistema não funcionar corretamente dentro do esperado;

- Nível 4: Testar não é uma ação. É uma disciplina mental que resulta em software de baixo risco sem a necessidade de muito esforço de teste.

Embora Verificação e Validação exijam objetivos particulares da atividade de testes, parte deles é comum entre elas. Assim como Myers define o objetivo, identificar defeitos, realizar testes visa mais: impedir que tais defeitos ocorram em ambiente produtivo. Em outras palavras, testes são realizados com o objetivo de encontrar o mais cedo possível um defeito.

\subsubsection{Casos de Testes}

Um bom caso de teste deve estar de acordo com objetivos dos testes. Quanto maior a probabilidade de um caso de teste encontrar um defeito, melhor será. Pode-se considerar que um caso de teste é composto por três partes: Entradas, Saídas e Ordem de Execução ou Passos [46].

As entradas são o conjunto de dados que alimentam o caso de teste e servem como ponto de partida para uma série de requisitos do sistema. Tais dados podem ser providos de diversas fontes, desde entrada através do teclado, até leitura de arquivos, etc.

As saídas também possuem uma vasta variedade. Os dados que resultam do processamento do sistema podem ser enviados para uma interface com outros sistemas, para dispositivos externos, ou simplesmente disponibilizados na tela para o usuário final.

Os passos de execução determinam em que ordem cada ação deve ser realizada de modo que as condições desejadas no sistema sejam obtidas. Existem dois tipos de projeto de casos de testes:

- Casos de testes em cascata: Um dado caso de testes precisa ser executado com sucesso para que o sistema esteja em um estado definido, de modo que o próximo caso de teste possa ser executado. A vantagem é que cada caso de teste é pequeno e simples. A desvantagem é que, se um falha, os demais falharão também;

- Casos de testes independentes: Cada caso de testes é inteiramente auto-contido. Eles não provêm informações ou condições para outros testes, nem precisam da execução bem sucedida de outros. A vantagem é que os casos de testes podem ser executados em qualquer ordem sem que o resultado seja diretamente afetado. A desvantagem é que cada caso de teste tende a ser maior e mais complexo, tornando-se mais difícil de projetar e manter. 


\subsubsection{Processo de Teste}

A engenharia de software sugere que o sistema seja submetido a uma série de testes, desde a sua concepção até a sua entrega [80,2]. O processo se inicia com o Levantamento de Necessidades, seguido pelo Detalhamento dos Requisitos. Após isso, a fase de Projeto e Arquitetura do sistema é realizada, concluindo a construção com a codificação do Software. Com a construção concluída, iniciam-se as fases de teste: teste de unidade, de integração, de aceite e de sistemas.

Durante a fase construção, os testes são realizados no produto de cada etapa. Por exemplo, testes de requisitos aplicados ao resultado da fase de Detalhamento de Requisitos. As seções seguintes detalham melhor cada uma das fases específicas de testes, definidas por Pressman [80].

\section{Testes de unidade}

Também chamados de testes unitários, têm o objetivo de exercitar unidades do sistema, tais como funções, módulos, componentes. Testadas individualmente, procura-se garantir que cada unidade tenha funcionamento adequado dentro do domínio esperado.

Nesta fase, são avaliadas as estruturas de dados e do código. Para isso, são analisados os caminhos independentes, condições de fronteira, tratamentos de condições excepcionais, entre outros pontos.

Estruturas de dados e de código são fontes comuns de erro. Os cenários de testes devem descobrir defeitos de tipos inconsistentes de dados, inicialização equivocada de variáveis e objetos, situações de underflow e overflow, além de exceções de acesso a dados e arquivos.

Execução e análise dos caminhos independentes têm por objetivo de identificar erros em detrimento de cálculos mal projetados, comparações incorretas e problemas de fluxo de controle. Exercitar base de laços e os caminhos que são originados em tais laços auxiliam na identificação de erros de caminhos.

Análise das condições de fronteira é uma das principais tarefas do teste de unidade. Softwares são propensos a falhas com valores limites. Existem técnicas específicas de testes caixa-preta e caixa-branca que auxiliam na execução desta análise. Elas serão abordadas nos tópicos seguintes.

O tratamento de exceções também deve ser validado nesta fase dos testes. Alguns erros potenciais podem ser identificados, por exemplo, descrição incompreensível, erro exibido não correspondente ao erro de fato, condições de erro causam intervenções do software antes do tratamento da exceção, etc.

Para Web Services, cada função disponível pode ser vista como uma unidade, pois é possível considerar um serviço como sendo um componente do qual o sistema consumidor fará uso [1, 63]. Assim como em sistemas orientados a objetos, é importante também levar em consideração o contexto, pois as operações muitas vezes são encapsuladas por classes e dependem de um estado determinado do sistema.

O Teste de Unidade deve ser considerado adjunto à etapa de codificação, sendo realizado logo após a geração do código-fonte.

\section{Testes de Integração}

Quando as unidades do sistema estão validadas, é necessário integrá-las. Neste ponto, a interface de comunicação entre os componentes e módulos são o foco dos testes. Tais testes são chamados Testes de Integração.

Mesmo com as unidades funcionando adequadamente, quando colocadas juntas, algumas situações podem ocorrer, por exemplo, perda de informações. Isso leva as partes a erros. Além disso, o comportamento de uma determinada unidade pode não ser esperado por outra.

Para fazer essa integração, pode-se adotar estratégia incremental, onde os módulos e componentes vão sendo acoplados e testados à medida que vão se agrupando, ou não-incremental, onde todos os módulos e componentes são agrupados e somente após são testados. Segundo Pressman, a estratégia não-incremental é caótica, pois é difícil identificar a origem de um defeito caso ele ocorra [80]. Isso não ocorre no modo incremental: conforme um componente novo é acoplado ao sistema, testes são realizados visando aquela integração, facilitando a identificação da origem de problemas. 
Os testes incrementais podem ter uma abordagem Top Down ou Bottom up. Na primeira, os módulos são integrados de modo hierárquico partindo do componente principal, do mais alto-nível. Na segunda, os módulos mais de baixo-nível são combinados e testados.

Além da validação dos componentes e módulos, é nesta fase que são realizados testes regressivos. Para softwares já existentes, esses testes são realizados para garantir que as funcionalidades desenvolvidas não afetaram o funcionamento do sistema como um todo.

Quando um sistema é composto por Web Services, comum em uma estrutura orientada a serviços [63], a realização de testes de integração faz-se também necessária. Utiliza-se com frequência serviços fictícios para avaliação do comportamento e da comunicação entre do sistema e seus serviços [22]. Estes serviços fictícios são chamados Stubs.

\section{Testes de Aceitação}

Com o software completo e integrado, os defeitos de integração já identificados e devidamente corrigidos, o teste de aceitação visa validar a conformidade da aplicação com os requisitos definidos. Também chamados de testes de funcionalidades, será avaliada cada funcionalidade do sistema e, para isso, é importante que os critérios de aceite de cada uma seja confrontado com os resultados de execução do sistema.

As funcionalidades dos sistemas neste ponto são vistas como uma caixa preta, para a qual se passa alguma informação e se recebe um resultado, confrontado com o resultado esperado. Para Web Services, as funcionalidades também são as especificações WSDL. Com isso, um teste de aceitação de um serviço tem por objetivo validar se o resultado de determinada chamada está de acordo com o especificado.

\section{Testes de Sistema}

A fase de testes de sistemas permitem a validação do sistema em relação a outros elementos, tais como hardware, banco de dados, ou até mesmo o próprio usuário. Durante esta fase, são executados testes de recuperação, de tolerância a falhas, de segurança, de usabilidade, de estresse, carga e desempenho.

Em particular, para testes Web, condições de navegação devem ser levadas em consideração. Iniciando-se pela validação da interface e aspectos de arquitetura, até chegar a questões tecnológicas, como versões do navegador e sistemas operacionais.

Já para Web Services, existem dois modos em que os testes de sistemas podem ser aplicados: quando um serviço é uma composição de outros serviços e; quando um sistema utiliza um determinado serviço.

\subsubsection{Técnicas de Testes}

Os testes podem ser classificados em Testes Caixa-Preta, Testes Caixa-Branca e Testes CaixaCinza. Nos testes Caixa-Branca, os casos de testes utilizam informações da estrutura de código da aplicação para explorar melhor os resultados, por exemplo uma condicional em uma determinada função. Em testes Caixa-Preta, os casos de testes são desenhados com base na interface do sistema e na especificação de entrada e saída, desconsiderando condições internas da aplicação. Os testes Caixa-Cinza são uma combinação das duas abordagens.

\section{Testes Caixa-Preta}

É uma estratégia no qual os testes são projetados com base nos requisitos e na especificação [27]. Não há necessidade de conhecimento de caminhos internos ao software, sua estrutura ou detalhes de sua implementação.

Podem ser aplicados em todos os níveis de teste, desde o teste de unidade até o teste de sistema. Quanto maior o tamanho da parte ou módulo a ser testado, maior a "caixa" a ser avaliada. 
Além disso, quanto maior o módulo, o número de combinações aumenta drasticamente, tornando inevitável a abordagem dos testes através da técnica caixa-preta [27].

A grande desvantagem da utilização da técnica é que o responsável pelo teste nunca tem certeza o quanto de código do sistema de fato foi coberto pelos testes. Por maior que seja o número de casos de testes, dificilmente todos os caminhos serão executados.

Mesmo diante da impossibilidade de se testar tudo, técnicas caixa-preta ajudam a direcionar os responsáveis pelo teste a selecionar um conjunto de testes que é tanto efetivo quanto eficiente na detecção de defeitos.

Dentro do conjunto das técnicas caixa-preta, podem-se citar as seguintes:

- Classes de equivalência: usada para reduzir o número de caso de teste para um número substancialmente menor, mas mantendo ainda assim maior parte da cobertura. Consiste em especificar um caso de teste para um conjunto de condições válidas, consideradas da mesma classe, e para um conjunto de condições inválidas, também consideradas da mesma classe. Na Figura 3.3 é possível notar 3 classes, sendo 1 de entradas válidas e duas de entradas inválidas para os testes, projetam-se 3 casos de testes, cada um com um valor específico daquela classe.

- Teste de fronteira: possui foco nos valores de fronteira simplesmente pelo fato de muitos defeitos residirem lá $[64,80]$. Geralmente são os valores que separam uma classe de outra. Com isso, servem de complemento para a técnica de Classe de equivalência, pois orientam a seleção dos casos de testes não simplesmente a pegar qualquer valor que pertence a determinado conjunto, mas sim a sua fronteira limite (Figura 3.4. Uma análise de condições de fronteira também pode levar a foco também a considerar o domínio de saída [64];

- Combinação dupla: chamada também de paiwise ou all-pairs, usada quando existem muitas variáveis de entradas e muitas combinações entre elas. Consiste em combiná-las aos pares e extrair os casos de testes com base nessa combinação, em vez de simplesmente testar todas as combinações. É uma técnica bastante eficiente, mas não se sabe ao certo porque a funciona bem [27].

- Transição de estados: direciona a elaboração dos casos de testes através da identificação de estados, eventos, ações e transições que devem ser testados. O objetivo é elaborar um caso de teste para exercitar pelo menos uma vez cada transição do sistema.

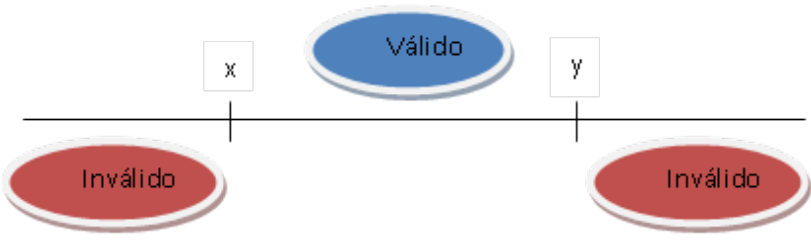

Figura 3.3 Visualização de classes de equivalência

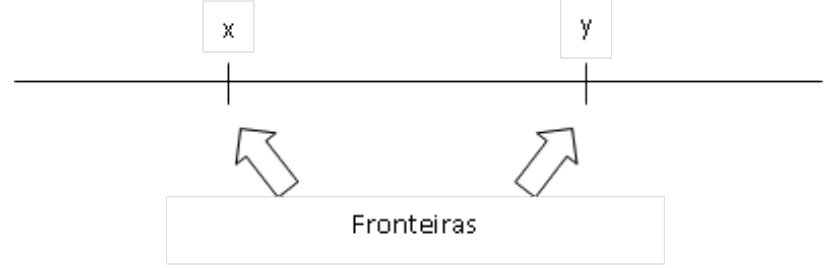

Figura 3.4 Visualização de Valores de Fronteiras 


\section{Testes Caixa-Branca}

As técnicas de testes de caixa-branca têm como base o conhecimento de caminhos internos, estruturas e detalhes de implementação. Diferentemente das técnicas de caixa-preta, testes de caixabranca exigem boa habilidade de programação.

São aplicáveis a vários níveis de testes também, desde os testes de unidade até os testes de sistemas. É muito mais do que simplesmente avaliar código - é avaliar caminhos de execução. Geralmente são aplicados em caminhos dentro de um mesmo módulo, mas podem (e devem) avaliar caminhos entre módulos, entre subsistemas e até mesmo entre sistemas.

A quantidade de caminhos de execução pode ser tão grande que fica praticamente inviável testar todas. Isso é uma das desvantagens dos testes de caixa-branca. Outra desvantagem é que a aplicação desse tipo de teste assume que o fluxo está correto, sendo assim impossível descobrir que um determinado caminho não existe [27].

Existem muitas técnicas de testes de caixa-branca. Alguns são os seguintes:

- fluxo de controle: ou Control Flow, permite avaliar o fluxo do programa para identificar casos de testes que atendam a determinado critério, por exemplo, todas as decisões, todas as condições, etc.;

- fluxo de dados: ou Data Flow, consiste em avaliar a vida útil da informação, desde seu surgimento até sua extinção. Dentre as técnicas específicas, podem-se citar: todas as definições, pares de definição e uso, etc.

\section{Testes Caixa-Cinza}

Esta abordagem é chamada de Caixa-Cinza por combinar elementos e técnicas de caixa-preta e de caixa-branca. Ela permite utilizar conhecimento de partes internas do código para explorar melhor e ter resultados mais efetivos das técnicas de caixa-preta.

Teste de caixa-cinza são muito bem aplicáveis a testes Web [68]. Devido a existência de muitos fatores que influenciam o comportamento, desde componentes (hardware e software) até a interoperabilidade com outros sistemas. Como as informações sobre o código e operações sobre o comportamento interno da aplicação podem guiar a construção dos casos de testes, muitos pontos que normalmente ficariam fora do escopo de teste passam a ser considerados. Erros referentes a contextos específicos são descobertos com frequência com este tipo de abordagem.

\subsubsection{Execução dos testes}

Após o planejamento e a escolha da estratégia de testes, os casos de testes são desenhados e projetados. A execução desses casos de testes pode ser manual, semi-automatizada ou automatizada.

Devido à grande necessidade de velocidade na construção de soluções, existe também a necessidade por testes velozes, e mais baratos, demandando cada vez mais a automação de testes [92]. Para testes web, por exemplo, avaliar o desempenho e a confiabilidade é praticamente inviável se não for realizada de maneira automatizada.

Testes automáticos, quando desenvolvidos de forma adequada, podem ser bastante úteis devido principalmente à facilidade de execução [83]. Por exemplo, com testes unitários automatizados, pode-se a cada alteração do sistema rapidamente executar os testes para certificar-se de que a aplicação não sofreu impactos.

\subsubsection{Critérios de Testes}

Tão importante quanto realizar testes em uma determinada aplicação, é definir o que se deve testar e quando se deve parar. Critérios de testes devem estar relacionados a metas de qualidade, para as quais é difícil estabelecer qual a ideal [99]. Existem diversos fatores que podem determinar o término da atividade de teste, por exemplo, quando o prazo termina ou quando os recursos se esgotam [80]. 
Dependendo da abordagem, podem-se utilizar, por exemplo, cobertura de código, cobertura de condições, definições, entre outras. Para cada característica do sistema ou do código é necessário um critério diferente de cobertura [103].

A seguir serão vistos alguns dos principais critérios de testes, tanto do ponto de vista de código quanto do ponto de vista de qualidade e de negócio. Cada uma delas tem uma série de vantagens e desvantagens se comparadas entre si.

- Código:

Cobertura de código: este critério condiciona o teste a um percentual de cobertura do código da aplicação [32]. Durante a execução dos testes, analisa-se a quantidade de instruções executadas da aplicação e também as não executadas. Pode-se estipular um percentual mínimo de cobertura das instruções coberta por um conjunto de testes que determine que a aplicação foi suficientemente testada (de acordo com este critério). Contudo, a execução de uma instrução específica não significa que ela nunca causará uma falha no funcionamento da aplicação. Outro ponto a ser ponderado é a questão de que grande parte das aplicações podem depender de componentes externos para os quais não se tem acesso ao código ou não é viável medir sua cobertura;

Cobertura de condições e Decisões: as decisões em um determinado código são compostas por uma ou mais condições. Este critério de cobertura tem como objetivo avaliar os caminhos possíveis dentro de uma aplicação;

MCDC: Modified Condition Decision Coverage é uma forma de cobertura de condições, mas com uma forma mais otimizada de cobertura, que permite analisar apenas condições independentes, reduzindo assim o número de combinações, se comparada a cobertura de todos os caminhos;

Pares de Definição e Uso: consiste em definir um conjunto de pares que devem ser exercitados. A formação desse conjunto é dada a partir de cada definição de objeto e, seguindo o fluxo da aplicação, cada uso do mesmo objeto sem que haja uma definição entre um e outro [25];

- Qualidade:

Taxa de detecção de defeito: a partir de um número estimado de defeitos que se espera identificar na aplicação, pode-se medir a eficácia dos testes avaliando o quanto já foi encontrado e quanto ainda resta encontrar (de acordo com a quantidade estimada). A cada versão da aplicação liberada para testes, a quantidade de defeitos detectados tende a diminuir [27, 80, 64]. Dependendo da criticidade do defeito, pode-se estabelecer uma curva que determina o critério para que os testes sejam considerados concluídos. A Figura 3.5 ilustra esta situação. Segundo o critério, os testes deveriam parar na semana 18 ;

- Negócio ou Processo:

Estados: consiste em construir o conjunto de testes de modo a cobrir os estados previstos do sistema. A cobertura dos estados determina o critério de parada dos testes;

Casos de Uso: semelhante ao de estados, permite estabelecer a parada dos testes se um percentual aceitável de casos de uso foi devidamente coberto pelos testes;

Casos de Testes: ao contrário dos critérios de cobertura de estado e de casos de uso, este critério está relacionado ao número de casos de testes executados dentro de um conjunto de casos de testes previstos.

\subsection{Testes aplicados a Web Services}

Ao aplicar testes em Web Services, alguns pontos devem ser levados em consideração, devido principalmente às suas particularidades. As abordagens atuais não são suficientes por serem mais 


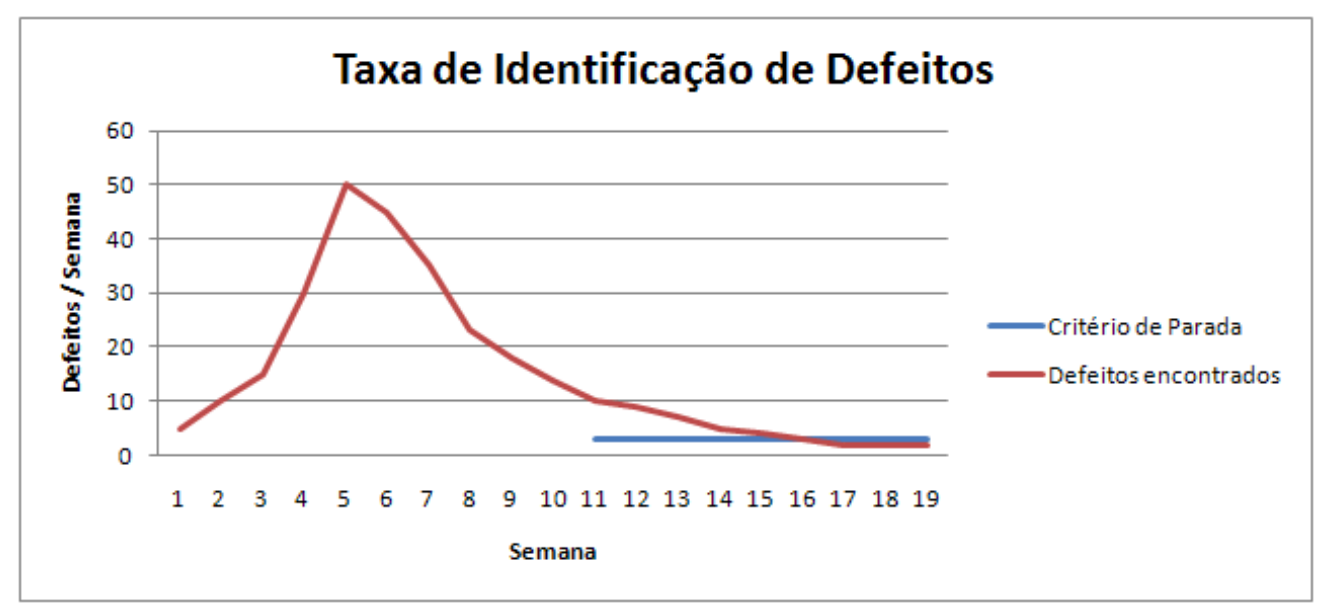

Figura 3.5 Taxa de identificação de defeitos

heterogêneas que componentes e que aplicações Web. Serviços web, além de também poderem ser escritos em diversas linguagens, ele podem utilizar-se de diversos Sistemas Operacionais e serem executados em containers de aplicação diferentes [101]. Serviços Web também apresentam baixo controle entre provedor, consumidor e integrador, que afetam diretamente no custo dos testes (necessidade de teste tanto por parte do provedor quanto por parte do consumidor) e do QoS (Quality of Service) [78, 8].

Com isso, é necessário que o conjunto de testes realize uma cobertura nos principais requisitos de testes, especificamente para Web Services, funcionais e não funcionais. Dentre os funcionais, se o serviço apresenta respostas adequadas, de acordo com as especificações fornecidas. Já dentre as não funcionais, deve-se avaliar: a capacidade de atender de maneira eficiente a um dado número de requisições (desempenho); aspectos de autorização, criptografia e proteção contra ataques (segurança) e; aderência a um determinado conjunto de padrões pré-estabelecidos (interoperabilidade).

A abordagem deste trabalho será avaliação de testes de interoperabilidade.

\subsubsection{Exemplo de teste para Web Services}

O seguinte exemplo será apresentado para ilustrar o processo de realização de teste de um Web Services. Com base em um serviço de agendamento de entrega, serão apresentadas as etapas para criação dos casos de teste que visem validar os requisitos do serviço.

No exemplo ${ }^{1}$, existe um serviço para agendar a entrega de um produto determinado em um dado endereço. Na requisição, fornecem-se as informações do produto, além do próprio endereço.

Como são passados dois parâmetros do tipo string (identificação do produto e endereço), a técnica de classe de equivalência se adéqua bem ao caso. Para isso, são necessários 5 casos de testes, como mostra a Tabela 3.1.

\begin{tabular}{|c||c|c|c|c|c|}
\hline caso de teste & 1 & 2 & 3 & 4 & 5 \\
\hline \hline productId & "541" & "541" & "xpto" & "541" & “" \\
\hline Address & "1st av, 2" & "xpto" & "1st av, 2" & “"” & "1st av, 2" \\
\hline \hline Resultado Esperado & OK & Não OK & Não OK & Não OK & Não OK \\
\hline
\end{tabular}

Tabela 3.1 Casos de testes para o sistema de agendamento de entrega

No caso de testes 1, passam-se uma identificação de produto e um endereço, ambos válidos, esperando-se como resposta uma confirmação. Os casos de testes 2, 3, 4 e 5 se referem a situações nas quais o retorno não é de confirmação. No caso de testes 2 , é passado um endereço inválido. No caso de testes 3 , é a vez do produto. Nos casos de testes 4 e 5 são passadas informações em

\footnotetext{
${ }^{1}$ exemplo elaborado para ilustrar a aplicação de testes para Web Services
} 
branco, para avaliar o comportamento do sistema diante de um dado, embora válido, não esperado. As requisições podem ser vistas nas Listagens 3.1, 3.2, 3.3, 3.4 e 3.5.

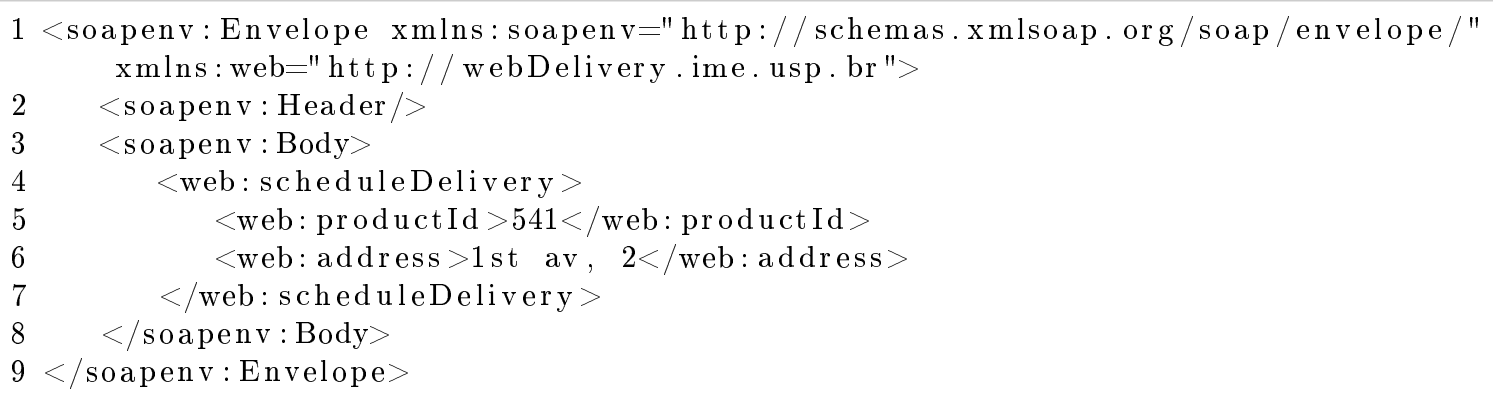

Listagem 3.1 Requisição realizada no caso de teste 1

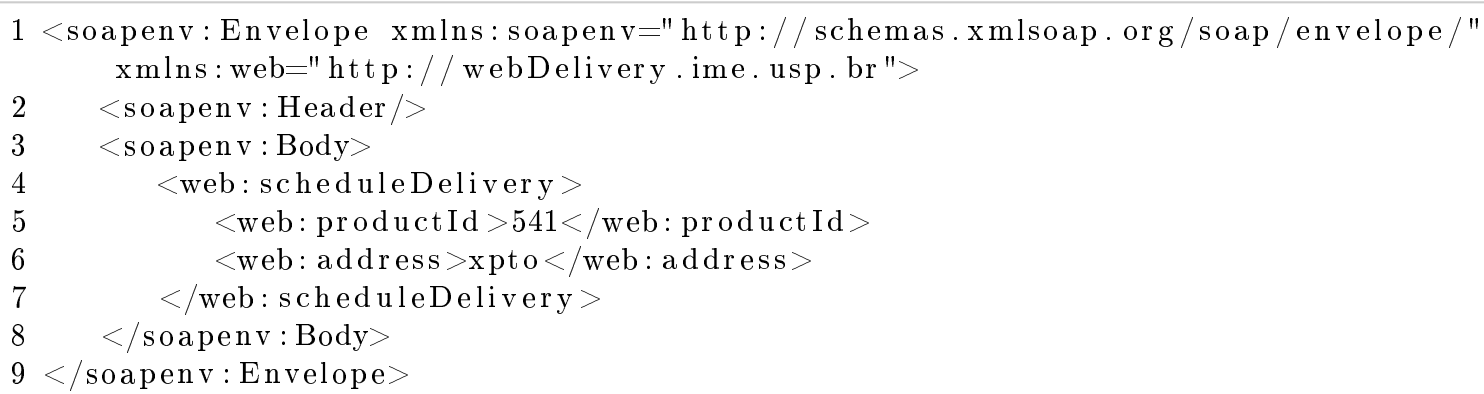

Listagem 3.2 Requisição realizada no caso de teste 2

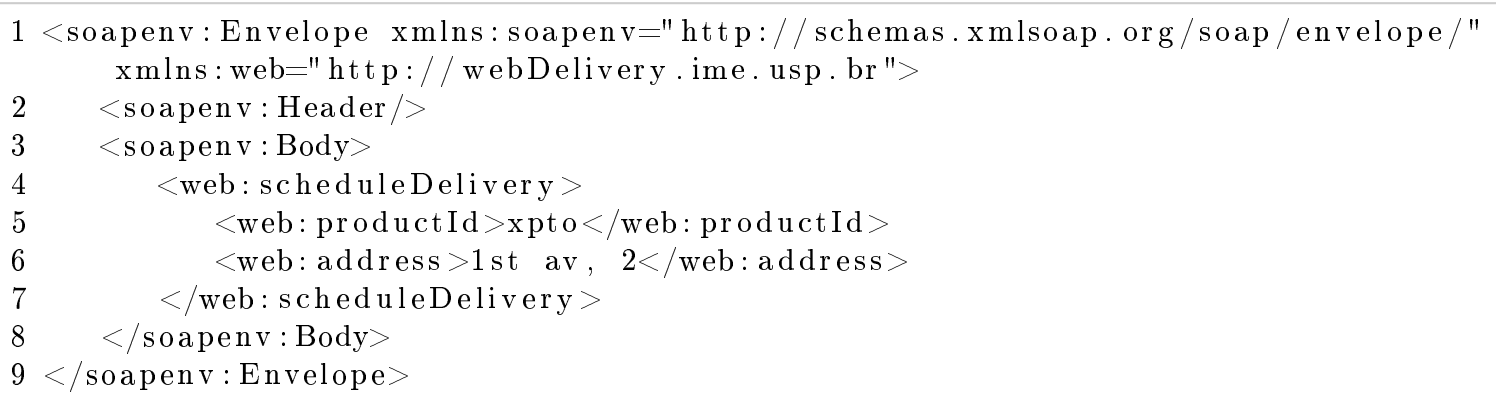

Listagem 3.3Requisição realizada no caso de teste 3

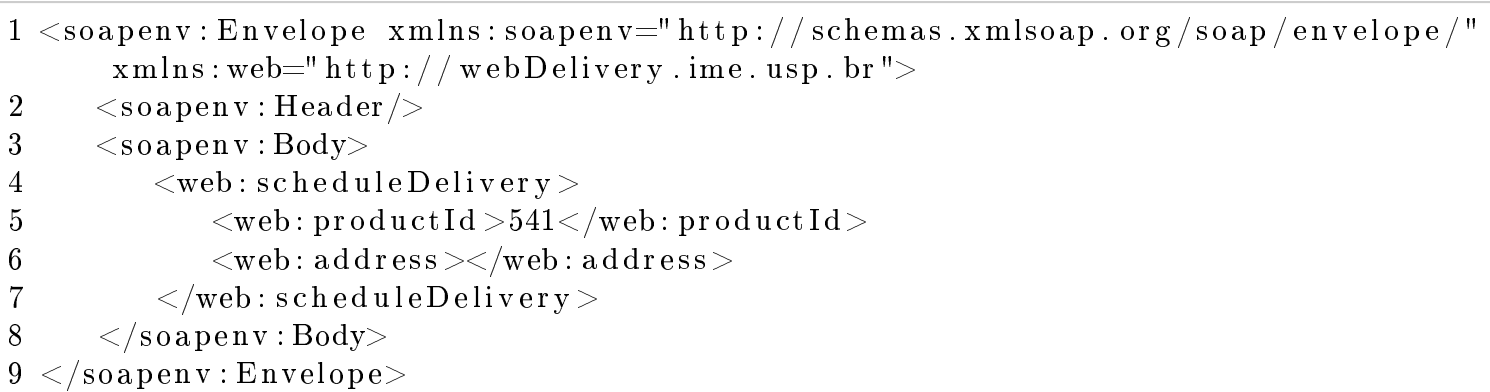

Listagem 3.4Requisição realizada no caso de teste 4

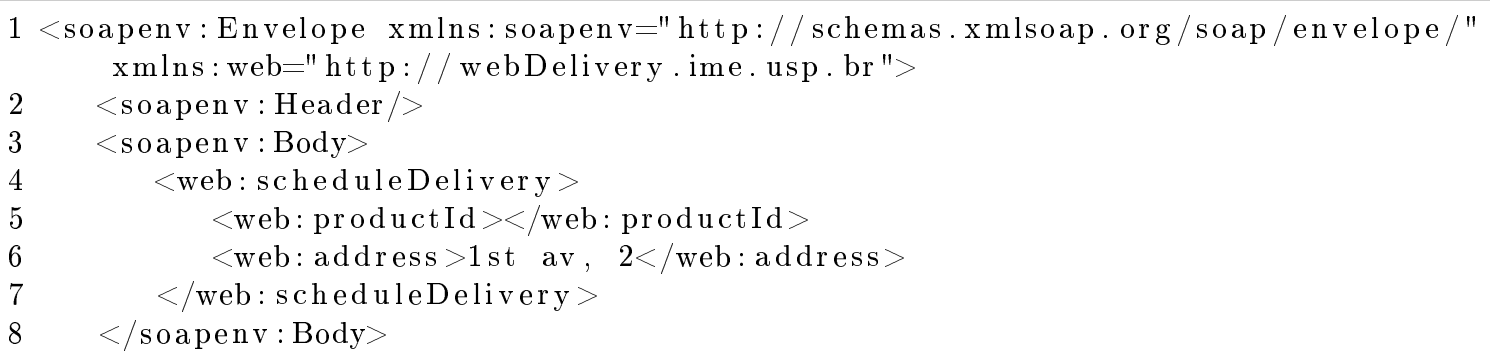


Listagem 3.5 Requisição realizada no caso de teste 5

\subsubsection{Critérios para testes de Web Services}

Após vasta pesquisa nos assuntos discutidos atualmente, pouco se encontrou na literatura sobre critérios específicos para testes de Web Services[44, 63]. Algumas iniciativas de estudo analisam o panorama atual de modo a avaliar questões relevantes sobre testes de Web Services[9, 63]. Por se tratar de um meio distribuído, alguns pesquisadores defendem que os testes devem ser diferentes dos convencionais [93, 18].

Analisando um serviço web e comparando-o com os paradigmas atuais, principalmente o Orientado a Objetos, podemos classificar os critérios de testes em dois tipos: critérios para testes funcionais, e não funcionais $[17,63]$. Muitos dos critérios aplicados a esse paradigma não são aplicáveis a serviços [19].

Levando-se em consideração aspectos que possibilitam enxergar um serviço como uma função disponível para utilização remota, podem-se utilizar critérios que norteiam testes unitários, por exemplo, avaliando suas características funcionais. Dependendo da abordagem de implementação, o critério de teste pode ser variado. Blanco et al.[16] sugerem adotar critérios de cobertura de transições de estado, em virtude da modelagem adotada. Mei et al. [58] adotaram o critério de teste baseado em fluxo de dados, mais especificamente na cobertura de definições e uso.

Para testes não funcionais, muitos critérios relacionados a qualidade podem ser definidos [81]. Aspectos, tais como disponibilidade, confiabilidade, segurança e robustez, podem ser especificados através de SLA (Service Level Agreement) e requisitos de segurança.

\subsubsection{Confiabilidade de Web Services}

Um sistema é dito confiável se o seu funcionamento ocorre da maneira para o qual foi especificado e não falha em situações inesperadas [7]. Com base nessa ideia conceitual, Shooman [88] define confiabilidade de um dado sistema como a probabilidade de funcionar corretamente em um determinado período. Essa definição é aplicada para sistemas de maneira geral. Quando se trata de Web Services, a confiabilidade também envolve características devidas aos meios de disponibilização. Erradi et al. [36] atribuem parte dos problemas à forma com que a comunicação ocorre em meios sem garantias de funcionamento correto.

Existem padrões e técnicas que auxiliam os desenvolvedores a prover Web Services mais confiáveis. Atestar tal confiabilidade é possível através da execução de testes específicos. Quando a questão é justamente avaliar o quão confiável é um Web Service, existe uma gama de técnicas e ferramentas que permitem auxiliar na realização da atividade.

\section{Técnicas de mutação e perturbação para testes de Web Services}

Técnicas para perturbação de dados e de comunicação, além de técnicas de mutação de dados, são utilizadas como base na geração de casos de testes para Web Services[89, 31, 73, 30], sendo assim uma alternativa para avaliar sua confiabilidade. De acordo com o cenário, pode-se utilizar determinada técnica.

A perturbação de dados é feita com base em técnicas de valores limite [12], tanto sobre tipos primitivos como sobre restrições. A definição de casos de testes ocorre através da criação de um conjunto de regras para os tipos primitivos em XML e também com base em restrições. A técnica é ainda incrementada com a consideração de valores inválidos para chamadas feitas a Web Services. A Tabela 3.2 resume a lista de possíveis pertubações aos dados tomados como base tipos primitivos, enquanto a Tabela 3.3 apresenta as facetas que permitem também perturbação baseada em restrições.

Já a técnica de perturbação de comunicação permite focar no relacionamento e nas restrições das mensagens trocadas. 


\begin{tabular}{|c|c|}
\hline Tipo de Dados & Valores Limites \\
\hline String & Tamanho Máximo, Mínimo, Maiúsculo e Minúsculo \\
Numérico & Valor Máximo, mínimo e zero \\
Booleano & True, False \\
data & Valor Máximo, Mínimo \\
binário & Valor Máximo, Mínimo
\end{tabular}

Tabela 3.2 Perturbação de Dados

\begin{tabular}{|c|c|}
\hline Faceta & Descrição \\
\hline enumeration & lista de valores aceitáveis \\
fractionDigits & o número máximo de casas decimais permitidas \\
length & o número exato de caracteres ou quantidade de itens em uma lista \\
maxExclusive & valor máximo - menor que o valor \\
maxInclusive & valor máximo - menor ou igual ao valor \\
maxLength & quantidade máxima de caracteres ou quantidade de itens em uma lista \\
minExclusive & valor mínimo - maior que o valor \\
minInclusive & valor mínimo - maior ou igual ao valor \\
minLength & quantidade mínima de caracteres ou quantidade de itens em uma lista \\
pattern & a sequência exata de caracteres permitidos \\
totalDigits & número exato de dígitos permitidos \\
whiteSpace & determina a quantidade de espaços em branco \\
\hline
\end{tabular}

Tabela 3.3 XML Facets

A mutação é realizada através de operadores de mutação que combinam os dados originais. A Tabela 3.5 apresenta os operadores de mutação.

A Tabela 3.6 apresenta alguns exemplos de aplicação das técnicas de perturbação e mutação nas mensagens.

\subsubsection{Ferramentas para auxiliar testes de Web Services}

Existem cada vez mais ferramentas para realização de testes específicas para Web Services.

- WSUnit [104]: ferramenta Open Source, permite elaborar mensagens de requisição e de resposta de um dado serviço. Isso viabiliza sua utilização pelo consumidor mesmo que o serviço ainda esteja indisponível, possibilitando a seleção de respostas específicas para testar determinados comportamentos do sistema. A ferramenta também pose ser utilizada do ponto de vista do fornecedor para simular a requisição do serviço.

WSUnit utiliza uma estrutura de diretório, no qual são armazenados os arquivos de requisição e de resposta. Além disso, é semelhante ao JUnit. Mais detalhes podem ser obtidos na página da ferramenta [104].

- SoapUI [91]: pode ser utilizada para realização de testes de carga e de desempenho. Além disso, também pode ser usada para inspeção e invocação de serviços. Através de uma visualização hierárquica do WSDL, a inspeção das operações torna-se mais simples. A ferramenta também permite criar um modelo de chamada de requisição, possibilitando a utilização em testes futuros através de parametrização do modelo.

Pode ser integrada com diversas APIs que trabalham com Web Services (JBossWS, JWSDP, Axis 1 e 2, XFire, .Net e Gsoap). Com isso, a ferramenta auxilia a criação de código para consumidor e fornecedor de serviço;

- JXWeb [48]: extensão do JXUnit, permite a geração de um script de teste descrito em um arquivo XML. Cada passo desse script corresponde a uma invocação de um serviço web;

- BPELUnit [52]: framework desenvolvido para prover condições de realizar teste de unidade de códigos escritos com BPEL;

- WebSob [55]: ferramenta para geração e execução de casos de testes a partir da especificação WSDL, com a finalidade de avaliar a robustez do serviço testado; 
Tabela 3.4Perturbação de relacionamento (comunicação de dados)

\begin{tabular}{|c|c|}
\hline Indicador & Descrição \\
\hline minOccurs $(?)$ & zero ou mais ocorrências \\
maxOccurs $\left(+,{ }^{*}\right)$ & no mínimo uma ocorrência \\
minOccurs, maxOccurs $(\mathrm{x}, \mathrm{y})$ & no mínimo x e no máximo y \\
choice $(\mathrm{|})$ & um elemento filho ou outro \\
all & elementos filhos podem aparecer em qualquer ordem; \\
& todos devem ocorrer pelo menos uma vez \\
anyElement ( . ) & elemento não especificado no $X M L$ Schema, qualquer elemento
\end{tabular}

\begin{tabular}{|c|c|}
\hline Operador & Descrição \\
\hline Divide (c) & Modifica o valor de $c$ para $1 \div c$, onde $c$ é um double \\
\hline Multiply (c) & Modifica o valor de $c$ para $c \times c$ \\
\hline Negative (c) & Modifica o valor de $c$ para $-c$ \\
\hline Absolute (c) & Modifica o valor de $c$ para $|c|$ \\
\hline Exchange $\left(c_{2}, c_{2}\right)$ & Substitui o valor $c_{1}$ por $c_{2}$ e vice-versa, onde $c_{1}$ e $c_{2}$ possuem o mesmo tipo \\
\hline Unauthorized (c) & Modifica o valor da string contida em $c$ de $\operatorname{str}$ para str' OR $\mathbf{1}=\mathbf{1}$ ' \\
\hline Null (c) & Associa null a um campo $c$ na mensagem SOAP \\
\hline Incomplete (c) & Apaga um nó $c$ e seus filhos de uma mensagem SOAP \\
\hline Inversion (c) & Inverte a ordem dos nós dentro de um nó $c$ em uma dada mensagem SOAP \\
\hline ValueInversion (c) & Inverte a ordem dos valores associados aos nós filhos de um nó $c$ em uma dada mensagem XML \\
\hline Mod_Len (c) & Altera o tamanho de um valor associado a um nó $c$ em uma dada mensagem XML \\
\hline Space (c) & Atribui espaços (' ') ao valor associado ao nó $c$ \\
\hline
\end{tabular}

Tabela 3.5 Mutação de Dados - operadores

- wsrbench [50]: ferramenta para avaliação de robustez de serviços web;

- WSTD-Gen [51]: Web Services Test Data Generator, é uma ferramenta baseada no método apresentado por Li et al. para geração de dados para testes;

- GenAutoWS [89]: desenvolvida com base no SoapUI, implementa diversas técnicas de perturbação de dados e tem como principal característica geração automática de casos de testes. Pode ser utilizada do ponto de vista do provedor do serviço para simular as requisições e assim avaliar se as respostas estão adequadas. Também pode ser utilizada do ponto de vista de consumidor, para que seja avaliada o quão tolerante e robusto é o provedor do serviço. Esta ferramenta é detalhada na próxima sessão.

A ferramenta GenAutoWS implementa as técnicas de perturbação e mutação de dados apresentadas na Seção 3.3.3 e será usada no presente trabalho para auxiliar os testes de confiabilidade dos Web Services e aplicações Web. A seção seguinte mostra o uso dessa ferramenta em detalhes.

\section{A Ferramenta GenAutoWS}

A ferramenta GenAutoWS foi um dos resultados do trabalho de mestrado de Paulo Silveira [89]. Estendida da ferramenta soapUi [91], a GenAutoWS implementa técnicas de geração automática de casos de teste voltados para Web Services.

A GenAutoWS permite validar Web Services sob dois aspectos: do ponto de vista do consumidor do serviço, possibilitando avaliar a qualidade do que se deseja utilizar, sem necessariamente ter acesso ao código-fonte; do ponto de vista do provedor do serviço, para que mensagens automáticas sejam geradas, não havendo necessidade de se criar um sistema consumidor para testar o Web Services.

Em sua essência, a GenAutoWS possui as seguintes funcionalidades:

- geração automática de casos de teste usando pertubação sobre mensagens previamente existentes;

- indicador de erro esperado para cada caso de teste gerado;

- captura de mensagens SOAP e criação de casos de testes com essas mensagens; 


\begin{tabular}{|c|c|}
\hline Técnica & Exemplo \\
\hline String & $<\operatorname{model}>$ AA...AA $</$ model $>$ \\
\hline Numérico & $<$ size $>2^{32}-1</$ size $>$ \\
\hline Booleano & $<$ acessories $>$ true $</$ acessories $>$ \\
\hline data & $<$ web:date $>9999-12-31$ T23:59:59.999Z </web:date $>$ \\
\hline binário & $<$ binCode $>00</$ binCode $>$ \\
\hline enumeration & $<$ model $>$ Fatboy $</$ model $>$ \\
\hline fractionDigits & $<$ price $>9.99</$ price $>$ \\
\hline length & $<$ state $>\mathrm{XX}</$ state $>$ \\
\hline maxExclusive & $<$ price $>999</$ price $>$ \\
\hline maxInclusive & $<$ price $>1000</$ price $>$ \\
\hline maxLength & $<$ state $>\mathrm{XX}</$ state $>$ \\
\hline minExclusive & $<$ price $>1</$ price $>$ \\
\hline minInclusive & $<$ price $>0</$ price $>$ \\
\hline minLength & $<$ state $></$ state $>$ \\
\hline pattern & $<$ code $>$ ABC $-000</$ code $>$ \\
\hline totalDigits & $<$ state $></$ state $>$ \\
\hline whiteSpace & $<$ state $\rangle</$ state $\rangle$ \\
\hline Divide (c) & $<$ price $>0.01</$ price $>$ \\
\hline Multiply (c) & $<$ price $>999999999</$ price $>$ \\
\hline Negative (c) & $<$ price $>-9.99</$ price $>$ \\
\hline Absolute (c) & $<$ price $>9.99</$ price $>$ \\
\hline Exchange $\left(c_{2}, c_{2}\right)$ & $\begin{array}{l}<\text { price }>12</ \text { price }> \\
<\text { size }>9.99</ \text { size }>\end{array}$ \\
\hline Unauthorized (c) & $<$ model $>$ Fatboy' OR $1=1</$ model $>$ \\
\hline Null (c) & $<$ price $>$ null $</$ price $>$ \\
\hline Space $(c)$ & $</$ price $>$ \\
\hline
\end{tabular}

Tabela 3.6Dados de testes derivados a partir de técnicas de perturbação e mutação

\section{- integração com UDDI.}

Sua interface é bastante semelhante ao soapUI. A Figura 3.6 mostra a tela para criar um novo projeto, e a Figura 3.7 apresenta a tela de entrada da GenAutoWS, já com o projeto WSDL carregado. Na parte esquerda são apresentadas as operações contidas no serviço a ser testado, além de apresentar também referências aos PartnerLinks utilizados por ele. Cada operação pode ser composta por diversas mensagens de testes. Na figura é apresentada a mensagem Request 1, pertencente a operação process.

A GenAutoWS implementa técnicas de geração automática baseadas em valores limite, mutação (proposto por Xu e Offut [73]). A Figura 3.8 mostra o menu exibido ao clicar-se com o botão direito do mouse em qualquer das requisições. Tais requisições podem ser utilizadas como matriz para que a ferramenta gere os casos de teste. Essas matrizes podem ser criadas manualmente, pelo usuário, ou automaticamente através de uma funcionalidade de obtenção de mensagens SOAP, da própria GenAutoWS. Essas mensagens capturadas e armazenadas, podendo ser utilizadas posteriormente para gerar outros casos de teste.

A Figura 3.9 apresenta a lista de casos de testes gerados utilizando valor limite, juntamente com a lista de casos de teste obtidos com base na técnica de mutação.

\subsection{Conclusão}

A qualidade, como item fundamental de qualquer produto, de qualquer segmento, pode ser garantida através da realização de testes. Testes de software possuem características específicas e, em particular, testes para Web Services. Com seu surgimento, testá-los passa a ser fundamental, trazendo assim benefícios e aumentando a qualidade do produto.

Este capítulo apresentou os conceitos envolvidos com testes de software, especificamente testes de Web Services, destacando-se os principais conceitos envolvidos e ilustrando com a apresentação de um exemplo de teste. Foi também discutida a confiabilidade de um Web Service. Por fim, foram listadas diversas ferramentas que auxiliam na realização da atividade de teste, com destaque especial para a ferramenta GenAutoWS. 


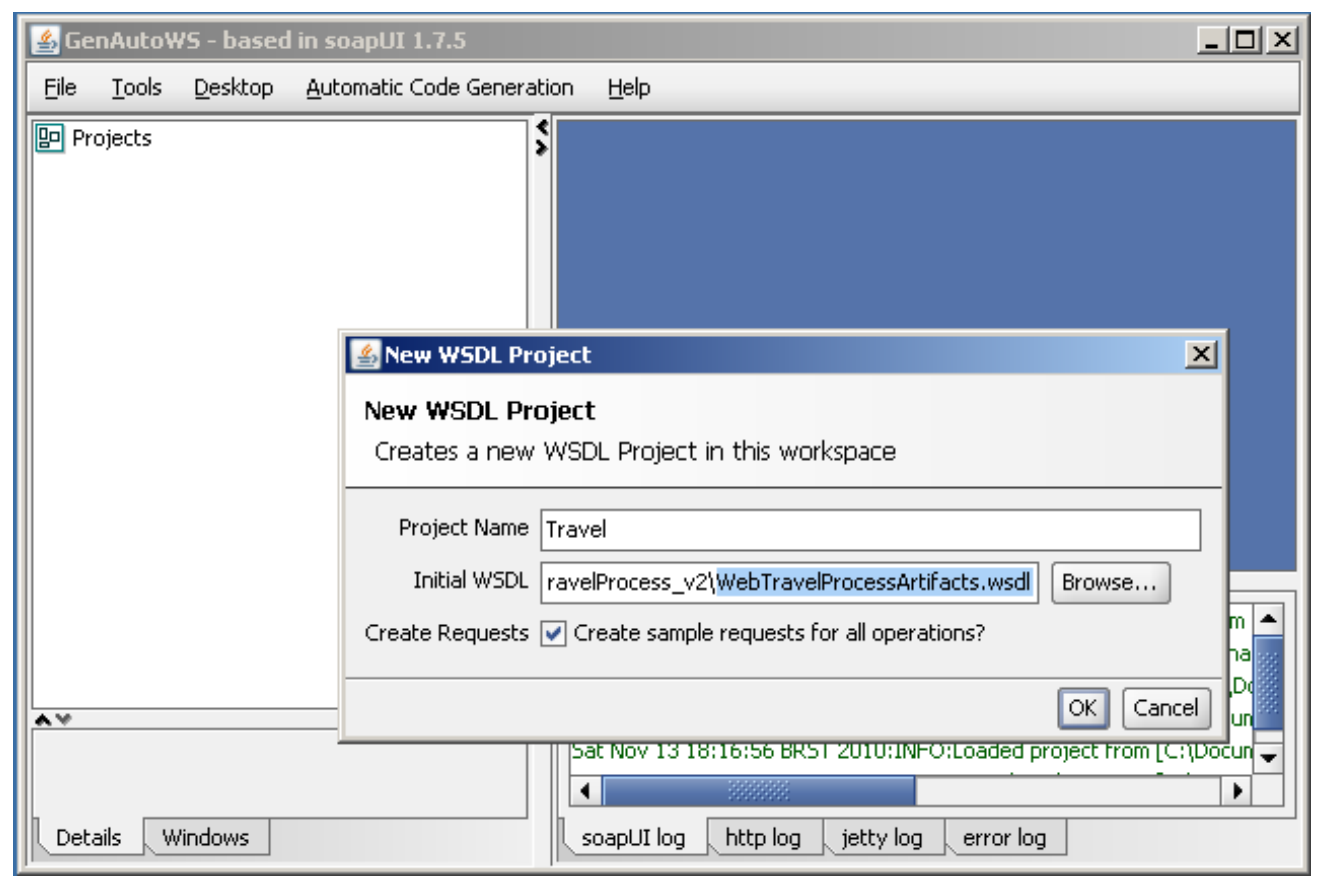

Figura 3.6Criação de Novo Projeto WSDL

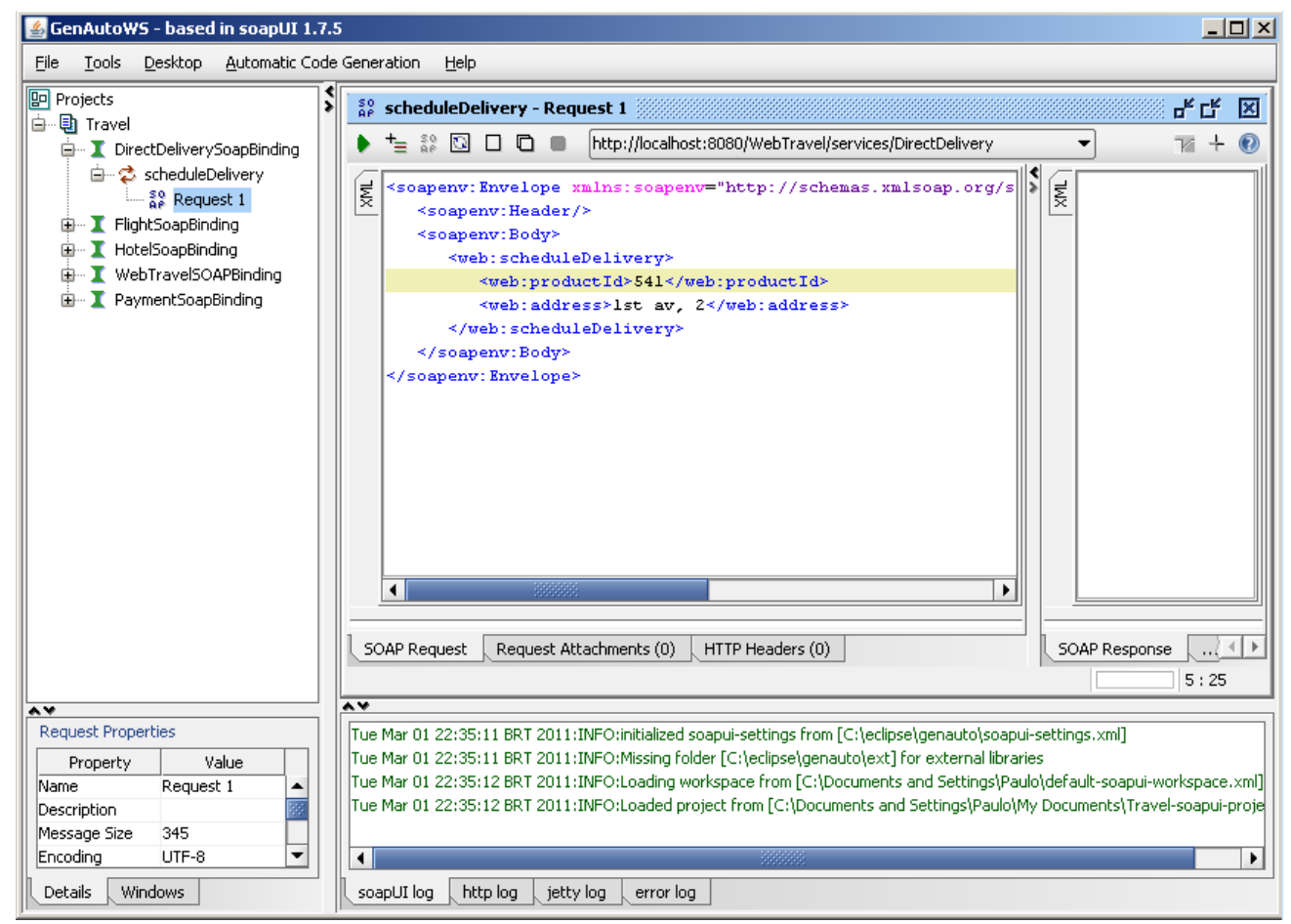

Figura 3.7 Tela de entrada GenAutoWS com projeto aberto 


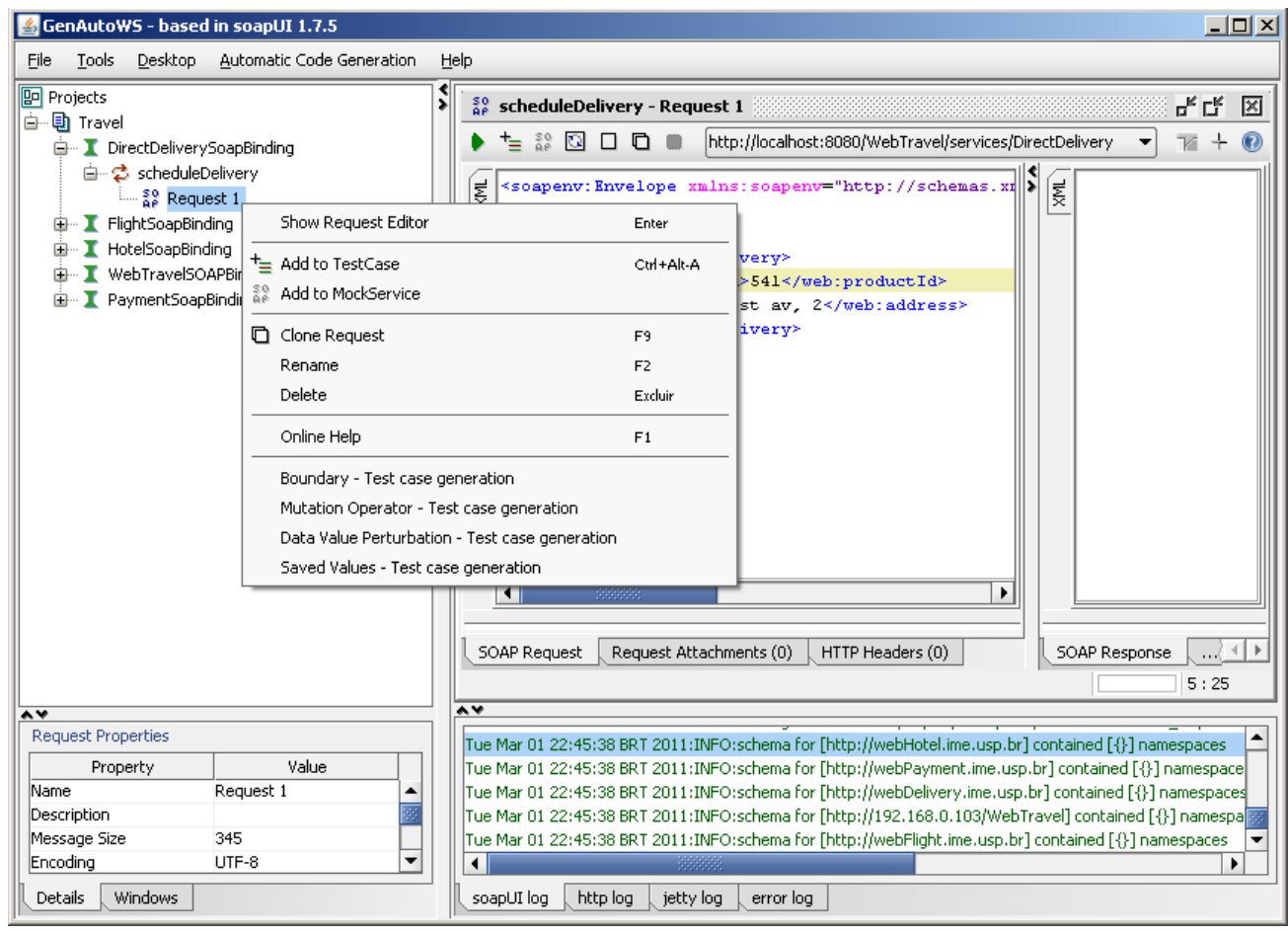

Figura 3.8Menu de contexto para geração automática de casos de teste

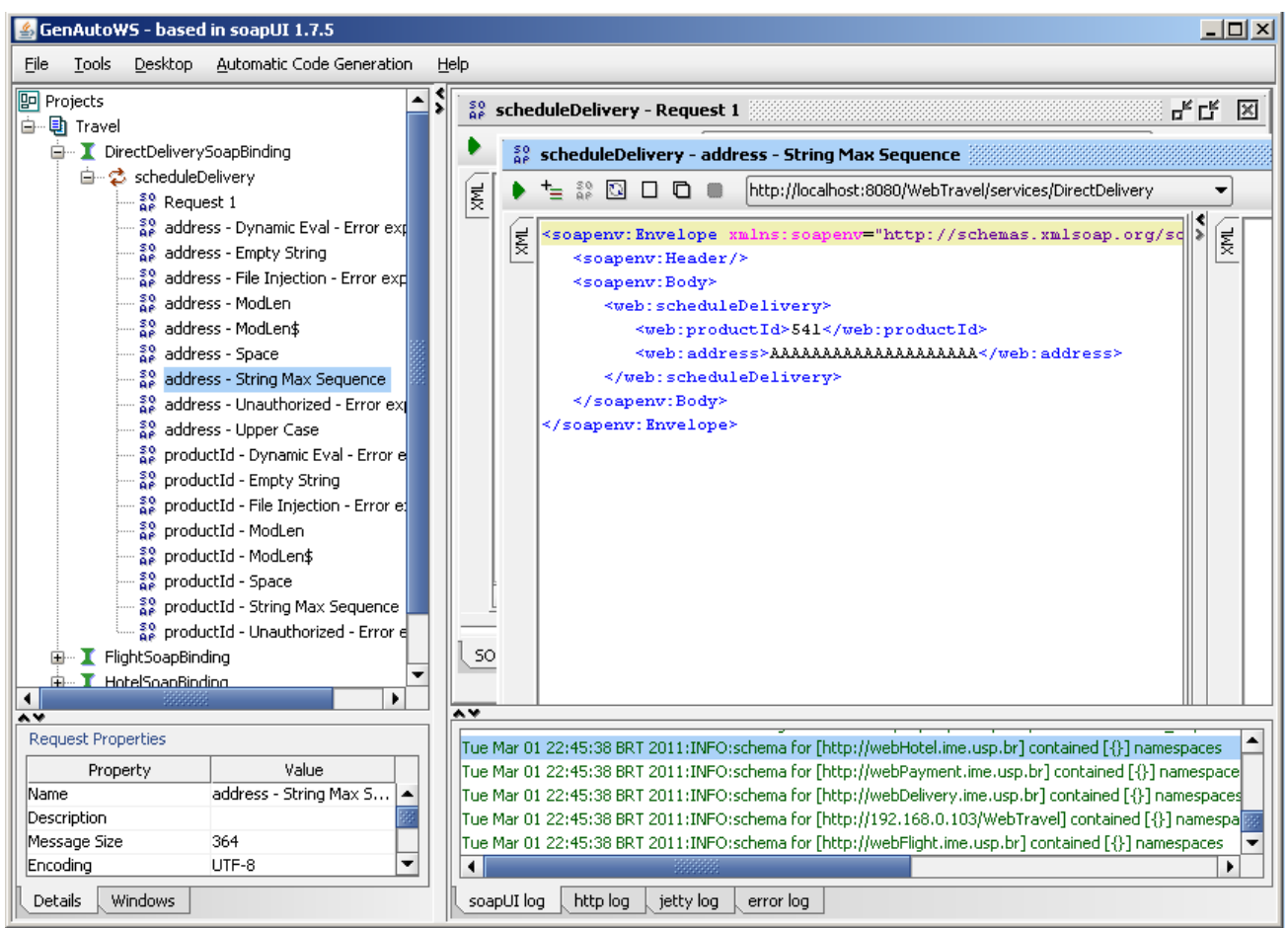

Figura 3.9 Lista de casos de teste gerados automaticamente 


\section{Capítulo 4}

\section{Testes de confiabilidade de Web Services Transacionais}

\subsection{Introdução}

Em computação, lidar com transações é um problema clássico, com algumas soluções já definidas. Porém, quando aplicadas a Web Services, a abordagem passa por algumas alterações, dificultando a aplicação de diversas soluções. As características heterogêneas dificultam a previsão do comportamento completo dos Web Services dentro de algumas aplicações. Por exemplo, o tempo de execução é, em geral, dependente de uma série de fatores e necessitam ser 'negociados' no momento em que o serviço é requisitado. Soluções puras podem até garantir bons níveis de confiabilidade no serviço[14], mas, devido à rigidez, não são suficientes para dar suporte à flexibilidade necessária para modelagens de processos com Web Services. Diante disso, a confiabilidade de composições para Aplicações Web pode ficar aquém do que se entende como aceitável.

Para avaliar o quão confiável um sistema é, pode-se executar um conjunto de casos de testes, de acordo com a tecnologia adotada. Padrões que consideram o fluxo do sistema e como a composição dos Web Services é feita podem ajudar a contornar o problema. Segundo Bhiri et al. [14], dependências entre o solicitante e o requisitado são sensíveis e críticas em termos de confiabilidade do sistema. Neste contexto, padrões transacionais podem ser utilizados como meio de se aumentar sua confiabilidade, pois facilitam a especificação de mecanismos de recuperação e manipulação de falhas. Assim, pode-se explorar técnicas que permitem avaliar as características de Web Services, individualmente ou composição deles.

Este capítulo apresenta um estudo sobre o teste de confiabilidade de Web Services Transacionais mediante critérios definidos sobre padrões de transações e assistidos pela GenAutoWS. O estudo está concentrado em como utilizar as técnicas de perturbação e mutações de dados para teste de Web Services (Seção 3.3.3), implementadas na GenAutoWS, para verificar a aderência, ou não, de padrões transacionais. Para tanto, os Web Services Transacionais e padrões transacionais serão inicialmente definidos e posteriormente o estudo será apresentado.

\subsection{Web Services Transacionais}

Segundo Bhiri et al. [14], um Web Service Transacional é um Web Service cujo comportamento apresenta características especiais, tais como ser [57, 100]:

retriable: um serviço é dito retriable se após a execução de um conjunto finito de tentativas ele será concluído com certeza.

compensatable: um serviço é dito compensatable se são oferecidas políticas de compensação que desfazem semanticamente tudo o que foi feito.

pivot: um serviço é dito pivot se, uma vez completo, seu efeito não pode ser desfeito. 
Web Services Transacionais podem assegurar apenas uma das propriedades acima, assim como um conjunto de propriedades, desde que sejam consistentes. Desta forma, Web Services Transacionais consistentes podem ter as seguintes propriedades:

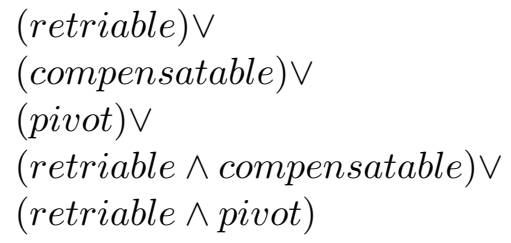

Uma transação em um sistema pode ser composta por uma ou mais transições entre seus estados. Em uma composição de Web Services Transacionais, uma transação possibilita a combinação das transições para que formem sua consistência. Ou seja, o conjunto de estados e transições depende das propriedades transacionais. Cada serviço deve obrigatoriamente ter os estados Initial, aborted, active, cancelled, failed, completed e as transições abort(), activate(), cancel(), fail(), complete() [15]. Web Services do tipo retriable e compensatable têm a mais as transições retry() e compensate() respectivamente. Parte das transições descrevem o comportamento interno dos Web Services Transacionais (complete(), fail(), retry()), sendo denominadas Transições Internas. As demais denotam as transições que acionam o comportamento de outros Web Services e, por isso, são chamadas de Transições Externas.

\section{Definição 1 Transições e Estados dos Web Services Transacionais[15]}

As transições internas e externas, e os possiveis estados de um Web Service Transacional são definidos por:

- $T i=\{\operatorname{complete}()$, fail (), retry ()$\}$ o conjunto de transições internas de um Web Service;

- $T e=\{$ abort () , activate (), cancel (), compensate ()$\}$ o conjunto de transiçôes externas de um Web Service; $e$

- Sts $=\{$ Initial, aborted, active, cancelled, failed, completed, compensated $\}$ o conjunto de estados internos de um Web Service;

Definição 2 Web Service Transacional Um Web Service Transacional $T W S\left(s_{i}\right)$ (do inglês, Transactional Web Service) é definido pela tupla $\left\{\operatorname{Initial}\left(s_{i}\right), T i\left(s_{i}\right), T e\left(s_{i}\right), S t s\left(s_{i}\right), B i, B e\right\}$ onde,

- Initial $\left(s_{i}\right)$ representa o estado inicial de $s_{i}$;

- $T i\left(s_{i}\right) \subseteq T i$ representa o conjunto de transições internas de $s_{i}$;

- $T e\left(s_{i}\right) \subseteq T$ e representa o conjunto de transições externas que saem de $s_{i}$;

- $T e^{-1}\left(s_{i}\right) \subseteq T$ e representa o conjunto de transições externas que chegam em $s_{i}$;

- $\operatorname{Sts}\left(s_{i}\right) \subseteq$ Sts representa o conjunto de estados internos de $s_{i}$;

- $B i\left(s_{i}\right): S t s\left(s_{i}\right) \times T i\left(s_{i}\right) \times S t s\left(s_{i}\right)$ representa a relação de transições internas entre estados;

- $\operatorname{Be}\left(s_{i}\right): S t s\left(s_{i}\right) \times T e\left(s_{i}\right) \times S t s\left(s_{j}\right)$ representa a relação de transições externas originadas em $s_{i} \mid j \neq i$

- $B e^{-1}\left(s_{i}\right): S t s\left(s_{j}\right) \times T e^{-1}\left(s_{i}\right) \times S t s\left(s_{i}\right)$ representa a relação de transições externas que terminam em $s_{i} \mid j \neq i$.

TWS denota o conjunto infinito de todos os Web Services Transacionais $T W S\left(s_{i}\right)$.

As transições, independente se internas ou externas, promovem comunicação entre os Web Services. A comunicação ocorre através de trocas de mensagens entre os serviços. 
Definição 3 Dada uma mensagem $m_{i-j} \in M$ enviada de um serviço $s_{i}$ para o serviço $s_{j}, K_{i-j}=$ $\left\{c_{1}, c_{2}, \ldots, c_{n}\right\}$ é o conjunto campos de $m_{i-j}$.

$M$ denota o conjunto infinito de todas as mensagens $m$.

Proposição 1 Sejam $s_{i}$ e $s_{j}$ Web Services Transacionais. Se te é uma transição de $s_{i}$ para $s_{j}$ (cuja mensagem trocada na transição é $\left.m_{i-j}\right)$, então te $\in T e\left(s_{i}\right) \wedge t e \in T e^{-1}\left(s_{j}\right) \wedge\left(s_{i}, t e, s_{j}\right) \in B e\left(s_{i}\right)$

O comportamento transacional de um Web Service é dado por todas as possíveis execuções das transições, internas e externas, de um Web Service Transacional. Vale destacar que comportamentos transacionais internos e externos de um Web Service podem ser separados. Da mesma forma, podese observar que as transições e estados disponíveis para cada Web Service Transacional dependem de suas propriedades transacionais. Por exemplo, um Web Service Transacional com propriedade pivot não possui transições do tipo compensate(), tampouco o estado compensated.

Essas características transacionais (já apresentadas no Capítulo 2) podem, por exemplo, ser descritas em BPEL ${ }^{1}$ :

- Transição de Conclusão (complete()): ocorre sempre que a execução de um serviço é concluída. Em BPEL, pode ser identificada após a ocorrência de uma $($ tag $<$ invoke $>)$;

- Transição de aborto (abort()): dentro de uma captura de falha, pode ocorrer uma tag <exit $>$. Com isso, identifica-se uma situação de aborto, ou seja, a transição específica de um comando resultou em uma exceção que causou uma interrupção do processo;

- Transição de ativação(activate()): ocorre ao ser invocado um serviço (tag < invoke>);

- Transição de Cancelamento (cancel): o processamento ocorrido dentro de uma captura de falha, desde que seja diferente de $<$ exit $>$ e $<$ empty $>$, pode ser identificado como sendo um conjunto de ações que compõem uma transição de cancelamento;

- Lançamento de falha (fail()): quando a $t a g<$ throw > é acionada ocorre a transição de falha;

- Transição de "Nova Tentativa" (retry()): a tag < retry> representa que o serviço invocado é do tipo retriable;

- Transição de Compensação (compensate()): a tag <compensate> representa que o serviço invocado é do tipo compensatable;

\subsection{Web Services Transacionais Compostos}

Aplicações Web podem representar uma composição de Web Services existentes. Essas composições são desenvolvidas, em geral, por meio de padrões transacionais. Quando um sistema é construído com base na integração de Web Services, pode-se vê-lo como um processo, formado por um conjunto de Web Services, sendo um inicial, e pelas transições entre eles. Para que as transições possam ocorrer, existem as pré-condições que precisam ser respeitadas, permitindo assim que o serviço seja executado com sucesso.

O fluxo de transações da composição de Web Services Transacionais é constituído de um conjunto de transições externas entre os serviços, neste caso, estados da aplicação. Cada transição possui o seu próprio conjunto de pré-condições, que devem ser atendidas nas transições de um estado para outro, ou simplesmente na invocação de um determinado serviço. Por consequência, existe um conjunto de pré-condições que precisam ser respeitadas para que o Web Service Transacional seja executado corretamente.

As pré-condições de cada Web Services constituem um conjunto de situações esperadas, sem as quais não se tem a garantia de que o serviço funcionará conforme especificado.

\footnotetext{
${ }^{1}$ BPEL é utilizada neste trabalho para ilustrar as situações, não sendo assim alvo do estudo.
} 


\section{Definição 4 Pré-condição de Serviços}

Seja Prop uma propriedade, Prec é uma função que define para cada transição externa de um Web Service Transacional a propriedade que ele deve garantir para que seja ativado.

Prec: Te $\times T W S \mapsto$ Prop. $\forall s_{i}, t e \mid s_{i} \in T W S \wedge t e \in T e^{-1}\left(s_{i}\right) \Rightarrow \operatorname{Prec}\left(t e, s_{i}\right)=$ Prop.

PROP denota o conjunto infinito de todas a propriedades que Web Services Transacionaisdevem garantir para que sejam ativados.

\section{Definição 5 Web Services Transacionais Compostos [15]}

Um Web Service Transacional Composto, tcs (do inglês, Transactional Composite Web Service), é definido pelo par tcs $=(t w s \subseteq T W S$, Prec $)$ onde:

- tws denota o conjunto dos Web Services Transacionais que compõem o serviço (tws $=\left\{s_{1}, \ldots, s_{n}\right\}$, $s_{i}$ é um Web Service Transacional componente de tcs)

TCS denota o conjunto de todos os Web Services Transacionais Compostos. Como um tcs pode conter vários Web Services Transacionais, seus estados são representados por: $\langle$ s.e $\rangle$, onde $s \in$ tws $e e \in \operatorname{Sts}(s)$. Da mesma forma, as transições também são representadas com a identificação dos serviços que as geraram: $\langle$ s.t( ()$>$, onde $s \in$ tws e $t \in T e(s)$.

Pré-condições expressam, em forma de dependência, a relação entre os serviços, demonstrando como podem ser combinados. Além disso, estabelece-se que determinados serviços podem influenciar o comportamento de outros. Existem dependências essenciais para a execução dos serviços[14]. Testar um Web Service isoladamente permite identificar problemas, mas, no contexto de composição de Web Services, é necessário que outros conjuntos de testes sejam executados.

\subsection{Padrões de transações}

Um dos requisitos para se ter uma composição confiável é a não-existência de inconsistências em seu fluxo de controle. Para garantir a consistência entre as transições e as diversas chamadas entre os serviços, Bhiri et al. sugerem a utilização de uma gramática livre de contexto, capaz de avaliar a qualidade da especificação das conexões[14].

Como resultado, o fluxo transacional tem algumas características:

- cada serviço é, por padrão, retriable ou pivot;

- cada serviço destino de uma compensação deve ser compensable;

- cada serviço origem de uma compensação, cancelamento ou dependência alternativa não deve ser retriable.

Para que a composição possa ser constituída, é necessário que um dado Web Service Transacional siga essas características. Além disso, é essencial que as devidas transições sejam realizadas em condições adequadas para suas respectivas execuções, e que o fluxo de controle da própria composição seja consistente e padronizada.

\subsubsection{Dependências e Condições para Transições}

Conforme pode ser visto anteriormente, um dado estado pode conter pré-condições, as quais dependem das transições a serem realizadas. Desta forma, para que cada transição ocorra segundo os padrões estabelecidos, pré-condições relativas aos serviços que as ativaram precisam ser respeitadas.

No contexto de pré-condições, dependências de execução acabam referenciando a relação entre os serviços. Para isso, é necessário descrevê-las de forma mais precisa. 


\section{Definição 6 Propriedade: Dependência de Serviços}

Sejam $s_{i}$ e $s_{j}$ dois Web Services Transacionais, $s_{i} . e\left|e \in S t s\left(s_{i}\right), s_{j} . t_{l}()\right| t_{1} \in T^{-1}\left(s_{j}\right)$, dep $\left(s_{i} . e, s_{j} . t_{l}()\right)$ define que para que a transição $s_{j} . t_{l}()$ possa ocorrer, é necessário que $s_{i} . e_{k}$ seja o estado atual de $s_{i}$.

As dependências existem de acordo com a situação. Ao todo, são 5 situações, descritas a seguir:

Ativação: O conjunto de pré-condições de ativação de um serviço consiste em situações necessárias para que seja ativado e que o sistema continue em estado consistente. Em um processo composto por Web Services Transacionais, o primeiro serviço a ser executado possui précondições idênticas às do processo todo. Para serviços que não são executados inicialmente, a pré-condição é que o imediatamente anterior tenha sido completado com sucesso;

Dependência e Condição de Ativação: expressa a relação que um dado serviço tem com outros para que seja acionado, além de conter as condições necessárias para a ativação. A dependência de ativação, em uma transição do serviço $s_{i}$ para o serviço $s_{j}$ pode ser expressa da seguinte forma:

$$
\operatorname{depAtivacao}\left(s_{i}, s_{j}\right)=\operatorname{dep}\left(s_{i} . \text { completed }, s_{j} . \operatorname{activate}()\right)
$$

Para que $s_{j}$ seja ativado, é necessário que $s_{i}$ esteja completo e que a sua finalização dispare a ativação de $s_{j}$. A Figura 4.1 apresenta tal situação. A mensagem $m_{i-j}$, neste caso, tem por função ativar $s_{j}$, podendo um (ou mais) campo $c \in K_{i-j}$ levar a informação necessária para a realização da ativação. Por exemplo, para que o sistema de controle de estoque registre a saída de um produto, é necessário que antes seja realizada a venda do item, ou seja, a realização da venda ativa o serviço "baixa de estoque";

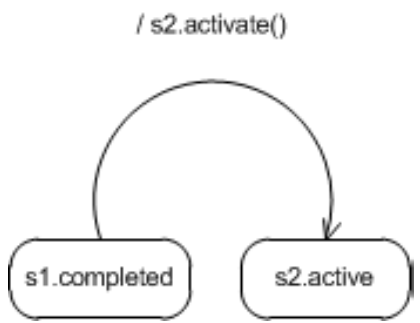

Figura 4.1 Transição de Ativação

Alternativa: Uma execução alternativa deve necessariamente ser originada por uma falha. Isso permite que o processo mantenha o seu fluxo sem que haja necessidade de ser interrompido, dado que existe um serviço alternativo;

Dependência e Condição Alternativa: permite definir as alternativas em caso de falhas, assim como as pré-condições para que cada alternativa seja viável. Isso permite a implementação de mecanismos de recuperação, especificando que a execução de um segundo serviço é uma possível alternativa caso o primeiro venha a falhar. A dependência alternativa do serviço $s_{i}$ para o serviço $s_{j}$ (Figura 4.2) existe se a falha de $s_{i}$ pode ativar $s_{j}$, expressa da seguinte forma:

$$
\operatorname{depAlternativa}\left(s_{i}, s_{j}\right)=\operatorname{dep}\left(s_{i} \text {.failed, } s_{j} \text {.activate }()\right)
$$

A mensagem $m_{i-j}$ tem por função ativar $s_{j}$. Ela pode carregar a informação de que $s_{i}$ falhou, mas, não necessariamente sempre. Por exemplo, o serviço principal de entrega, ao ser acionado, apresenta alguma falha de execução, disparando a invocação de um outro serviço de entrega. O segundo não precisa saber que o primeiro falhou, dependendo da necessidade. 


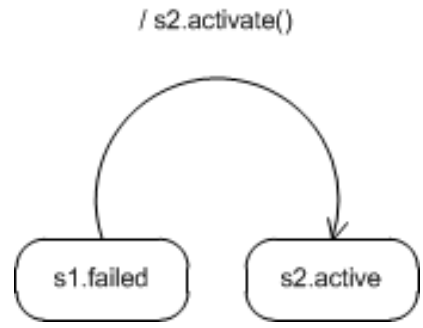

Figura 4.2 Transição de Alternativa

Aborto: originada também a partir de uma falha, podem acontecer dois cenários distintos: o primeiro, a falha simplesmente é responsável pela interrupção do processo; o segundo, a falha inicia um cancelamento do serviço que em seguida aborta os demais, que por consequência aborta o processo;

Dependência e Condição de Aborto: permite interromper a execução de um determinado serviço e impedir que o sistema propague um estado de falha. Em uma transição do serviço $s_{i}$ para o serviço $s_{j}$, como pode ser visto na Figura 4.3, a execução de $s_{j}$ é abortada se $s_{i}$ falhar ou se for cancelado. A relação pode ser descrita da seguinte forma:

$$
\operatorname{depAborto}\left(s_{i}, s_{j}\right)=\operatorname{dep}\left(s_{i} . \text { failed } \vee s_{i} . \text { cancelled, } s_{j} . \text { abort }()\right)
$$

Esta funcionalidade permite a propagação de falhas de um serviço para os seus sucessores. Um ou mais campos da mensagem $m_{i-j}$ podem informar que $s_{j}$ deve ser abortado. Por exemplo, o processo de compra de um produto pode ser abortado se o processo de baixa de estoque não foi concluído;
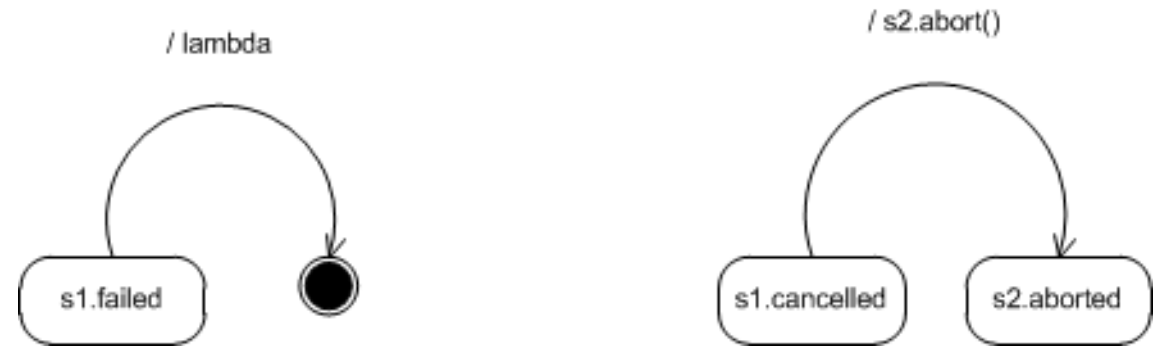

Figura 4.3 Transição de Aborto

Compensação: para esta transição, de forma similar à transição de aborto, existem dois conjuntos viáveis de pré-condições: originadas a partir de uma falha que dispara uma compensação; originadas seguindo uma série de compensações;

Dependência e Condição de Compensação: define um mecanismo de recuperação de um determinado estado através da execução de estados compensatórios. Isso ocorre através da especificação dos passos necessários para desfazer semanticamente o que já foi realizado por um determinado serviço, indicando o que deve ser desfeito. Uma transição de compensação, de um serviço $s_{i}$ para um serviço $s_{j}$, ocorre se $s_{i}$ falhar, ou se a compensação de $s_{j}$ disparar a compensação de $s_{j}$. A Figura 4.4 ilustra a transação de compensação, definida mais especificamente da seguinte forma:

$$
\begin{gathered}
\text { depCompensao }\left(s_{i}, s_{j}\right)= \\
\operatorname{dep}\left(s_{i} . \text { failed }, s_{j} . \text { compensate }()\right) \vee \operatorname{dep}\left(s_{i} . \text { compensate }(), s_{j} . \text { compensate }()\right)
\end{gathered}
$$

Para esta situação, a mensagem $m_{i-j}$ pode ter em um dos campos a informação que acionará a compensação de $s_{j}$. Por exemplo, supondo em uma venda de um determinado produto, a 
baixa de estoque é realizada com sucesso, contudo, ao efetuar o pagamento, ocorre uma falha. A compensação consiste em estornar a baixa do estoque, desfazendo assim o que já havia sido realizado. Ou seja, a falha do pagamento dispara o estorno da baixa de estoque.
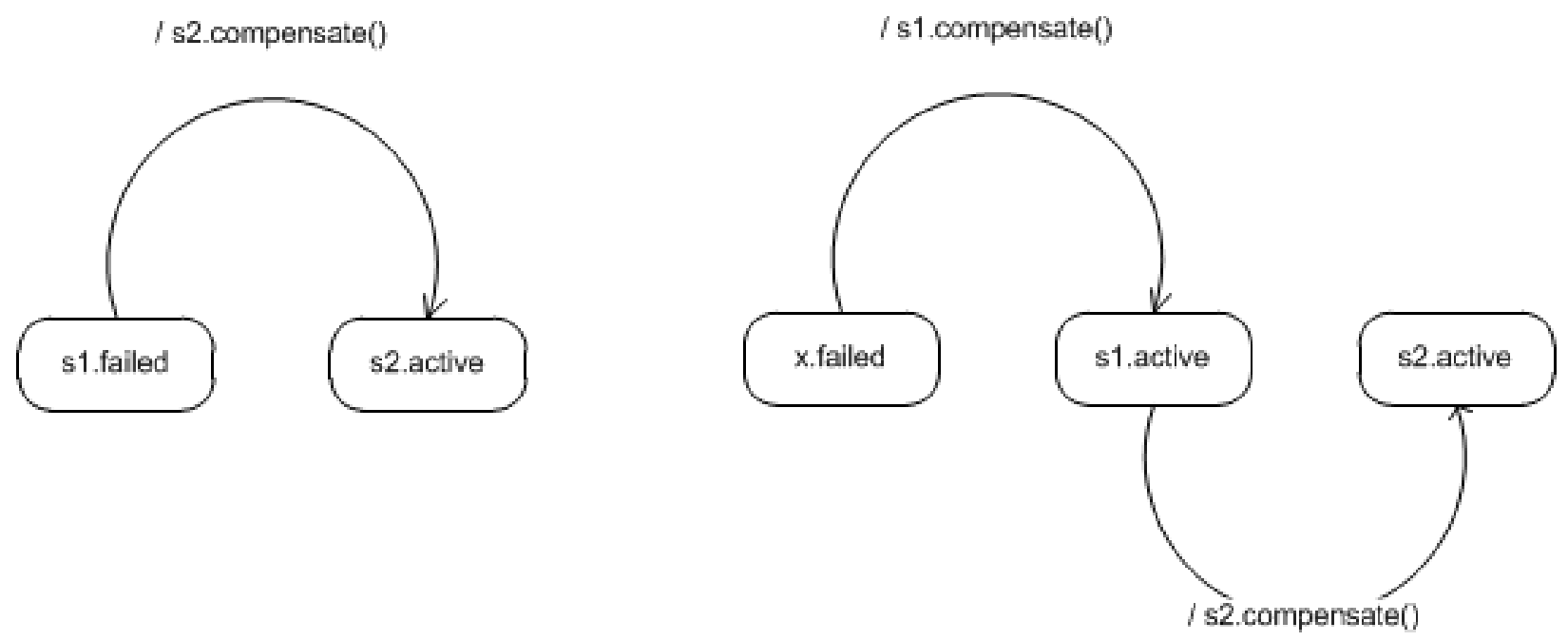

Figura 4.4Transição de Compensação

Cancelamento: surge a partir de uma falha, que dispara um cancelamento. Neste cenário, a précondição é determinada pela falha do(s) serviço(s) imediatamente anterior(es).

Dependência e Condição de Cancelamento: permite a definição de regras de cancelamento de determinados serviços. É semelhante ao item de Aborto, tendo como diferença o fato de que o serviço inteiro é cancelado. Uma transição de cancelamento, de um serviço $s_{i}$ para um serviço $s_{j}$ (Figura 4.5), ocorre se $s_{i}$ falhar e disparar o cancelamento de $s_{j}$. Essa relação pode ser descrita da seguinte forma:

$$
\text { depCancelamento }\left(s_{i}, s_{j}\right)=\operatorname{dep}\left(s_{i} . \text { failed }, s_{j} . \operatorname{cancel}()\right)
$$

A mensagem $m_{i-j}$ tem por função disparar o cancelamento de $s_{j}$. Os campos de $m_{i-j}$ podem conter informação de que $s_{i}$ falhou e que esta falha resultou no cancelamento de $s_{j}$. Por exemplo, suponha que um determinado sistema contábil não prevê estorno, impedindo assim que um lançamento de compensação seja realizado. Nesta situação, caso haja necessidade, o cancelamento é realizado através de um crédito em uma outra conta.

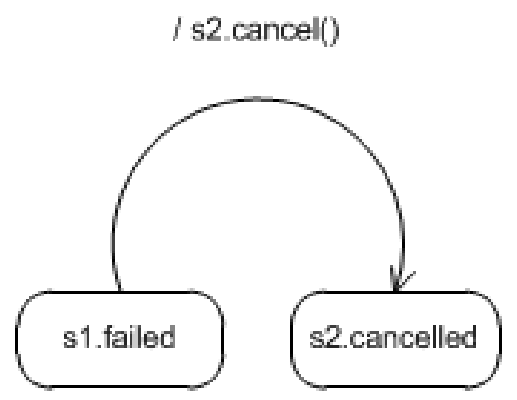

Figura 4.5 Transição de Cancelamento

\subsubsection{Padrões de Fluxos de Controle e Transações}

Quando o contexto é composição de Web Services, pode-se dizer que há dois níveis na definição de fluxos de controle: o fluxo interno, no qual o próprio serviço executa suas operações de 
acordo com a necessidade e; o fluxo externo, também conhecido como fluxo de coordenação (ou orquestração), o qual organiza as entradas e saídas de cada Web Service, seguindo uma sequência determinada. A maneira que o fluxo de coordenação é definido influencia diretamente na qualidade e na confiabilidade da composição [14].

Nesse contexto, van der Aalst e van Hee [95] apresentam os modelos sequence, AND-Split, ANDJoin, OR-Split, OR-Join, XOR-Split e XOR-Join, a partir dos quais, podem-se definir padrões para os fluxos de controle e, assim, determinar padrões transacionais. Tais padrões definidos por Bhiri et al. [14] se baseiam nos modelos propostos por van der Aalst e van Hee.

- Sequence ocorre quando pontos do processo são executados de maneira sequencial, sendo um iniciado após o término do outro. O modelo Sequence é uma representação de execução em série do processo. Em BPEL é representada pela tag < sequence>;

- AND-Split ocorre quando um ponto no fluxo do processo aponta para dois ou mais pontos. Os subsequentes devem ser iniciados após a conclusão do primeiro. O modelo AND-Split é uma representação de início de processos que ocorrem em paralelo cuja descrição BPEL é representada pela $t a g<$ flow $>$;

- AND-Join ocorre quando dois ou mais pontos, no fluxo, apontam para um único processo. O processo subsequente deve ser iniciado após a conclusão de todos os seus antecessores. O modelo AND-Join representa o término de execução dos processos, através da mesma tag do AND-Split, porém, de conclusão ( </flow $>$ - o processo seguinte é o AND-Join);

- OR-Split é semelhante ao AND-Split, que ocorre quando um ponto no fluxo do processo aponta para dois ou mais pontos. Os subsequentes devem ser iniciados após a conclusão do primeiro;

- OR-Join ocorre quando dois ou mais pontos, no fluxo, apontam para um único processo. O processo subsequente deve ser iniciado após a conclusão de pelo menos um de seus antecessores. Tanto o OR-Split quanto o OR-Join não são facilmente representados ou identificados em BPEL e em qualquer outra linguagem de processo [60];

- XOR-Split ocorre quando um processo, no fluxo, aponta para dois ou mais processo, mas apenas um deles deve ser iniciado. Um único processo subsequente será iniciado após a conclusão do primeiro.

- XOR-Join semelhante ao OR-Join, que ocorre ocorre quando dois ou mais pontos, no fluxo, apontam para um único ponto do fluxo. O ponto subsequente deve ser iniciado após a conclusão de um de seus antecessores. O modelo XOR-Split, que representa execução exclusiva de um processo, pode ser descrita em BPEL através de uma condicional $(<\mathrm{IF}>$ ou $<$ SWITCH $>$ ), ou através de um tratamento de exceção - o processo descrito no tratamento de exceção só é executado caso o primeiro processo falhe. Neste caso, é necessário que o processo seguinte não seja um abortivo (<exit $>$ ), ou que seja o mesmo processo que seria invocado caso o primeiro tivesse sido completado com sucesso;

A construção inapropriada ou a definição indevida podem causar inconsistências ao fluxo. Por exemplo, quando um XOR-Split é seguido de um AND-Join (Figura 4.6): apenas um dos dois serviços, Web Services WS 1 ou WS 1, é executado; em um AND-Join é aguardado o retorno de ambos. Assim, é possível garantir a consistência do fluxo através da aplicação desses padrões.

O fluxo de execução dos serviços de uma composição, em outras palavras, o fluxo de execução dos Web Services Transacionais de um Web Service Transacional Composto, pode ser visto como um processo e permite chegar ao resultado esperado da aplicação. Os modelos apresentados fazem parte da composição, onde cada Web Service, incluindo suas transições e pré-condições, interagem entre si. Em um processo com essas características, é necessário avaliar as pré-condições de cada transação para as distintas situações, além do fluxo de controle do próprio processo. 


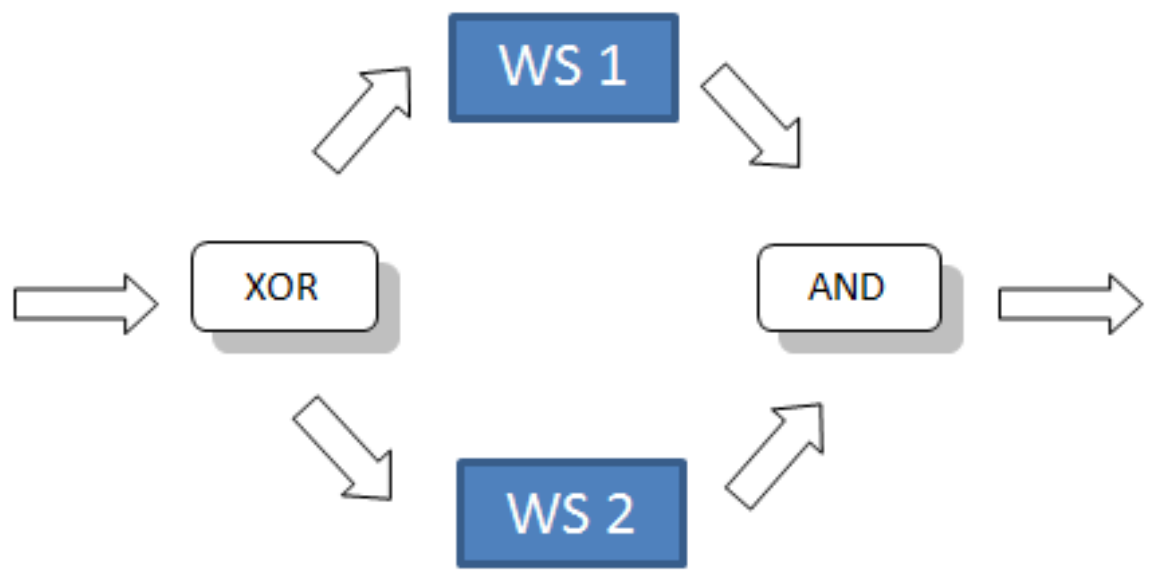

Figura 4.6Exemplo de fluxo inconsistente

\subsection{Uma Sistemática para Testes de Confiabilidade de Web Services Transacionais Compostos baseada em Padrões de Transação}

Para certificar-se de que o processo funciona de acordo com o esperado, pode-se submetê-lo a um conjunto de testes, visando identificar falhas e assim melhorar o produto final. Em um processo composto por serviços (nesta pesquisa, implementados como Web Services), o ideal é que todos tenham qualidade e que a integração entre eles não comprometa a composição.

Aplicações Web, assim como Web Services isolados, necessitam ter confiabilidade destacada. Desta forma, os Web Services Transacionais Compostos devem ter seus Web Services Transacionais testados isoladamente, assim como a composição deles. No presente trabalho tem-se como objetivo explorar o uso das técnicas de perturbação e mutação de dados apresentadas no Capítulo 3 para o teste de confiabilidade de composições de Web Services Transacionais, além de avaliá-los de forma isolada. Para tanto, utilizam-se como guia de confiabilidade dos Web Services Transacionais Compostos a aderência aos padrões transacionais definidos na Seção 4.4.

A GenAutoWS implementa as técnicas para teste de Web Services exploradas no Capítulo 3 e, portanto, gera um conjunto amplo de testes, que podem ser utilizados para as abordagens citadas (perturbação de tipos, perturbação de comunicação e mutação de dados). Silveira, em sua dissertação [89], mostra duas formas de aplicar a perturbação sobre comunicação: RPC e Document. Cada uma é adotada de acordo com o padrão estabelecido na comunicação. A forma baseada em RPC permite testar o uso que o serviço faz dos dados, enquanto a forma baseada em Document possibilita testes de relacionamentos e restrições, pois fazem uso de documentos completos.

Através dessas técnicas, pode-se explorar as condições de testes e assim potencializar a detecção de problemas no sistema. O conjunto de técnicas utilizadas por Silveira e Melo [31] permite a criação automática de casos de testes, usando como base mensagens submetidas de um serviço para outro.

Definição 7 Seja PertDados o conjunto das técnicas de perturbação de dados, PertCom o conjunto das técnicas de perturbação de comunicação, e MutDados de mutação de dados utilizadas por Silveira e Melo [31]. Tem-se:

- PertDados $=\{$ string, boolean, numerico, data, binario, enumeration, fractionDigits, length, maxExclusive, maxInclusive, maxLength, minExclusive, minInclusive, minLength, pattern, totalDigits, whiteSpace \}

- PertCom $=\{$ minOcurrs, maxOcurres, choice, any element $\}$

- MutDados $=\{$ divide, Multiply, Negative, Absolute, Exchange, Unauthorized, Null, Incomplete, Inversion, ValueInversion, Mod_Len, Space $\}$ 
- $T E C=$ PertDados $\cup$ PertCom $\cup$ MutDados

Definição 8 Seja $m_{i-j}$ uma mensagem enviada de um serviço $s_{i}$ para o serviço $s_{j}$.

$M S G: M \times T E C \times K \mapsto m s g\left(M S G\left(m_{i-j}, t e c, c_{k}\right) \mid t e c \in T E C \wedge c_{k} \in K\right)$ é o conjunto de mensagens geradas a partir de $m_{i-j}$ utilizando a técnica tec. Assim, tem-se:

- Perturbação de Dados

- string $\left(m_{i-j}, c\right)=M S G\left(m_{i-j}\right.$, string,$\left.c\right)$

- boolean $\left(m_{i-j}, c\right)=M S G\left(m_{i-j}\right.$, boolean, $\left.c\right)$

- numerico $\left(m_{i-j}, c\right)=M S G\left(m_{i-j}\right.$, numerico,$\left.c\right)$

$-\operatorname{data}\left(m_{i-j}, c\right)=M S G\left(m_{i-j}\right.$, data,$\left.c\right)$

- $\operatorname{binario}\left(m_{i-j}, c\right)=M S G\left(m_{i-j}\right.$, binario, $\left.c\right)$

- enumeration $\left(m_{i-j}, c\right)=M S G\left(m_{i-j}\right.$, enumeration, $\left.c\right)$

- fractionDigits $\left(m_{i-j}, c\right)=M S G\left(m_{i-j}\right.$, fractionDigits, $\left.c\right)$

- length $\left(m_{i-j}, c\right)=M S G\left(m_{i-j}\right.$, length,$\left.c\right)$

- maxExclusive $\left(m_{i-j}, c\right)=M S G\left(m_{i-j}\right.$, maxExclusive, $\left.c\right)$

- maxInclusive $\left(m_{i-j}, c\right)=M S G\left(m_{i-j}\right.$, maxInclusive,$\left.c\right)$

- maxLength $\left(m_{i-j}, c\right)=M S G\left(m_{i-j}\right.$, maxLength,$\left.c\right)$

- minExclusive $\left(m_{i-j}, c\right)=M S G\left(m_{i-j}\right.$, minExclusive,$\left.c\right)$

- minInclusive $\left(m_{i-j}, c\right)=M S G\left(m_{i-j}\right.$, minInclusive, $\left.c\right)$

- minLength $\left(m_{i-j}, c\right)=M S G\left(m_{i-j}\right.$, minLength,$\left.c\right)$

- pattern $\left(m_{i-j}, c\right)=M S G\left(m_{i-j}\right.$, pattern,$\left.c\right)$

- totalDigits $\left(m_{i-j}, c\right)=M S G\left(m_{i-j}\right.$, totalDigits,$\left.c\right)$

- whiteSpace $\left(m_{i-j}, c\right)=M S G\left(m_{i-j}\right.$, whiteSpace, $\left.c\right)$

- Perturbação de Comunicação

- $\operatorname{minOcurrs}\left(m_{i-j}, c\right)=M S G\left(m_{i-j}\right.$, minOcurrs,$\left.c\right)$

- maxOcurres $\left(m_{i-j}, c\right)=M S G\left(m_{i-j}\right.$, maxOcurres, $\left.c\right)$

- choice $\left(m_{i-j}, c\right)=M S G\left(m_{i-j}\right.$, choice,$\left.c\right)$

- anyElement $\left(m_{i-j}, c\right)=M S G\left(m_{i-j}\right.$, anyElement,$\left.c\right)$

- Mutação de Dados

$-\operatorname{divide}\left(m_{i-j}, c\right)=M S G\left(m_{i-j}\right.$, divide, $\left.c\right)$

- Multiply $\left(m_{i-j}, c\right)=\operatorname{MSG}\left(m_{i-j}\right.$, Multiply, $\left.c\right)$

- Negative $\left(m_{i-j}, c\right)=M S G\left(m_{i-j}, N\right.$ egative, $\left.c\right)$

- Absolute $\left(m_{i-j}, c\right)=M S G\left(m_{i-j}\right.$, absolute,$\left.c\right)$

- Exchange $\left(m_{i-j}, c_{1}, c_{2}\right)=M S G\left(m_{i-j}\right.$, exchange, $\left.c_{1}, c_{2}\right)$

- Unauthorized $\left(m_{i-j}, c_{1}, c_{2}\right)=M S G\left(m_{i-j}\right.$, Unauthorized, $\left.c\right)$

- $\operatorname{Null}\left(m_{i-j}, c_{1}, c_{2}\right)=\operatorname{MSG}\left(m_{i-j}, N u l l, c\right)$

- Incomplete $\left(m_{i-j}, c_{1}, c_{2}\right)=M S G\left(m_{i-j}\right.$, Incomplete, $\left.c\right)$

- Inversion $\left(m_{i-j}, c_{1}, c_{2}\right)=M S G\left(m_{i-j}\right.$, Inversion, $\left.c\right)$

- ValueInversion $\left(m_{i-j}, c_{1}, c_{2}\right)=M S G\left(m_{i-j}\right.$, ValueInversion, $\left.c\right)$

- Mod_Len $\left(m_{i-j}, c_{1}, c_{2}\right)=M S G\left(m_{i-j}, M o d \_L e n, c\right)$

- Space $\left(m_{i-j}, c_{1}, c_{2}\right)=M S G\left(m_{i-j}\right.$, Space, $\left.c\right)$ 
Definição 9 Seja $s_{i}$ o estado inicial, $s_{j}$ o estado final, $m_{i-j}$ a mensagem enviada de $s_{i}$ para $s_{j}$, $\mathcal{C} \mathcal{T}\left(m_{i-j}\right)$ é o conjunto de casos de testes gerados com base na mensagem $m_{i-j}$. Ou seja:

$\mathcal{C} \mathcal{T}\left(m_{i-j}\right)=\mathcal{P D}\left(\right.$ PertDados,$\left.m_{i-j}\right) \cup \mathcal{P C}\left(\right.$ PertCom,$\left.m_{i-j}\right) \cup \mathcal{M D}\left(\right.$ MutDados, $\left.m_{i-j}\right)$ onde:

1. $\mathcal{P D}\left(p d, m_{i-j}\right)$ é o conjunto de casos de testes gerados segundo a técnica de perturbação de tipos e pd $\subseteq$ PertDados;

2. $\mathcal{P C}\left(p c, m_{i-j}\right)$ é o conjunto de casos de testes gerados segundo a técnica de perturbação de comunicação e pc $\subseteq$ PertCom;

3. $\mathcal{M D}\left(m d, m_{i-j}\right)$ é o conjunto de casos de testes gerados segundo a técnica de mutação de dados e md $\subseteq$ MutDados;

A mensagem $m_{i-j}$ é utilizada como semente, servindo como originadora dos casos de testes $\mathcal{P D}\left(\right.$ PertDados,$\left.m_{i-j}\right), \mathcal{P C}\left(\right.$ PertCom, $\left.m_{i-j}\right)$ e $\mathcal{M} \mathcal{D}\left(\right.$ MutDados,$\left.m_{i-j}\right)$. A validação dos Web Services Transacionais que pertencem ao sistema pode ocorrer através da validação isoladamente, assim como da verificação das pré-condições de cada um, além de validação do resultado obtido. Considerando o cenário ideal, na execução com dados válidos, passa-se por todos os serviços seguindo uma determinada ordem, trocando mensagens entre si e retornando a resposta do sistema no estado final. Porém, em situações normais de utilização, podem ocorrer violação de pré-condições ou até mesmo da sequência de uso. No exemplo do sistema de viagem, pode acontecer um problema na comunicação entre os sistemas de reserva aérea, reserva de hotel e o de pagamento. Para que não haja problemas com o sistema de pagamento, é necessário que ele faça tratamentos adequados, prevendo situações em que os dados se perdem, são corrompidos, ou simplesmente ignorados.

Para tanto, é necessário validar o processo completo, testando-se tais situações, simulando cenários em que aconteça perda (ou modificações acidentais) de dados. É preciso também avaliar se o fluxo montado e a ordem de execução dos serviços estão vulneráveis a problemas no processamento. Para que essas validações possam ser realizadas, pode-se criar alguns cenários de testes que possibilitem explorar as situações:

1. Validação de Web Services Transacionais isolados: empregam-se as variações das técnicas de perturbação e mutação de dados;

2. Validação de pré-condições e sequência: mantendo-se a sequência do processo e perturbando as mensagens trocadas (respeitando as pré-condições);

3. Violação de sequência: alterando a sequência e;

4. Violação de pré-condições: mantendo-se a sequência do processo, perturbando as mensagens trocadas e não respeitando as pré-condições.

Nas seções seguintes são apresentadas situações possíveis na composição de Web Services Transacionais, destacando quais alternativas podem-se identificar para validá-los isoladamente e para validar se sistemas constituídos através de combinação deles atendem as propriedades esperadas.

\subsubsection{Validação de Web Services Transacionais isolados}

Como pode ser visto no Capítulo 3, Web Services possuem características específicas. Como visto no mesmo capítulo, a ferramenta GenAutoWS pode gerar automaticamente um conjunto de testes para Web Services. Para gerar os testes que possam validar o processo e suas transações, pode-se utilizar como semente geradora a mensagem trocada entre os serviços.

Sob o ponto de vista de unidade, através de técnicas de perturbação e mutação de mensagens (perturbação baseada em tipos de dados e em restrições), buscam-se defeitos, executando testes de classes de equivalência. A perturbação de dados altera valores por meio do uso de informações de seus tipos. Tais tipos são determinados através do XML Schema da própria mensagem. Com a técnica de análise de valores de fronteira, casos de testes podem ser elaborados de acordo com 
o tipo primitivo da entrada. Assim, usando a Definição 9, o conjunto de testes gerados segundo a técnica de perturbação de dados é

$$
\mathcal{P D}\left(p d, m_{i-j}\right) \mid p d=\text { PertDados }
$$

A Tabela 4.1 apresenta as condições de testes úteis para validação de Web Services Transacionais isolados com uso de valores limites para dados primitivos. Já a Tabela 4.2 apresenta as condições de testes que permitem validar Web Services Transacionais isolados através do uso de restrições de facetas.

\begin{tabular}{|c|c|}
\hline Teste Valor Limite & Web Services Transacionais isolados \\
\hline String & $\mathrm{X}$ \\
\hline Numérico & $\mathrm{X}$ \\
\hline Booleano & $\mathrm{X}$ \\
\hline data & $\mathrm{X}$ \\
\hline Binário & $\mathrm{X}$ \\
\hline
\end{tabular}

Tabela 4.1Perturbação de Dados com base em Valores Limite - Aplicação para testes isolados de Web Services

\begin{tabular}{|l|c|}
\hline Restrições com Facetas & Web Services \\
\hline enumeration & $\mathrm{X}$ \\
fractionDigits & $\mathrm{X}$ \\
length & $\mathrm{X}$ \\
maxExclusive & $\mathrm{X}$ \\
maxInclusive & $\mathrm{X}$ \\
maxLength & $\mathrm{X}$ \\
minExclusive & $\mathrm{X}$ \\
minInclusive & $\mathrm{X}$ \\
minLength & $\mathrm{X}$ \\
pattern & $\mathrm{X}$ \\
totalDigits & $\mathrm{X}$ \\
whiteSpace & $\mathrm{X}$ \\
\hline
\end{tabular}

Tabela 4.2Perturbação de Dados com base em Facetas XML - Aplicação para testes isolados de Web Services

De maneira semelhante, para pertubações na comunicação, que tomam como base as restrições no relacionamento XML, é possível também validar de maneira isolada um Web Service Transacional, onde o conjunto de casos de testes é

$$
\mathcal{P C}\left(p c, m_{i-j}\right) \mid p c=\text { PertCom } .
$$

A Tabela 4.3 apresenta as situações de testes que auxiliam a validação de um dado Web Service.

\begin{tabular}{|l|c|}
\hline Teste Comunicação & Fluxo de Web Services Transacionais \\
\hline minOccurs & $\mathrm{X}$ \\
maxOccurs & $\mathrm{X}$ \\
minOccurs, maxOccurs & $\mathrm{X}$ \\
choice & $\mathrm{X}$ \\
all & $\mathrm{X}$ \\
any element & $\mathrm{X}$ \\
\hline
\end{tabular}

Tabela 4.3 Validação de pré-condições e sequência - Perturbação de Comunicação

A mutação, outra técnica bastante útil na validação de Web Services Transacionais isolados, é realizada através de operadores de mutação. Tais operadores são aplicados na mensagem original, aumentando a chance de um erro ser identificado, caso exista. Assim como para as demais técnicas, a mutação é aplicada para testes isolados, implicando que o conjunto de casos de testes baseado em mutação é

$$
\mathcal{M D}\left(m d, m_{i-j}\right) \mid m d=\text { MutDados }
$$




\begin{tabular}{|l|c|}
\hline Teste / Operador de Mutação & Web Services \\
\hline Divide (c) & $\mathrm{X}$ \\
Multiply (c) & $\mathrm{X}$ \\
Negative (c) & $\mathrm{X}$ \\
Absolute (c) & $\mathrm{X}$ \\
Exchange $\left(c_{1}, c_{2}\right)$ & $\mathrm{X}$ \\
Unauthorized (c) & $\mathrm{X}$ \\
Null (c) & $\mathrm{X}$ \\
Incomplete (c) & $\mathrm{X}$ \\
Inversion (c) & $\mathrm{X}$ \\
ValueInversion (c) & $\mathrm{X}$ \\
Mod_Len (c) & $\mathrm{X}$ \\
Space (c) & $\mathrm{X}$ \\
\hline
\end{tabular}

Tabela 4.4Mutação de Dados - Aplicação para testes isolados de Web Services

A Tabela 4.4 apresenta os casos de testes que contribuem para a validação de Web Services Transacionais isolados.

Em resumo, o conjunto de testes formado pela aplicação dos três tipos de técnicas, perturbação de dados, de comunicação e mutação de dados, é o seguinte:

$$
\mathcal{C} \mathcal{T}\left(m_{i-j}\right)=\mathcal{P} \mathcal{D}\left(p d, m_{i-j}\right) \cup \mathcal{P C}\left(p c, m_{i-j}\right) \cup \mathcal{M D}\left(m d, m_{i-j}\right) .
$$

Apesar de ter cobertura adequada quando testam-se Web Services como unidades, em uma composição deles (e quando envolve transações), o conjunto de testes passa a ser insuficiente.

\subsubsection{Validação de pré-condições e sequência}

$\mathrm{Na}$ execução de um processo, existe uma determinada ordem na sequência. Nesta abordagem, busca-se identificar condições de falhas, sem que a sequência do processo nem as pré-condições sejam violadas, atuando-se diretamente nas mensagens trocadas. Desta forma, situações causadas por perda de informações, interferências no meio ou problemas na execução de serviços são simuladas. Por exemplo, pode acontecer de todas as pré-condições para a execução de um determinado serviço estejam satisfeita, porém, com problemas na informação transmitida. A confiabilidade da composição depende da forma que tais situações são contornadas caso ocorram.

De modo independente dos tipos de dados de entrada de cada serviço, a perturbação com valores limite é aplicável, apresentados nas Tabelas 4.5. Este tipo de perturbação, tomando por base todos os tipos de dados, quando aplicado a campos específicos da mensagem, permite interferir na maneira que a informação é transmitida entre os serviços.

\begin{tabular}{|l|c|}
\hline Teste Valor Limite & Fluxo de Web Services Transacionais \\
\hline String & $\mathrm{X}$ \\
Numérico & $\mathrm{X}$ \\
Booleano & $\mathrm{X}$ \\
data & $\mathrm{X}$ \\
Binário & $\mathrm{X}$ \\
\hline
\end{tabular}

Tabela 4.5 Validação de pré-condições e sequência - Perturbação de Dados primitivos

A perturbação em restrição de tipos, através das facetas, são usadas para definir dados válidos e inválidos sobre restrições de tipos de dados. Situações simuladas através dos operadores fractionDigits, lenght, maxLength, minLength, totalDigits, whiteSpace, maxExclusive, maxInclusive, minExclusive e minInclusive já são cobertas pelas pertubações baseadas em valores limite de tipo de dados, mas também podem identificar inconsistência na solução. Os operadores enumeration, pattern permitem avaliar a confiabilidade de um serviço de forma semelhante. Ou seja, todas as técnicas de perturbação baseadas em facetas contribuem com este cenário de testes. A Tabela 4.6 resume os operadores de facetas aplicáveis considerando a perturbação sobre a comunicação. Somados com as técnicas baseadas em tipos primitivos, tem-se o conjunto $p d=$ PertDados representando as técnicas que auxiliam a geração de casos de testes. Com isso, o conjunto de casos de testes gerado através de técnicas de perturbação de dados para este cenário é 
$\mathcal{P D}\left(p d, m_{i-j}\right) \mid p d=$ PertDados

\begin{tabular}{|l|c|}
\hline Teste Faceta & Fluxo de Web Services Transacionais \\
\hline enumeration & $\mathrm{X}$ \\
fractionDigits & $\mathrm{X}$ \\
length & $\mathrm{X}$ \\
maxExclusive & $\mathrm{X}$ \\
maxInclusive & $\mathrm{X}$ \\
maxLength & $\mathrm{X}$ \\
minExclusive & $\mathrm{X}$ \\
minInclusive & $\mathrm{X}$ \\
minLength & $\mathrm{X}$ \\
pattern & $\mathrm{X}$ \\
totalDigits & $\mathrm{X}$ \\
whiteSpace & $\mathrm{X}$ \\
\hline
\end{tabular}

Tabela 4.6 Validação de pré-condições e sequência - Perturbação de Dados com base em restrições

A perturbação de comunicação possibilita criação de testes com foco no relacionamento e em restrições nas mensagens trocadas entre os serviços. É possível, por exemplo, simular situações de dependência entre os serviços: se um determinado serviço $s_{i}$ necessita receber 3 respostas provenientes de 3 outros serviços, faz parte das pré-condições de execução de $s_{i}$ a conclusão dos 3 serviços. Se na mensagem não houver as 3 respostas, mesmo com os serviços concluídos (pré-condição satisfeita), a confiabilidade estará comprometida. Neste caso, tem-se

$$
\mathcal{P C}\left(p c, m_{i-j}\right) \mid p c=\text { PertCom }
$$

conforme apresentado na Tabela 4.7.

\begin{tabular}{|l|c|}
\hline Teste Comunicação & Fluxo de Web Services Transacionais \\
\hline minOccurs & $\mathrm{X}$ \\
maxOccurs & $\mathrm{X}$ \\
minOccurs, maxOccurs & $\mathrm{X}$ \\
choice & $\mathrm{X}$ \\
all & $\mathrm{X}$ \\
any element & $\mathrm{X}$ \\
\hline
\end{tabular}

Tabela 4.7Validação de pré-condições e sequência - Perturbação de Comunicação

Além disso, são aplicáveis os operadores de mutação Exchange $\left(c_{1}, c_{2}\right), \operatorname{Null}(c)$, Incomplete $(c)$, Inversion(c), ValueInversion(c) e Mod_Len(c). Por exemplo, supondo-se uma sequência de dois Web Services Transacionais $s_{i}$ e $s_{j}$, cuja transição externa ocorre ao $s_{i}$ enviar uma mensagem $m_{i-j}$ para $s_{j}$. Supondo também que $s_{i}$.completed $\in \operatorname{Prec}\left(t e, s_{j}\right)$. Para que isso aconteça, $s_{j}$ precisa ser notificado que $s_{i}$ está em estado completed. Seja $c_{k}$ um campo qualquer de $m_{i-j}$, onde $1 \leq k \leq n$ e $n$ equivale ao total de campos em $m_{i-j}$. As pertubações Exchange, Null, Incomplete, Inversion, ValueInversion e Mod_Len, quando aplicadas a $c_{k}$ comprometem a notificação. Com isso, podese avaliar diretamente a confiabilidade de $s_{j}$, de acordo com a resposta que apresentar diante da mensagem perturbada.

Os demais operadores de mutação, tais como Divide, Multiply, Negative, Absolute não contribuem para a avaliação de confiabilidade esperada em uma validação de pré-condições e de sequência. O conjunto de casos de testes para este cenário é

$$
\mathcal{M D}\left(m d, m_{i-j}\right) \mid m d=\{\text { Exchange, Null, Incomplete, Inversion, ValueInversion, Mod_Len, }
$$
Space\}.

Nesse conjunto de casos de testes, md $\subset$ MutDados representa as técnicas aplicáveis neste cenário. O resumo da aplicabilidade é apresentado na Tabela 4.8.

O conjunto completo dos casos de testes é o seguinte: 


\begin{tabular}{|c|c|}
\hline Teste / Operador de Mutação & Fluxo de Web Services Transacionais \\
\hline Divide (c) & \\
Multiply (c) & \\
Negative (c) & \\
Absolute (c) & $\mathrm{X}$ \\
Exchange (c1, $\left.c_{2}\right)$ & \\
Unauthorized (c) & $\mathrm{X}$ \\
Null (c) & $\mathrm{X}$ \\
Incomplete (c) & $\mathrm{X}$ \\
Inversion (c) & $\mathrm{X}$ \\
ValueInversion (c) & $\mathrm{X}$ \\
Mod_Len (c) & $\mathrm{X}$ \\
Space (c) & \\
\hline
\end{tabular}

Tabela 4.8 Validação de pré-condições e sequência - Mutação de Dados

$\mathcal{C} \mathcal{T}\left(m_{i-j}\right)=\mathcal{P} \mathcal{D}\left(p d, m_{i-j}\right) \cup \mathcal{P C}\left(p c, m_{i-j}\right) \cup \mathcal{M D}\left(m d, m_{i-j}\right)$

onde:

$p d=$ PertDados,

$p c=$ PertCom e

$m d=\{$ Exchange, Null, Incomplete, Inversion, ValueInversion, Mod_Len, Space $\}$.

\subsubsection{Violação de sequência}

Executar serviços sem considerar a ordem na qual estão designados pode causar problemas ao sistema. Através desta abordagem, pode-se avaliar a capacidade de cada serviço em responder a situações adversas, uma vez que não está sendo executado na ordem inicialmente proposta. Com isso, é possível avaliar todas as combinações de execução dos serviços que compõem o processo. Contudo, o universo de testes passa a ser muito amplo. Para um processo composto por $n$ serviços, teremos $n$ ! combinações, sendo caro executar todas.

Avaliando-se a partir das pós-condições de cada serviço, no contexto de violação de sequência, espera-se que ocorra uma falha na execução, com exceção dos serviços que não dependem da execução anterior de outros serviços, chamados serviços iniciais do processo ${ }^{2}$. Como não existem serviços executados anteriormente no fluxo, espera-se que não ocorram falhas. A Figura 4.7(a) apresenta um fluxo que é iniciado por um único Web Service $s_{1}$ e a Figura 4.7(b) apresenta um fluxo que pode ser iniciado por dois ou mais Web Services.

Entretanto, para os demais serviços do processo, o resultado esperado é falha na execução. Para isso, perturbam-se as mensagens dos $n$ serviços, executam-se de maneira isolada, sem a necessidade de executar o restante da sequência em sua totalidade. Ou seja, para todo $s_{i} \in t w s, 1 \leq i \leq n$, com $s_{i}$ não sendo inicial, basta assegurar que o processo, simulado com $s_{i}$ como inicial, falha. A Figura 4.7(c) apresenta uma ilustração das validações realizáveis em uma dada sequência, considerando $s_{1}$ como sendo Web Services inicial.

Com isso, para esta abordagem, o conjunto de casos de testes é o mesmo dos testes isolados, sendo assim a aplicação idêntica à adotada na validação individual dos Web Services Transacionais. As Tabelas 4.1, 4.2, 4.3 e 4.4, apresentadas na Seção 4.5.1, resumem as aplicações para que a violação da sequência seja avaliada. O conjunto de casos de testes para perturbação de dados, perturbação de comunicação e mutação de dados são

$$
\begin{aligned}
& \mathcal{P D}\left(p d, m_{i-j}\right) \mid p d=\text { PertDados } \\
& \mathcal{P C}\left(p c, m_{i-j}\right) \mid p c=\text { PertCom } \\
& \mathcal{M D}\left(m d, m_{i-j}\right) \mid m d=\text { MutDados }
\end{aligned}
$$

O conjunto completo dos casos de testes é o seguinte:

$$
\mathcal{C} \mathcal{T}\left(m_{i-j}\right)=\mathcal{P D}\left(p d, m_{i-j}\right) \cup \mathcal{P C}\left(p c, m_{i-j}\right) \cup \mathcal{M D}\left(m d, m_{i-j}\right)
$$

\footnotetext{
${ }^{2}$ essa hipótese é valida para ambientes controlados, pois existem fatores externos que podem interferir nos resultados
} 


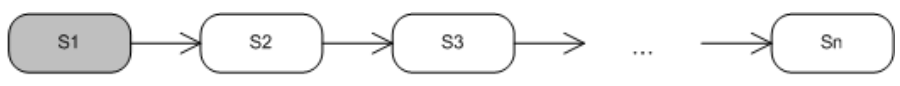

(a) parte1

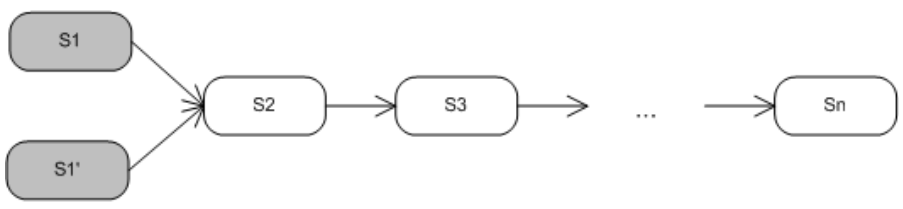

(b) parte2

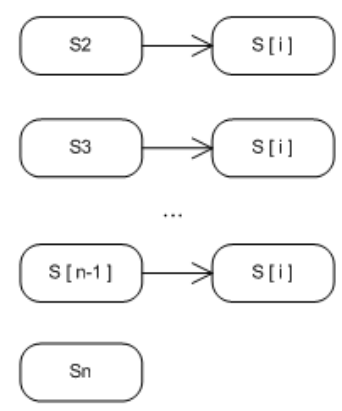

(c) parte3

Figura 4.7 Validações em uma dada sequência

\subsubsection{Violação de pré-condições}

Com a sequência do processo inalterada e com perturbação nas mensagens trocadas não respeitando as pré-condições, tem-se outro cenário de validação. Nesta abordagem, o objetivo passa a ser identificar problemas devido a não previsão de certos comportamentos no sistema. Por exemplo, se uma determinada pré-condição é violada, é esperado que o sistema falhe - se não o faz, ou a pré-condição estava errada, ou o sistema não a tratou corretamente.

Por atuar no fluxo, sem necessariamente alterar ordens de execução, os casos de testes apresentados por Silveira e Melo [31], por estarem diretamente ligados às mensagens, pouco acrescentam nessa abordagem. Ou seja, para a violação das pré-condições, é necessário executar também outros casos de testes. Como Web Services são projetados para serem independentes [10], por suposição, o estado de um serviço só é de conhecimento dos demais serviços apenas através da troca de mensagens.

Condição de ativação: Para a condição de Ativação, em uma transição de $s_{i}$ para $s_{j}$, é necessário que o serviço $s_{i}$ seja completo. Assim como nas situações anteriores, a mensagem enviada para $s_{j}$ indica a conclusão de $s_{i}$. Para testar esta condição, é necessário que, mesmo $s_{j}$ recebendo uma mensagem, ela não pode conter informações que se refiram à conclusão de $s_{i}$. Sem interferir no significado que os campos podem ter, os testes que permitem tal situação são as pertubações sobre tipos de dados que tratam String vazia, ou 0 (que pode significar, dependendo do contexto, ausência de informação), assim como a perturbação WhiteSpace. As pertubações sobre comunicação minOccurs, maxOccurs, choice, all e anyElement também possibilitam a realização de testes neste cenário, além dos operadores de mutação Exchange $\left(c_{1}, c_{2}\right), \operatorname{Null}(c)$, Incomplete $(c)$ e Space $(c)$. As Tabelas 4.9, 4.10, 4.11 e 4.12 resumem o conjunto de técnicas aplicáveis para Condição de ativação.

Para a situação de ativação, tem-se um caso de teste de ativação do estado $s_{j}$ sem que o estado $s_{i}$ esteja completed. A perturbação da mensagem entre $s_{i}$ e $s_{j}$ vai viabilizar a violação da pré-condição. A Figura 4.8 apresenta um exemplo de violação de pré-condição de ativação. Nesta situação, mensagens com a quantidade de ocorrências, de determinado campo, menor que a mínima exigida. Através da perturbação de facetas de ocorrências é possível obter esta 


\begin{tabular}{|c|c|}
\hline Teste Valor Limite & Fluxo de Web Services \\
\hline String & $\mathrm{X}$ \\
Numérico & $\mathrm{X}$ \\
Booleano & \\
data & $\mathrm{X}$ \\
Binário & $\mathrm{X}$ \\
\hline
\end{tabular}

Tabela 4.9 Violação de pré-condições - Condição de ativação - Perturbação de Dados

\begin{tabular}{|l|c|}
\hline Teste Faceta & Fluxo de Web Services Transacionais \\
\hline enumeration & \\
fractionDigits & \\
length & \\
maxExclusive & \\
maxInclusive & \\
maxLength & \\
minExclusive & \\
minInclusive & \\
minLength & \\
pattern & \\
totalDigits & \\
whiteSpace & $\mathrm{X}$ \\
\hline
\end{tabular}

Tabela 4.10 Violação de pré-condições - Condição de ativação - Perturbação de Dados com base em restrições

\begin{tabular}{|l|c|}
\hline Teste Comunicação & Fluxo de Web Services Transacionais \\
\hline minOccurs & $\mathrm{X}$ \\
maxOccurs & $\mathrm{X}$ \\
choice & $\mathrm{X}$ \\
all & $\mathrm{X}$ \\
any element & $\mathrm{X}$ \\
\hline
\end{tabular}

Tabela 4.11 Violação de pré-condições - Condição de ativação - Perturbação de Comunicação

\begin{tabular}{|c|c|}
\hline Teste / Operador de Mutação & Fluxo de Web Services Transacionais \\
\hline Divide (c) & \\
Multiply (c) & \\
Negative (c) & \\
Absolute (c) & $\mathrm{X}$ \\
Exchange $\left(c_{1}, c_{2}\right)$ & \\
Unauthorized (c) & $\mathrm{X}$ \\
Null (c) & $\mathrm{X}$ \\
Incomplete (c) & \\
Inversion (c) & \\
ValueInversion (c) & \\
Mod_Len (c) & $\mathrm{X}$ \\
Space (c) & \\
\hline
\end{tabular}

Tabela 4.12 Violação de pré-condições - Condição de ativação - Mutação de Dados 
violação.

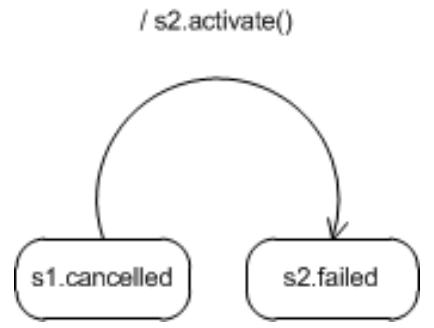

Figura 4.8 Violação de pré-condição de ativação

Assim, os casos de testes aplicáveis nesse cenário são os seguintes:

$$
\begin{aligned}
& C T\left(m_{i-j}\right)=P D\left(p d, m_{i-j}\right) \cup P C\left(p c, m_{i-j}\right) \cup M D\left(m d, m_{i-j}\right) \\
& \text { onde: } \\
& P D\left(p d, m_{i-j}\right) \mid p d=\{\text { String, Numerico, Binário, WhiteSpace }\} \\
& P C\left(p c, m_{i-j}\right) \mid p c=\{\text { minOccurs, maxOccurs, choice, all, anyElement }\} e \\
& M D\left(m d, m_{i-j}\right) \mid m d=\{\text { Exchange, Null, Incomplete, Space }\}
\end{aligned}
$$

Condição de alternativa: Na condição de Alternativa, é necessário que a falha de $s_{i}$ cause o início de $s_{j}$. Contudo, a mensagem $m_{i-j}$ pode não conter informações referentes à falha de $s_{i}$. Pertubações, nesta situação, não contribuem na identificação de falhas específicas desta condição. Por ser um XOR-Split, um caminho não necessariamente toma conhecimento da existência do outro. Em BPEL, a execução do caminho alternativo passa a respeitar a condição de Ativação, sendo assim coberto pelos primeiros casos de testes. As pertubações, para a condição de Alternativa, não afetam diretamente o cenário de testes. Assim,

$$
\begin{aligned}
& P D\left(\{\}, m_{i-j}\right)=\emptyset, \\
& P C\left(\{\}, m_{i-j}\right)=\emptyset \mathrm{e} \\
& M D\left(\{\}, m_{i-j}\right)=\emptyset .
\end{aligned}
$$

De modo semelhante, na situação de alternativa tem-se um caso de teste de ativação do estado $s_{j}$ sem que o estado $s_{i}$ esteja em failed. Um exemplo de violação desta pré-condição, representado pela Figura 4.9, é através do disparo de uma alternativa partindo de um serviço abortado.

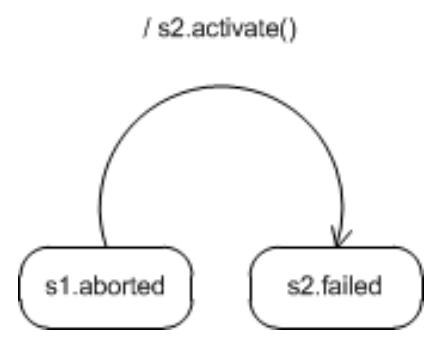

Figura 4.9 Violação de pré-condição de alternativa

Condição de compensação: A condição de Compensação é identificada, em uma transição de $s_{i}$ para $s_{j}$, através da mensagem enviada a $s_{j}$ sem informações a respeito de $s_{i}$. Por se tratar também de um XOR-Split, onde um caminho não necessariamente sabe da existência do outro, nem as pertubações nem as mutações afetam diretamente o cenário de testes. Assim, os testes de apresentados não contribuem para este caso, ou seja, 


$$
\begin{gathered}
P D\left(\{\}, m_{i-j}\right)=\emptyset, \\
P C\left(\{\}, m_{i-j}\right)=\emptyset \mathrm{e} \\
M D\left(\{\}, m_{i-j}\right)=\emptyset .
\end{gathered}
$$

Em uma situação de Compensação, a pré-condição é violada quando é disparada a compensação de $s_{j}$ sem que $s_{i}$ esteja em falha, como mostra a Figura 4.10.

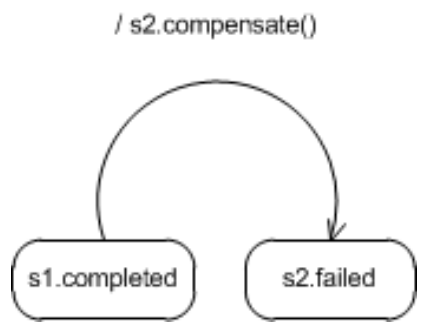

Figura 4.10 Violação de pré-condição de compensação

Condição de aborto: Já as condições de aborto, por se tratar de uma parada abrupta no processo, não representam cenário adequado para execução de testes gerados com base em pertubações. Assim,

$$
\begin{aligned}
& P D\left(\{\}, m_{i-j}\right)=\emptyset, \\
& P C\left(\{\}, m_{i-j}\right)=\emptyset \mathrm{e} \\
& M D\left(\{\}, m_{i-j}\right)=\emptyset .
\end{aligned}
$$

Para a situação de aborto, tem-se um caso de teste que aborta $s_{j}$ sem que o próprio $s_{j}$ tenha falhado ou sem que $s_{i}$ tenha sido cancelado. Ambas situações violam a pré-condição de aborto. A Figura 4.11 apresenta um exemplo que viola a condição de aborto.

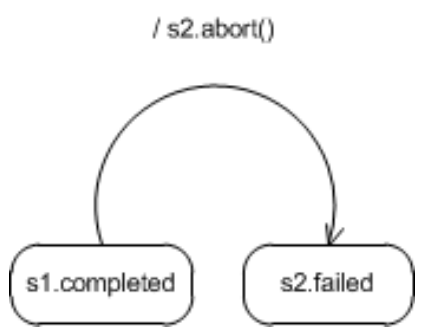

Figura 4.11 Violação de pré-condição de aborto

Condição de cancelamento: Por fim, na situação de Cancelamento, podem ser validadas através

\begin{tabular}{|c|c|}
\hline Teste Valor Limite & Fluxo de Web Services Transacionais \\
\hline String & $\mathrm{X}$ \\
\hline Numérico & $\mathrm{X}$ \\
\hline Booleano & \\
\hline data & \\
\hline Binário & $\mathrm{X}$ \\
\hline
\end{tabular}
dos operadores de perturbação Exchange $\left(c_{1}, c_{2}\right), N u l l(c)$, Incomplete $(c)$, ValueInversion $(c)$ e Space $(c)$. As pertubações sobre tipos de dados primitivos que tratam String vazia, ou 0 também contribuem para esses testes, assim como a perturbação sobre restrições WhiteSpaces. Semelhante à condição de Ativação, para o cancelamento é relevante informar dados que resultam do processamento do serviço de origem, que disparou o cancelamento do processo.

Tabela 4.13 Violação de pré-condições - Condição de cancelamento - Perturbação de Dados

Assim, tem-se a execução de um caso de teste que dispara o cancelamento de $s_{j}$ sem que $s_{i}$ tenha falhado. A Figura 4.12 representa essa violação. 


\begin{tabular}{|l|c|}
\hline Teste Faceta & Fluxo de Web Services Transacionais \\
\hline enumeration & \\
fractionDigits & \\
length & \\
maxExclusive & \\
maxInclusive & \\
maxLength & \\
minExclusive & \\
minInclusive & \\
minLength & \\
pattern & \\
totalDigits & \\
whiteSpace & $\mathrm{X}$ \\
\hline
\end{tabular}

Tabela 4.14 Violação de pré-condições - Condição de cancelamento - Perturbação de Dados com base em restrições

\begin{tabular}{|l|c|}
\hline Teste Comunicação & Fluxo de Web Services Transacionais \\
\hline minOccurs & $\mathrm{X}$ \\
maxOccurs & $\mathrm{X}$ \\
choice & $\mathrm{X}$ \\
all & $\mathrm{X}$ \\
any element & $\mathrm{X}$ \\
\hline
\end{tabular}

Tabela 4.15 Violação de pré-condições - Condição de cancelamento - Perturbação de Comunicação

\begin{tabular}{|c|c|}
\hline Teste / Operador de Mutação & Fluxo de Web Services Transacionais \\
\hline Divide (c) & \\
Multiply (c) & \\
Negative (c) & \\
Absolute (c) & $\mathrm{X}$ \\
Exchange (c1, $\left.c_{2}\right)$ & \\
Unauthorized (c) & $\mathrm{X}$ \\
Null (c) & $\mathrm{X}$ \\
Incomplete (c) & $\mathrm{X}$ \\
Inversion (c) & \\
ValueInversion (c) & $\mathrm{X}$ \\
Mod_Len (c) & \\
Space (c) & \\
\hline
\end{tabular}

Tabela 4.16 Violação de pré-condições - Condição de cancelamento - Mutação de Dados

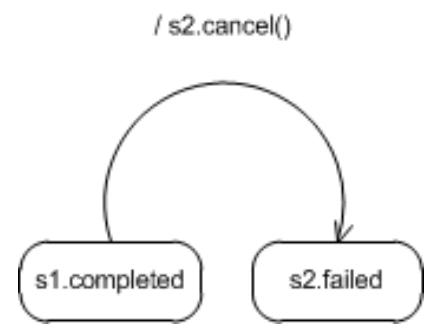

Figura 4.12 Violação de pré-condição de cancelamento 
Assim, o conjunto de casos de testes para a condição de cancelamento é o seguinte:

$C T\left(m_{i-j}\right)=P D\left(p d, m_{i-j}\right) \cup P C\left(p c, m_{i-j}\right) \cup M D\left(m d, m_{i-j}\right)$

onde:

$P D\left(p d, m_{i-j}\right) \mid p d=\{$ String, Numerico, Binário, WhiteSpace $\}$,

$P C\left(p c, m_{i-j}\right) \mid p c=\{$ minOccurs, maxOccurs, choice, all, anyElement $\} e$

$M D\left(m d, m_{i-j}\right) \mid m d=\{$ Exchange, Null, Incomplete, ValueInversion, Space $\}$

\subsection{Conclusão}

De acordo com a situação a qual se deseja validar, algumas técnicas podem ser efetivas. A perturbação de dados permite validar por completo as condições de execução de Web Services quando vistos como unidades. Para a validação de fluxo, mais precisamente de padrões transacionais, a perturbação com utilização das facetas tem cobertura parcial das situações necessárias.

O conjunto amplo de testes proposto por Silveira e Melo pode ser utilizados para as três abordagens citadas neste Capítulo. Embora a quantidade de casos de testes presentes em $C T\left(m_{i-j}\right)$ seja elevada, existem situações que não são cobertas. Além disso, alguns testes são redundantes. Considerando o sistema inteiro, é possível selecionar um subconjunto dos testes gerados pela ferramenta, com base nas pré-condições de cada tipo de serviço e nos padrões transacionais. Com isso, o conjunto de testes pode ser filtrado, tornando-o assim mais assertivos.

A Tabela 4.17 apresenta a lista das situações passíveis de testes e a aplicação das técnicas de perturbação de mensagens apresentada por Silveira e Melo [31].

Neste Capítulo foi apresentado o padrão de transações que considera o fluxo do sistema e determina condições de comportamentos, tornando possível identificar meios consistentes de como obter um estado seguro diante de qualquer um dos problemas apresentados anteriormente. São apresentadas também as características esperadas dos casos de testes para que Web Services transacionais possam ser validados adequadamente. Além disso, foram apresentado também situações nas quais o conjunto de testes apresentados por Silveira e Melo pode contribuir para identificação de defeitos.

A introdução do conceito de padrões transacionais permite construir uma composição de serviços que atendem a uma série de consistências, deixando claras quais as pré-condições para diversos cenários possíveis de problemas. Contudo, o sucesso das implementações depende de garantias de consistências de fluxo de controle e de transação, ou seja, consistências de especificação. O próprio artigo apresenta um meio de obter essas garantias, através de análises formais da especificação e extração de provas de corretude.

Diante de um número grande de possibilidades de se testar Web Services, pode-se adotar algumas abordagens que servem como guia para concentrar esforços nos principais pontos. Para Web Services Transacionais, esses pontos estão principalmente nas mudanças dos estados do sistema (mensagens trocadas pelos serviços), na ordem de execução dos serviços e nas pré-condições. 


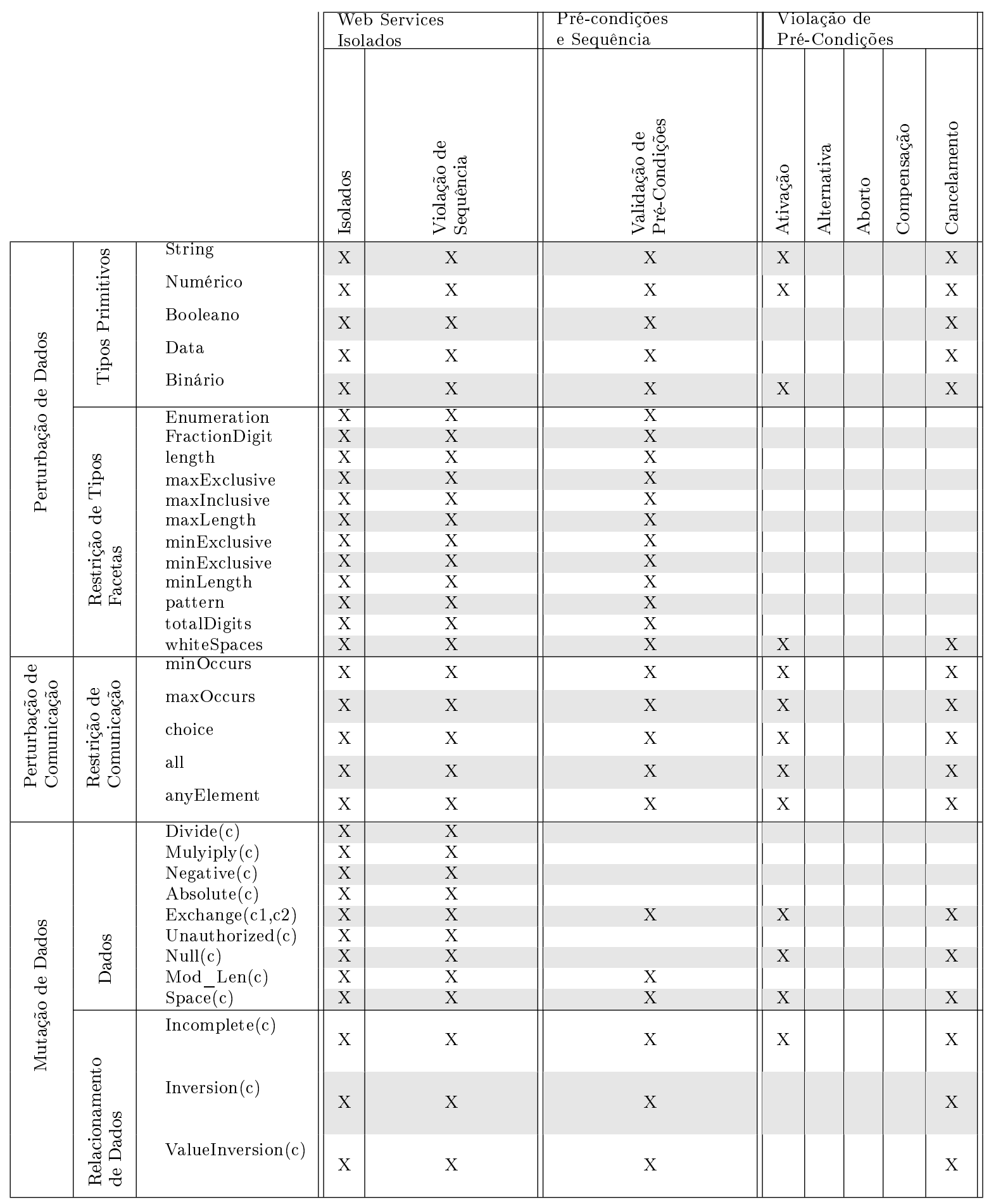

Tabela 4.17 Tabela de cobertura dos casos de testes apresentados por Silveira e Melo 


\section{Capítulo 5}

\section{Estudo de Caso - Sistema de Viagens}

\subsection{Introdução}

Para avaliar os critérios estudados, foi elaborado um cenário hipotético, com o mesmo exemplo utilizado como motivação no Capítulo 1. O objetivo deste estudo é avaliar a eficácia das técnicas apresentadas no Capítulo 4, que são implementadas pela ferramenta GenAutoWS para detecção de problemas relacionados ao comportamento e violação transacional. Não é objetivo avaliar problemas de interface gráfica. Para simplificar a avaliação, é suposto que os serviços de busca de informações de hoteis, horários de voos, origens e destinos de viagens estejam funcionando corretamente. Assim, pode-se manter o foco na parte mais crítica do negócio, representada pela confirmação das reservas, pagamento e entrega.

Este capítulo apresenta o sistema construído e seus pontos específicos de testes. Em seguida, são apresentados os testes gerados pela ferramenta GenAutoWS segundo as técnicas propostas. Com o intuito de analisar a efetividade das técnicas para situações de transações para Web Services, algumas das premissas transacionais são violadas e novamente testadas. Por fim, são apresentados os resultados obtidos e a conclusão do estudo.

\subsection{Sistema de Viagens}

Consiste em um sistema que possibilita ao cliente programar sua viagem utilizando uma única interface para fazer a reserva no hotel, compra de passagens aéreas, pagamento de ambos e solicitação de entrega. Cada serviço é oferecido por meio de Web Services, integrado no sistema de viagens.

Por suposição, o cliente informa a sua origem, seu destino, a data de saída e a data de retorno. O Sistema então informa os hotéis disponíveis e os horários de voo que atendem a sua busca. Após selecionar o hotel e a companhia aérea de sua preferência, o sistema tem a data e hora do voo, a data hora de check in e check out do hotel, o tipo de quarto, o preço total, as informações do cartão de crédito e o local de entrega dos tickets. O processo todo de confirmação é representado pela Figura 5.1. A Listagem 5.1 representa a mensagem SOAP enviada pelo sistema para iniciar a efetivação e confirmação dos serviços.

Seguindo as definições apresentadas no Capítulo 4, têm-se os seguintes itens:

$$
\begin{gathered}
t w s=\left\{s_{1}, s_{2}, s_{3}, s_{4}, s_{5}\right\} \\
s_{1}: \text { Serviço de Reserva de Hotel } \\
s_{2}: \text { Serviço de Reserva de Passagem Aérea } \\
s_{3}: \text { Serviço de Pagamento } \\
s_{4}: \text { Serviço de Entrega } 1 \\
s_{5}: \text { Serviço de Entrega } 2
\end{gathered}
$$

$1<$ soapenv: Envelope xmlns: soapenv="http://schemas.xmlsoap.org/soap/envelope/" xmlns: web="http://192.168.0.103/WebTravel"> 


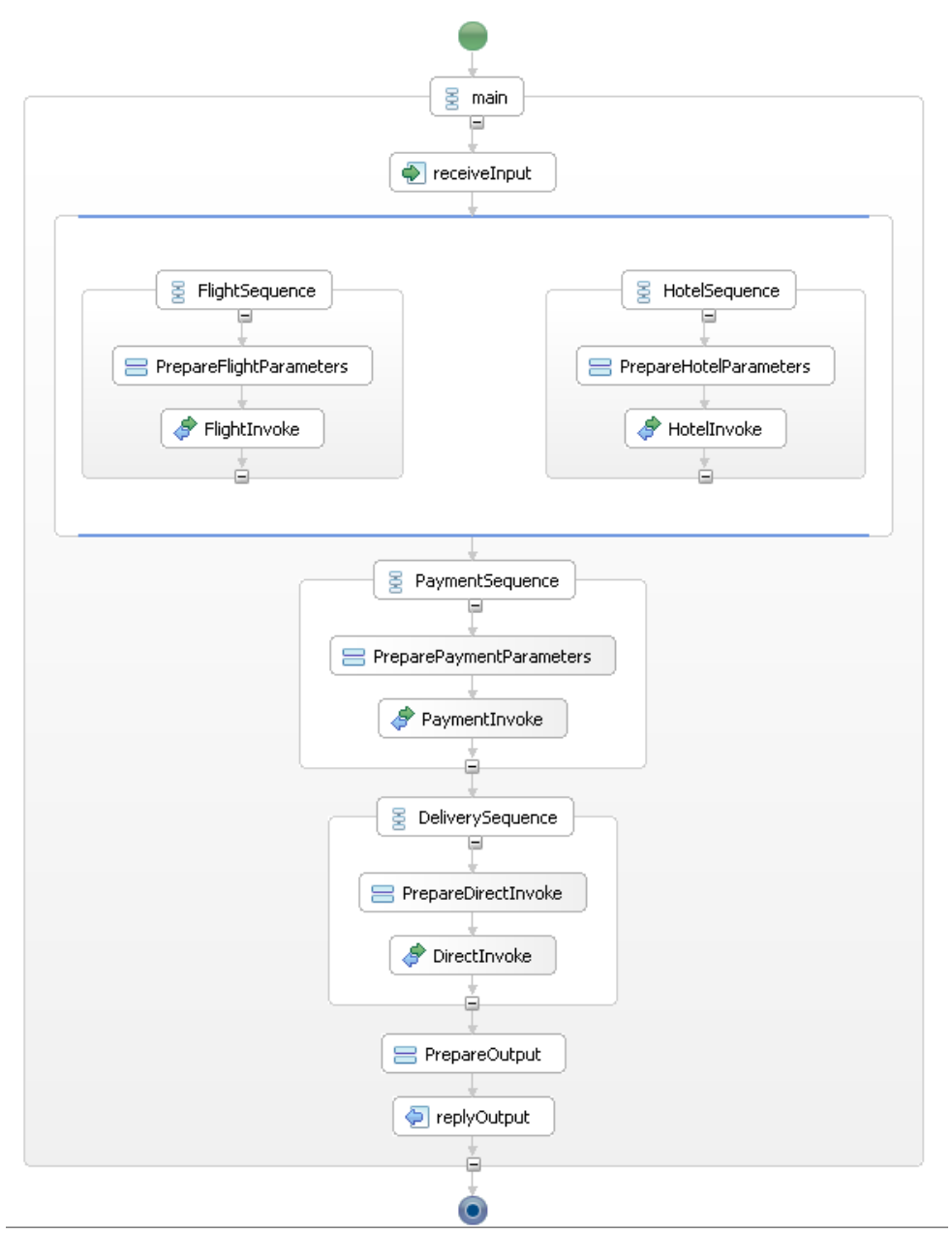

Figura 5.1 Processo BPEL do sistema de viagens 


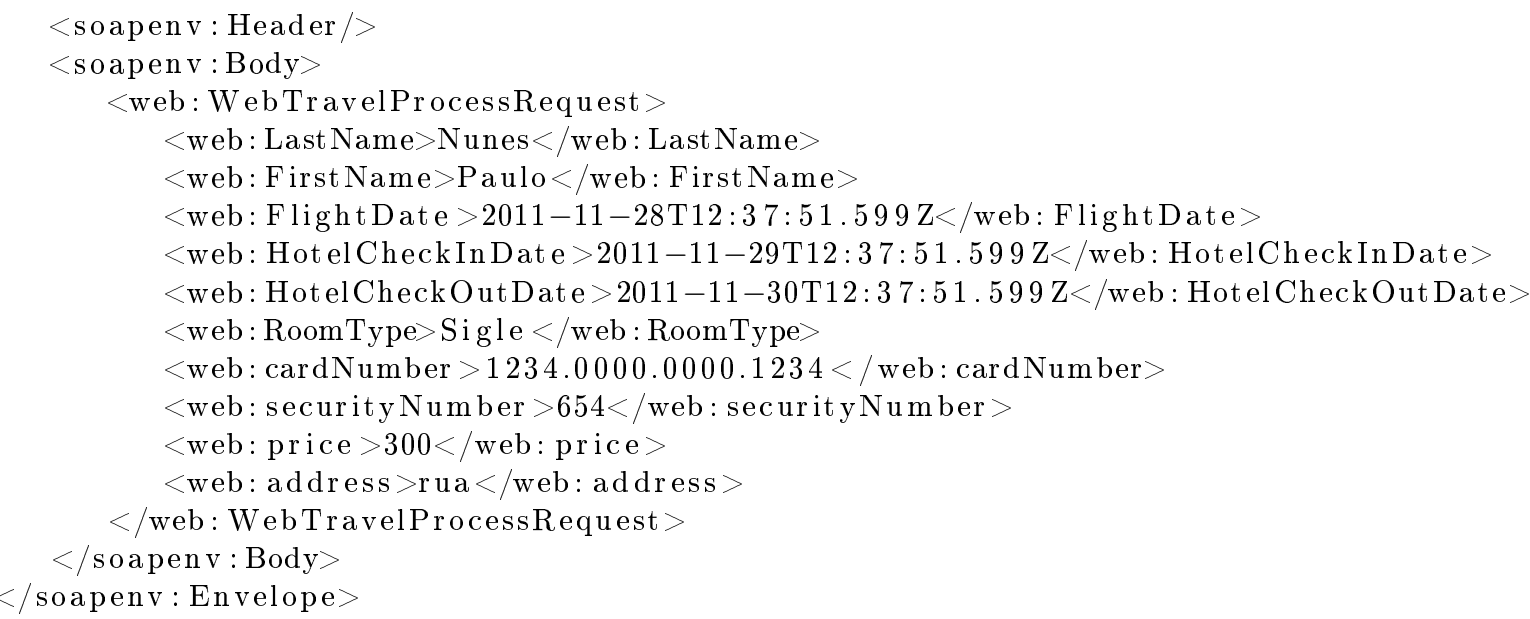

Listagem 5.1Dados de entrada para confirmação dos serviços

Por se tratar de um processo composto por Web Services, a partir dos dados enviados inicialmente através da mensagem SOAP da Listagem 5.1, os serviços se comunicam entre si, gerando uma série de outras mensagens. O motor BPEL, ao receber a primeira mensagem, cria as mensagens SOAP que serão enviadas aos serviços de Reserva de Hotel e de Reserva de voo, representadas respectivamente pelas listagens 5.2 e 5.3. A Tabela 5.1 apresenta o mapeamento entre as informações recebidas no processo e submetidas ao serviço de reserva hoteleira $s_{1}$. Já a Tabela 5.2 apresenta o mapeamento entre as informações recebidas no processo e submetidas ao serviço de reserva aérea $s_{2}$.

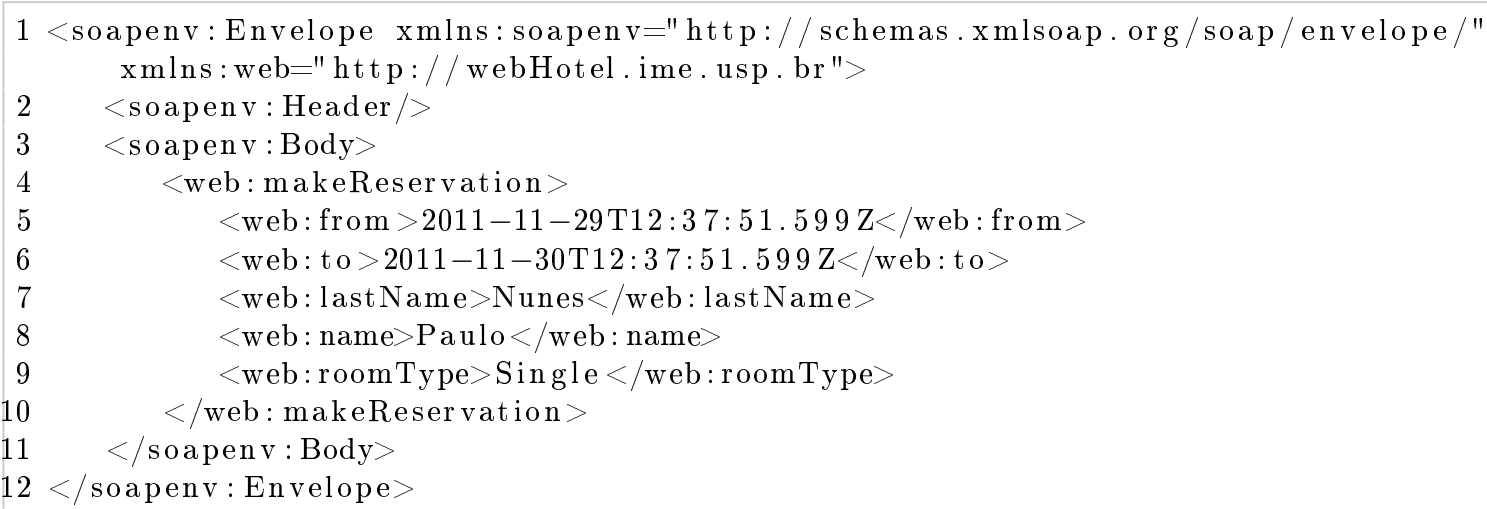

Listagem 5.2 Dados de entrada para o serviço de reserva aérea

\begin{tabular}{|c|c||c|c|}
\hline Informação Origem & Linha & Informação Destino & Linha \\
\hline \hline LastName & 5 & lastName & 7 \\
\hline FirstName & 6 & name & 8 \\
\hline HotelCheckInDate & 8 & from & 5 \\
\hline HotelCheckOutDate & 9 & to & 6 \\
\hline RoomType & 10 & roomType & 9 \\
\hline
\end{tabular}

Tabela 5.1 Mapeamento de informações das listagens 5.1 e 5.2

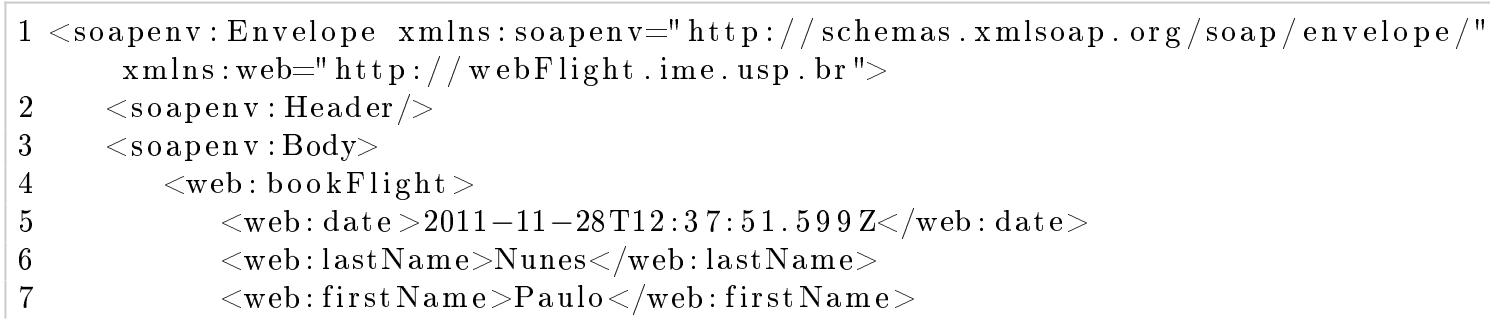


$8</$ web: bookFlight $>$

$9</$ soapenv: Body $>$

$10</$ soapenv: Envelope $>$

Listagem 5.3Dados de entrada para o serviço de reserva aérea

\begin{tabular}{|c|c||c|c|}
\hline Informação Origem & Linha & Informação Destino & Linha \\
\hline \hline LastName & 5 & lastName & 6 \\
\hline FirstName & 6 & firstname & 7 \\
\hline FlightDate & 7 & date & 5 \\
\hline
\end{tabular}

Tabela 5.2 Mapeamento de informações das listagens 5.1 e 5.3

Após o processamento dos serviços, o motor BPEL organiza as respostas e prepara a chamada para o Web Service seguinte. O serviço referente à reserva de quartos de hotel responde à requisição, informando dados da solicitação para que possa ser devidamente cobrada (Listagem 5.4). O serviço de reserva aérea retorna um arquivo XML contendo as informações do voo, para que também possa ser cobrada (Listagem 5.5), através de invocação do serviço $s_{3}$. A mensagem transmitida de $s_{1}$ para $s_{3}$ é $m_{1-3}$ e a mensagem transmitida de $s_{2}$ para $s_{3}$ é $m_{2-3}$. Neste ponto, BPEL faz a orquestração, consolidando as mensagens $m_{1-3}$ e $m_{2-3}$. O serviço de pagamento então pode ser invocado. Juntando informações fornecidas no início do processo com as informações recebidas dos serviços de reserva aérea e de reserva hoteleira, a mensagem de invocação é criada e pode ser vista na Listagem 5.6. A Tabela 5.3 mostra o mapeamento das informações recebidas dos serviços do hotel e da companhia aérea para o serviço de pagamento.

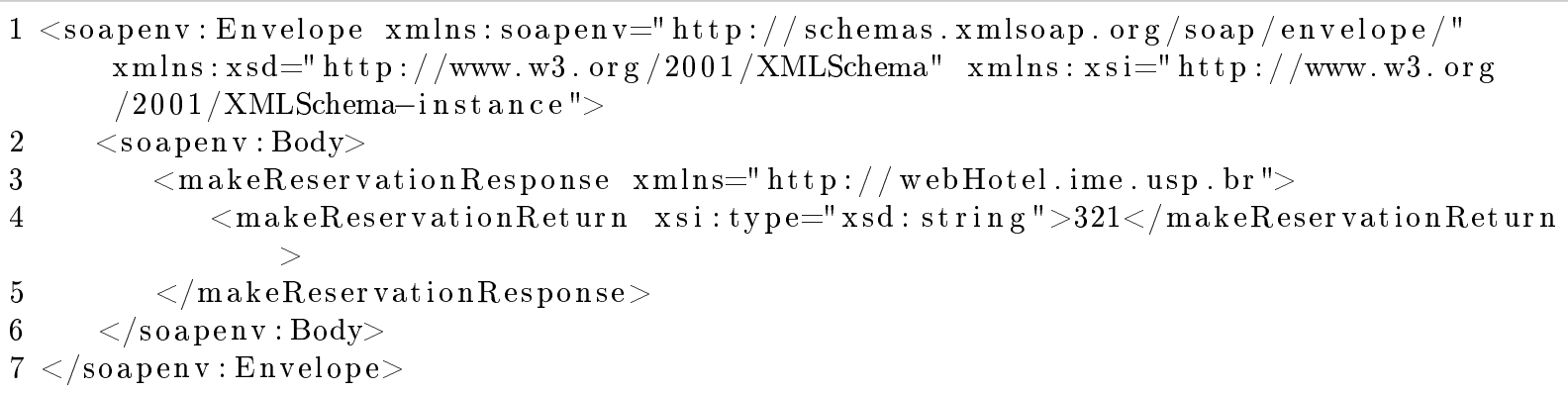

Listagem 5.4Dados de resposta do serviço de reserva hoteleira

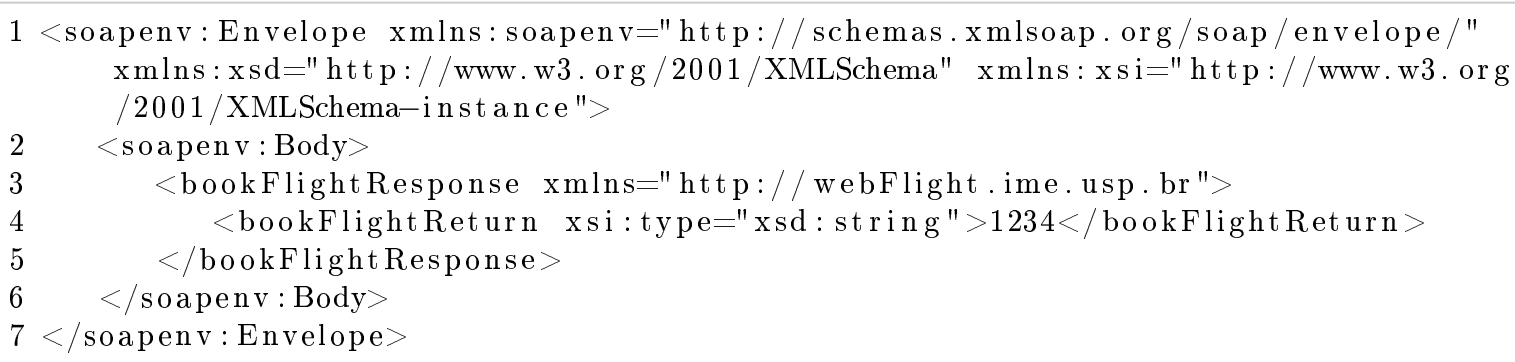

Listagem 5.5Dados de resposta do serviço de reserva aérea

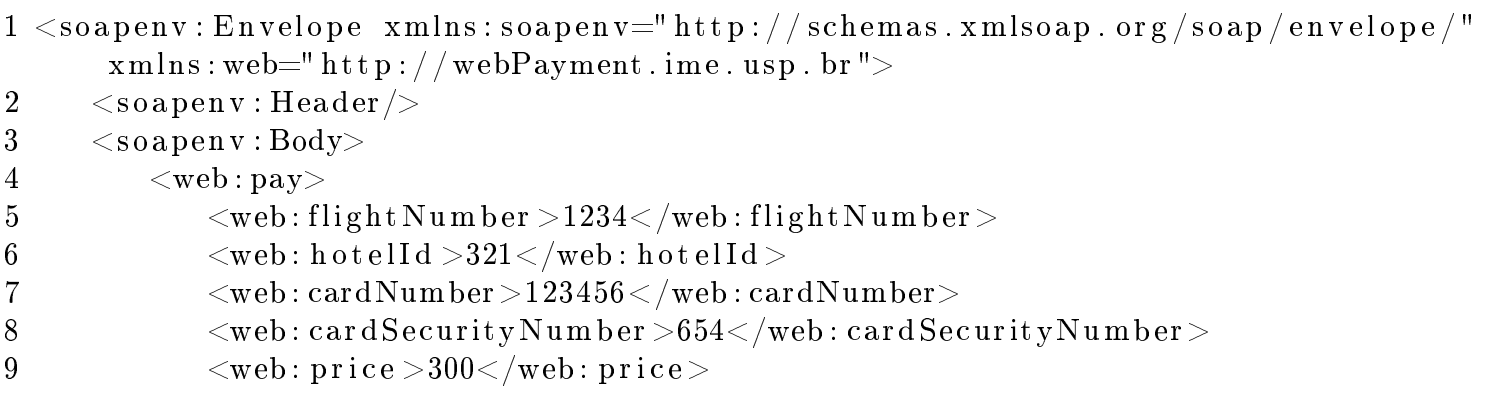


$\begin{array}{lc}10 & </ \text { web: pay }> \\ 11</ \text { soapenv : Body }> \\ 12<\text { /soapenv : Envelope }>\end{array}$

Listagem 5.6Dados de entrada para o serviço de pagamento

\begin{tabular}{|c|c||c|c|}
\hline Informação Origem & Linha & Informação Destino & Linha \\
\hline \hline makeReservationReturn (Listagem 5.4) & 4 & hotelId & 6 \\
\hline bookFlightReturn (Listagem 5.5) & 4 & flightNumber & 5 \\
\hline cardNumber (Listagem 5.1) & 11 & cardNumber & 7 \\
\hline securityNumber (Listagem 5.1) & 12 & cardSecurityNumber & 8 \\
\hline price (Listagem 5.1) & 13 & cardNumber & 9 \\
\hline
\end{tabular}

Tabela 5.3Mapeamento de informações das listagens 5.1, 5.4, 5.5 e 5.6

Assim como os serviços anteriores, o Web Service de pagamento processa a requisição e retorna informações referentes à efetivação da transação. A Listagem 5.7 apresenta a resposta do processamento do Web Service de pagamento. Com essas informações, o motor BPEL pode então combinar com outras informações e formar a mensagem para o serviço de entrega $s_{4}$, conforme apresenta a Listagem 5.8. A mensagem $m_{3-4}$ é transmitida de $s_{3}$ para $s_{4}$. O processamento é confirmado através da resposta do serviço, visto na Listagem 5.9, que é utilizado para compor a resposta do processo (Listagem 5.10). O serviço $s_{5}$ não é invocado caso o $s_{4}$ seja executado com sucesso e assim a mensagem $m_{3-5}$ não chega a ser gerada.

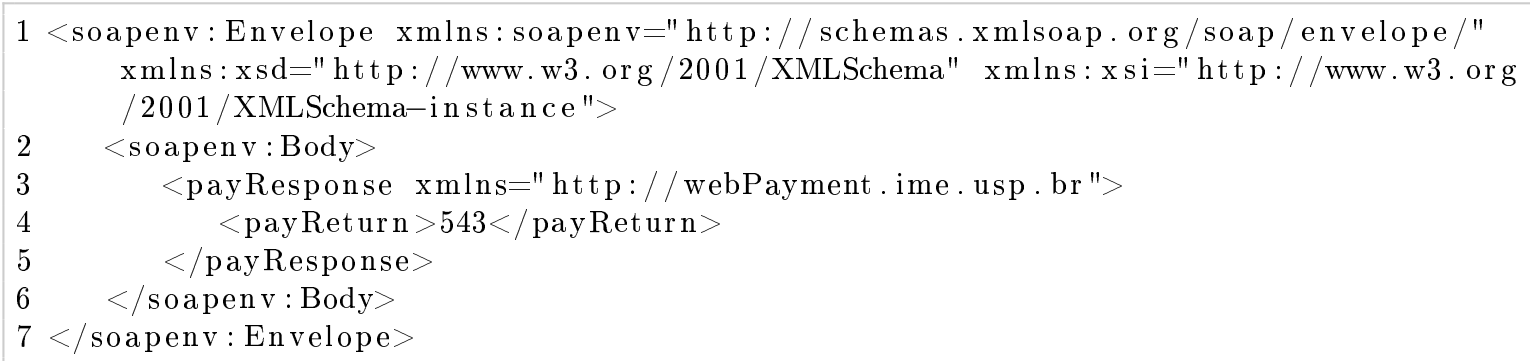

Listagem 5.7 Dados de entrada para o serviço de pagamento

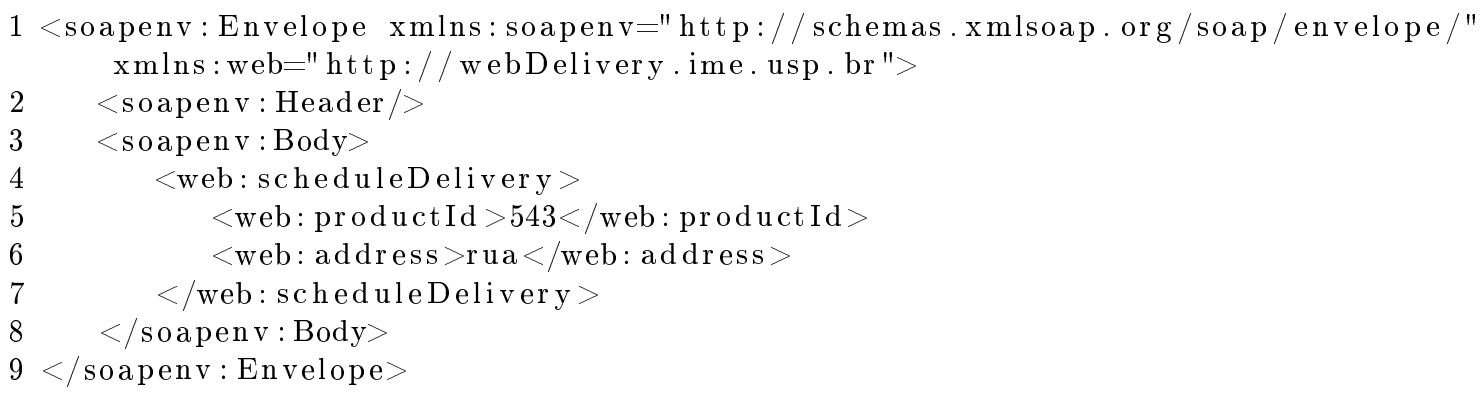

Listagem 5.8Dados de resposta do serviço de pagamento

\begin{tabular}{|c|c||c|c|}
\hline Informação Origem & Linha & Informação Destino & Linha \\
\hline \hline payReturn (Listagem 5.7) & 4 & productId & 5 \\
\hline address (Listagem 5.1) & 14 & address & 6 \\
\hline
\end{tabular}

Tabela 5.4Mapeamento de informações das listagens 5.1, 5.7 e 5.8

$1<$ soapenv: Envelope xmlns: soapenv="http://schemas.xmlsoap.org/soap/envelope/" xmlns : xsd="http://www.w3 . org/2001/XMLSchema" xmlns: xsi="http://www.w3.org / 2001 / XMLSchema-instance"> 
6 Track Identificatioin: 222.222.222.22

7 Other Informations: Problems, call Direct - (22) $2222-2222</$ scheduleDeliveryReturn $>$

$8</$ scheduleDeliveryResponse $>$

$9</$ soapenv: Body $>$

$10</$ soapenv: Envelope $>$

Listagem 5.9Dados de resposta do serviço de pagamento

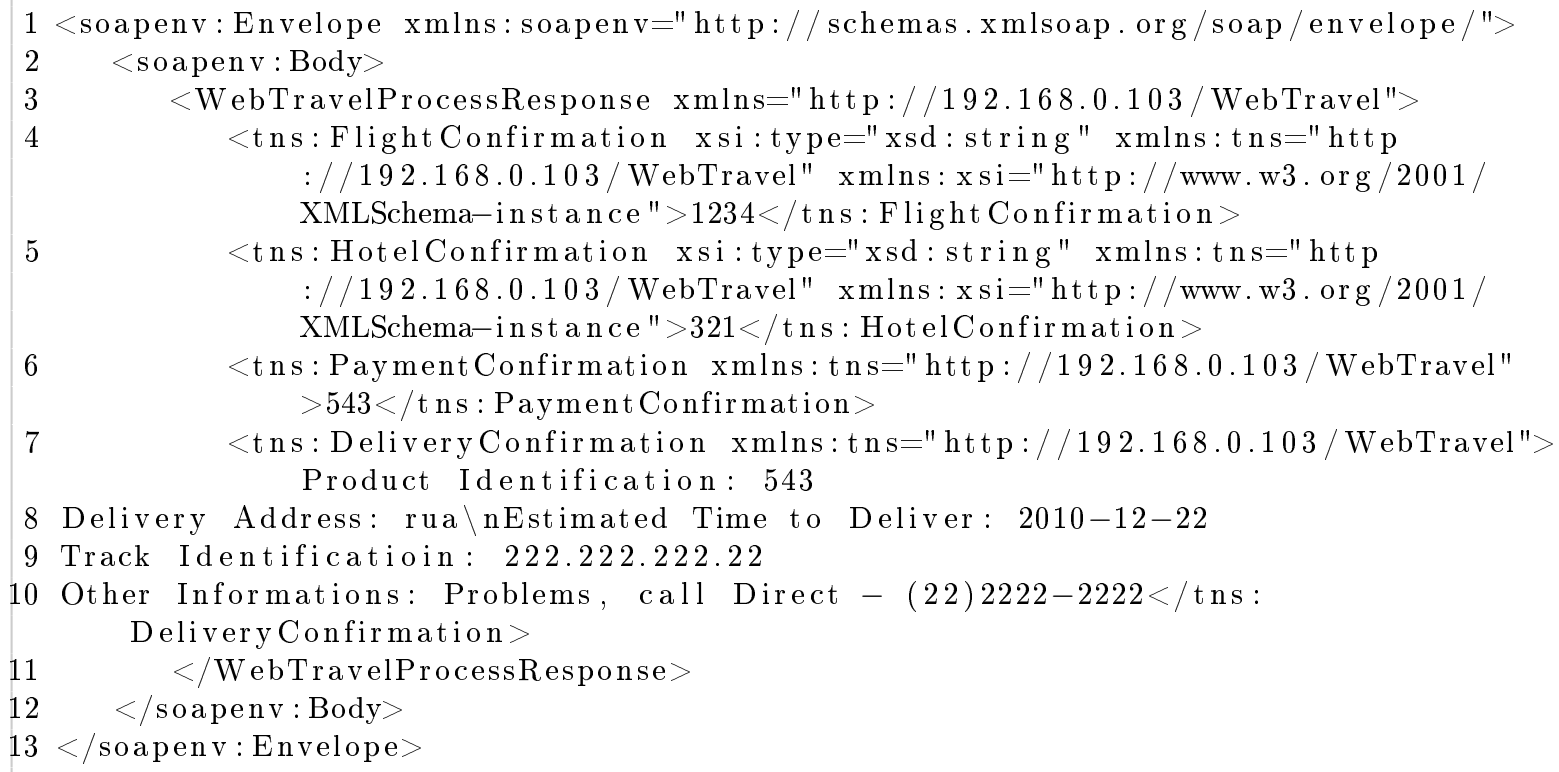

Listagem 5.10Dados de entrada para confirmação dos serviços

\begin{tabular}{|c|c||c|c|}
\hline Informação Origem & Linha & Informação Destino & Linha \\
\hline \hline bookFlightReturn (Listagem 5.5) & 4 & FlightConfirmation & 4 \\
\hline makeReservationReturn (Listagem 5.4) & 4 & HotelConfirmation & 5 \\
\hline payReturn (Listagem 5.7) & 4 & PaymentConfirmation & 6 \\
\hline scheduleDeliveryReturn (Listagem 5.9) & 4 & DeliveryConfirmation & 7 \\
\hline
\end{tabular}

Tabela 5.5 Mapeamento de informações obtidas nas respostas de cada serviço

\subsection{Ambiente de execução}

Para a realização deste estudo de caso foi criado um ambiente, no qual fosse possível analisar os resultados obtidos segundo as técnicas de perturbação e critérios listados no Capítulo 4. Assim, interferências de ambiente foram minimizadas, buscando-se utilizar condições controladas.

O sistema proposto foi desenvolvido em Java 1.6, utilizando a plataforma Eclipse versão 3.6. Para o desenvolvimento dos Web Services, utilizaram-se ferramentas do próprio Eclipse para automatizar a criação dos serviços ( Web Tools Platform). Para a modelagem do processo foi utilizado o plugin de BPEL para Eclipse (BPEL Designer Project). A publicação dos serviços foi feita em Tom Cat versão 6, utilizando Apache Ode (Orchestation Director Engine) versão 1.3.5 para orquestração do processo e combinação dos serviços.

O desenvolvimento, implantação e execução dos testes e demais atividades deste estudo de caso foram realizadas em uma máquina virtual VMWare®com Windows XPßcomo sistema operacional, com um processador de $1.2 \mathrm{GHz}, 2 \mathrm{~Gb}$ de memória e espaço em disco de $12 \mathrm{~Gb}$. 


\subsection{Técnicas e Geração Automática de casos de testes}

Existem diversas propriedades transacionais no sistema descrito que podem ser verificadas. Começando pelos serviços isolados, podem-se avaliar as unidades do sistema. A sequência de execução é também passível de avaliação, na qual podem-se considerar as pré-condições, principalmente em três pontos críticos para a composição: a execução paralela dos serviços de reserva aérea e de reserva de hotel (AND-SPLIT); a junção no momento de iniciar a execução do serviço de pagamento (AND-JOIN) e; a execução exclusiva do serviço de entrega (XOR-SPLIT).

\subsubsection{Testes realizados para Serviços Isolados e para a Sequência}

Para os Web Services do hotel e da companhia aérea $s_{1}$ e $s_{2}$, por serem serviços inicias, os testes a serem realizados são do mesmo tipo dos testes executados para a validação da sequência. A única restrição é apenas relacionada aos dados de entrada de cada serviço.

Nesta abordagem, a execução sob a forma de validação das unidades do sistema, os testes foram realizados de forma satisfatória. De acordo com o caso de teste, os resultados obtidos foram conforme esperado - tanto para falhas quanto para sucessos. Por exemplo, em inversões de valores para os campos FirstName e LastName não são esperadas falhas. Contudo, para inversões de valores dos campos from e to é esperado que seja apresentada uma inconsistência de data, pois supostamente a data from deve ser menor que a data to. A Listagem 5.11 exibe a mensagem de erro obtida após a execução de caso de teste que inverte os valores dos campos from e to.

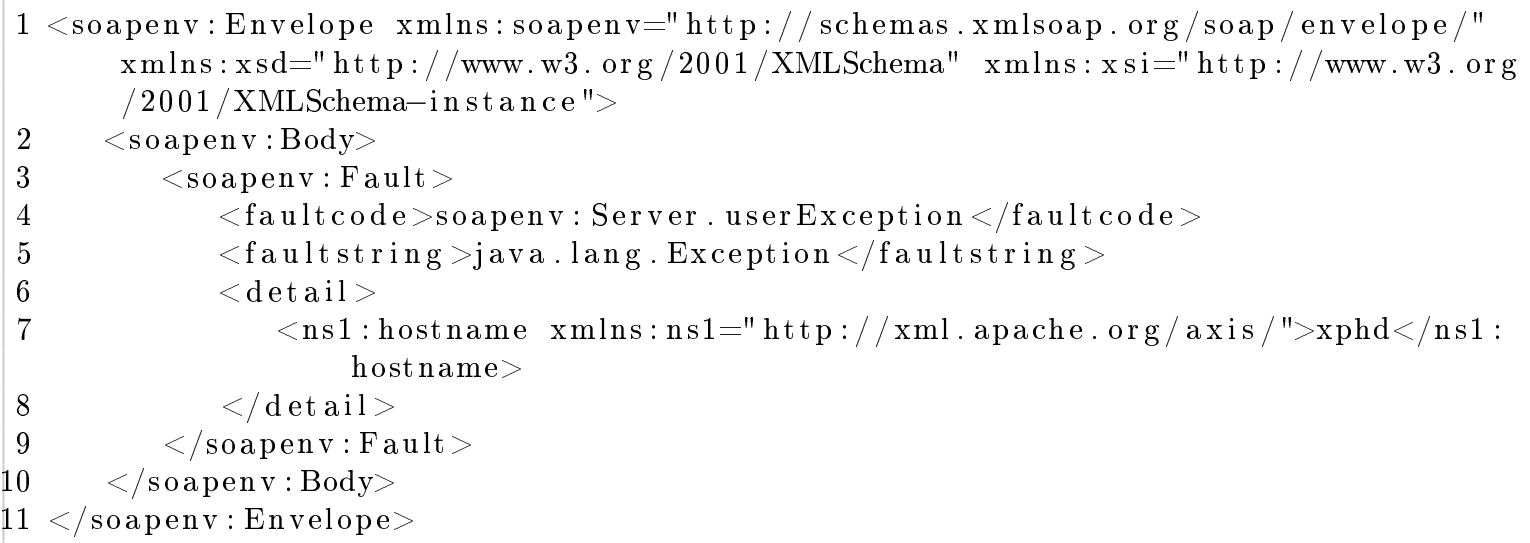

Listagem 5.11Falha apresentada após execução de inversão de data

Para os demais serviços, de pagamento e de entrega, é esperado que qualquer execução resulte em falha.

Para a avaliação da sequência, utilizando as técnicas destacadas no Capítulo 4 e os casos de testes gerados pela GenAutoWS, realiza-se uma bateria de testes, com o intuito de certificar os resultados esperados. Os testes são executados sob o ponto de vista de unidade, avaliando-os isoladamente. A Tabela 5.6 apresenta os testes executados para cada serviço $s_{i} \in t w s$.

\subsubsection{Validação de pré-condições e sequência}

Além dos testes de unidade, chamados também de testes de Web Services isolados, é importante validar as pré-condições na sequência apresentada pelo processo completo. Os pontos críticos do processo são o AND SPLIT, AND JOIN e XOR JOIN. O ponto de AND SPLIT inicia a execução em paralelo dos serviços de reserva de hotel e de passagem aérea. O ponto de AND JOIN é de junção das respostas dos serviços e sincronização para que o serviço de pagamento seja acionado. O ponto de XOR SPLIT determina a execução exclusiva de apenas um dos serviços de entrega.

Para essas situações, a abordagem adotada é avaliar a confiabilidade dos pontos críticos. Conforme Seção 4.5.2 do Capítulo 4, a ordem de execução e as pré-condições permanecem inalteradas.

Os serviços $s_{1}$ e $s_{2}$ são os primeiros serviços do processo. Não há restrição que impeça a execução de cada um. Os testes executados para avaliação isolada já são suficientes. Contudo, os serviços 


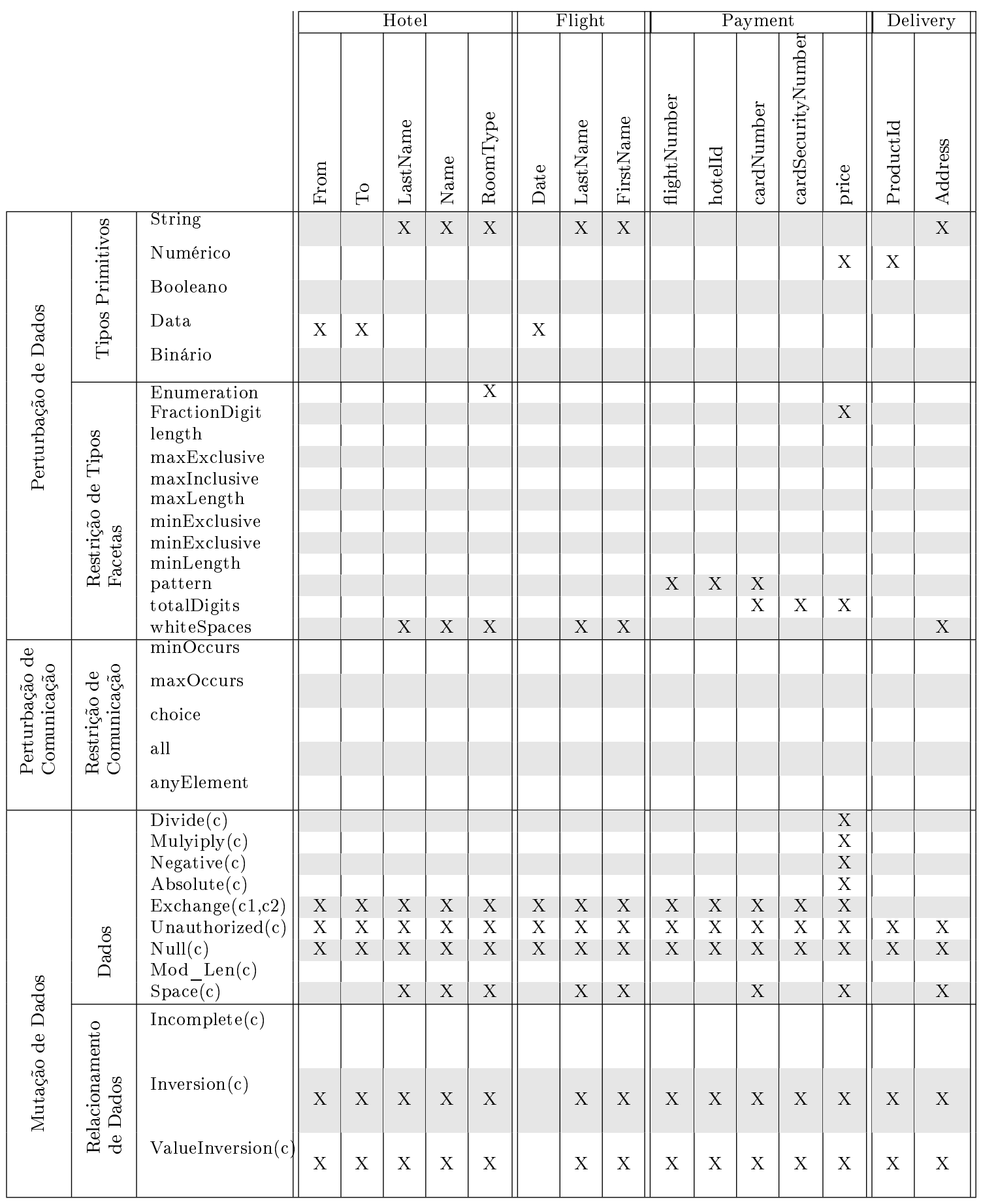

Tabela 5.6 Testes Isolados - Lista de Testes Executados com base em perturbação de valores para os Web Services do processo 
subsequentes, $s_{3}, s_{4}$ e $s_{5}$, possuem as condições necessárias para a realização dos testes. De acordo com o Capítulo 4, aplicam-se os testes mantendo as pré-condições e a sequência. A Tabela 5.7 apresenta os testes executados para cada serviço $s_{i} \in t w s$.

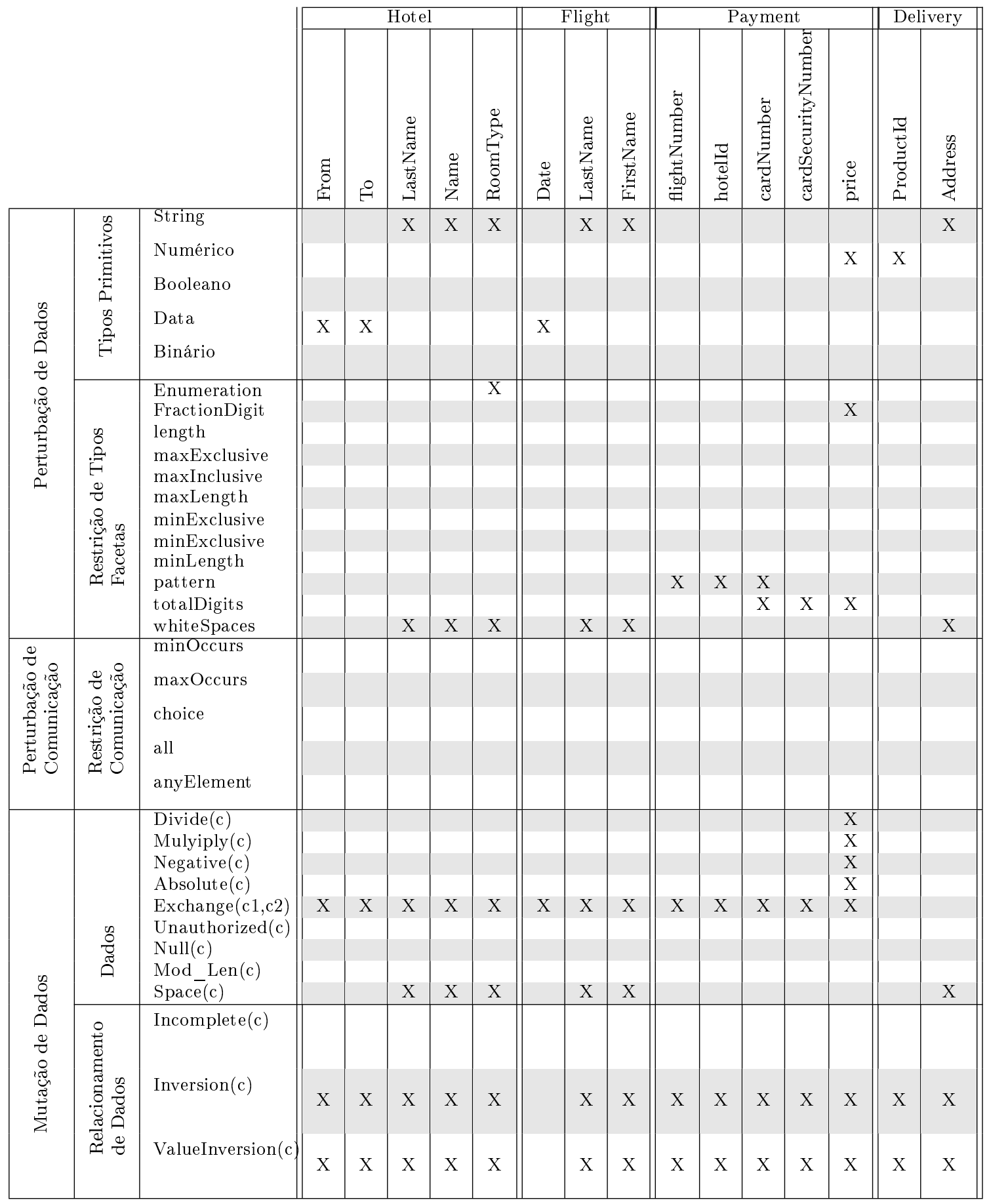

Tabela 5.7Testes de Validação de Sequência e Pré-condições - Lista de Testes Executados com base em perturbação de valores para os Web Services do processo

Através da execução do caso de teste que seguiu a técnica Exchange, aplicada aos campos FlightNumber e HotelId, era esperado que o sistema apresentasse uma falha ao invocar o serviço $s_{3}$. No entanto, obteve-se uma resposta positiva. O sistema entrou em um estado inconsistente ao aceitar a invocação contendo valores inválidos. Existem diversas maneiras de se corrigir o problema. Uma forma de fazê-lo é através da implementação de um mecanismo um pouco mais sofisticado que permita atestar que de fato a resposta gerada faz parte de uma mesma requisição. Por exemplo, ao iniciar o processo é gerado um identificador com base na data e hora do início. A partir deste 
ponto, os códigos trocados entre os serviços possuem esse identificador em sua composição.

\subsubsection{Violação de pré-condições}

Considerando a violação de pré-condições, o objetivo é avaliar como o sistema se comporta caso as pré-condições não sejam respeitadas. A composição dos serviços $s_{1}, s_{2}, \ldots, s_{5}$ segue os padrões específicos. Para validá-los, serão aplicados os testes Seção 4.5.4 do Capítulo 4.

\section{Serviços de Hotel e de Reserva Aérea}

No Sistema de Viagens, para os serviços de Hotel e de Reserva Aérea $s_{1}$ e $s_{2}$, não existem condições para que sejam ativados. Caso alguma solicitação seja enviada a algum desses serviços e que resulte em uma inconsistência, deverá ser tratada pelo próprio serviço. Por exemplo, para iniciar uma reserva de um determinado voo para um determinado assento, é necessário que esteja livre. O mesmo vale para um quarto no hotel. Contudo, como o objetivo do trabalho é avaliar características transacionais de composições Web, essas condições são supostamente tratadas de maneira adequada na interface gráfica do sistema. Com isso, sob o ponto de vista transacional, não existem condições pré-existentes para a ativação de ambos os serviços.

Pelos atributos do sistema, também não há serviços alternativos para $s_{1}$ e $s_{2}$. Em um outro cenário, é possível implementar serviços que apresentem alternativas de execução, ou para um hotel com conforto idêntico e que tenha disponibilidade, ou para outras companhias aéreas que ofereçam outros voos na mesma data e hora do primeiro, que tenha a mesma origem e o mesmo destino.

Ambos os serviços não são passíveis de aborto. A falha de um deve necessariamente garantir que o outro não foi executado. Com isso, também não há condições de aborto.

Com relação às Condições de Compensação, existem três situações: $s_{1}$ falha e $s_{2}$ não; $s_{2}$ falha e $s_{1}$ não; ambos, $s_{1}$ e $s_{2}$, falham. Nota-se que se ambos forem realizados com sucesso não há necessidade de compensação, não se caracterizando assim uma condição necessária para compensação. Nas três situações, não há casos de testes baseados em mutação e perturbação que contribua para a identificação de falhas neste cenário.

Por fim, a situação de Cancelamento não faz parte dos cenários existentes.

A Tabela 5.8 exibe os testes executados para avaliação das condições citadas.

\section{Serviço de pagamento e de Entrega}

O serviço de pagamento $s_{3}$ e os serviços de entrega $s_{4}$ e $s_{5}$ possuem diversas pré-condições para que sejam executados corretamente.

A ativação do serviço de pagamento só deve ocorrer em caso de sucesso na execução dos serviços anteriores $\left(s_{1}\right.$ e $\left.s_{2}\right)$. A ativação do serviço de entrega $s_{4}$ deve ocorrer mediante sucesso na execução do serviço $s_{3}$. Já a ativação do serviço de entrega $s_{5}$ somente deve ocorrer caso a execução do serviço $s_{3}$ tenha ocorrido com sucesso e que $s_{4}$ tenha apresentado alguma falha na execução.

O passo seguinte é a execução dos testes, conforme Seção 4.5.4 do Capítulo 4. Os resultados obtidos não apresentaram falhas nos serviços. Contudo, para os serviços $s_{4}$ e $s_{5}$, foram notadas algumas situações não esperadas no sistema. A execução é exclusiva: ou seja apenas um dos serviços deve ser executado. A execução de $s_{5}$, mesmo sem falha de $s_{4}$, obteve resposta positiva do sistema, sendo que o esperado era uma mensagem de inconsistência. Ou seja, a pré-condição de ativação de $s_{5}$ foi violada (era necessário que $s_{3}$ estivesse em estado concluído com sucesso e que $s_{4}$ estivesse em estado de falha, no entanto, $s_{5}$ foi ativado com $s_{3}$ em estado concluído com sucesso e também com $s_{4}$ em estado concluído com sucesso).

Embora o problema tenha sido identificado através da execução de casos de testes sugeridos pela técnica de perturbação de dados, é possível identificar o mesmo problema através da execução de outros casos de testes. 


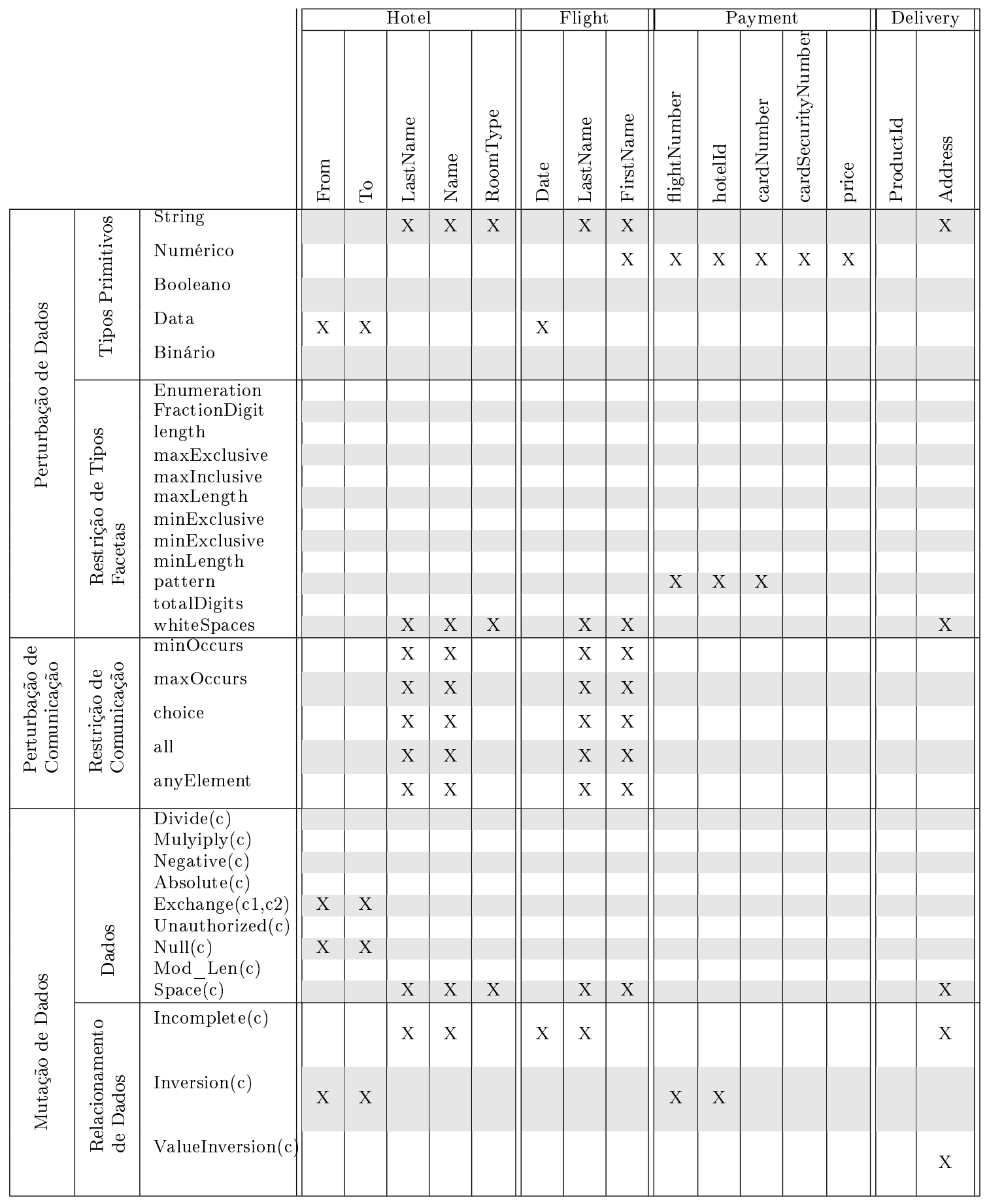

Tabela 5.8Testes de Violação de Pré-condições - Lista de Testes Executados com base em perturbação de valores para os Web Services do processo 


\subsection{Conclusão}

Neste Capítulo é apresentado um sistema exemplo no qual pode-se avaliar a aplicação das técnicas de testes e como pode contribuir na identificação de problemas relacionados a confiabilidade do sistema, principalmente no que diz respeito a padrões transacionais. O sistema, apesar de simples, contém algumas das principais características transacionais.

Os testes foram realizados conforme apresentado no Capítulo 4, abordando os Web Services isolados, a validação da sequência e das pré-condições, além da violação das próprias pré-condições. Para os testes isolados, as respostas obtidas foram conforme esperado, apresentando sucesso nos pontos com condições de sucesso, e apresentando falha nos pontos com condições de falha. Durante a validação da sequência e de pré-condições, foi possível constatar uma inconsistência na comunicação entre os serviços durante a execução do processo. A contribuição apresentada ocorre nesta pesquisa torna-se evidente, pois através da execução de testes tradicionais, dificilmente essas condições seriam notadas. Neste contexto, os critérios sugeridos mostraram-se relevantes e capazes de potencializar a identificação de defeitos em composições web.

Por fim, para a violação de pré-condições, também foi identificada uma inconsistência no processo. Os testes gerados a partir de técnicas de mutação e perturbação se mostram eficazes, por serem capazes de identificar condições de defeito nessa situação, ainda que esse mesmo problema pudesse ser identificado através da execução de testes simples. 


\section{Capítulo 6}

\section{Considerações Finais}

Diante de grandes mudanças tecnológicas, Web Services ganham destaque como alternativa para o desenvolvimento de sistemas. Apesar deste cenário favorável, existem diversos desafios na sua aplicação. Muitas iniciativas surgem para contornar os problemas, com o objetivo principal de tornar a adoção de Web Services simples e que sistemas compostos por eles sejam confiáveis. Dentre as formas de se abordar os problemas, estão a adoção de frameworks, padrões de utilização, padrões transacionais, além da realização de testes.

Esta pesquisa contribui principalmente em questões referentes a testes de Web Services, através da apresentação formal de composições de Web Services Transacionais e também da proposta de critérios que auxiliam na determinação de casos de testes específicos para padrões transacionais. No Capítulo 1 foram apresentados os principais problemas que se têm ao desenvolver sistemas utilizando Web Services. Diversos estudos foram avaliados de modo que tornasse evidente a linha de abordagem dos problemas. Sob o ponto de vista de testes, apresentado no Capítulo 2, existe um campo amplo de atuação, apesar de especificamente para Web Services não ter sido identificado um critério claro de verificação e validação de suas qualidades.

Com base nas características de Web Services, apresentadas no Capitulo 3, é possível estabelecer alguns pontos determinados para que sejam alvo de avaliação. Assim, como apresentado no Capítulo 4, pode-se avaliar se um sistema, formado por um conjunto de Web Services, é confiável ou não. O Capítulo 5 apresenta um estudo de caso que possibilita a avaliação dos itens apresentados no Capítulo 4.

Como resultado obtido, foi possível analisar um conjunto amplo de técnicas para geração de casos de testes e determinar a cobertura quando empregadas na verificação e validação de Web Services e composição deles. A aplicação dessas técnicas se mostrou satisfatória para validação de pré-condições, permitindo a identificação de situações especificas da composição de serviços. Contudo, para alguns aspectos, são consideradas as premissas de que a comunicação entre os serviços é suficiente para determinar o estado de cada ponto do sistema. Embora seja considerada uma boa prática, nem sempre Web Services são implementados seguindo essa linha de desenvolvimento. Por exemplo, pode-se persistir o estado do sistema em um banco de dados e manter a informação compartilhada com outros Web Services.

Além disso, a análise através da aplicação das técnicas possibilita avaliar a fundo as características da composição, os pontos críticos no comportamento do sistema. Assim, apesar de alguns dos casos de testes serem aplicáveis apenas a Web Services individuais, pode-se ainda obter informações valiosas da composição dos e como podem ser testadas.

\subsection{A ferramenta GenAutoWS, padrões e critérios}

As técnicas de perturbação e mutação apresentadas por Silveira e Melo [31] implementadas na GenAutoWS possuem aplicabilidade já avaliada para testes de Web Services isolados. Quando se analisa um Web Service como uma unidade de uma aplicação Web, os casos de testes apresentados são eficazes e possuem a capacidade de identificação de uma série de problemas [31, 89]. 
Ao analisar um sistema de modo mais completo, ou mais precisamente pontos de integração, pouco se tem informação sobre a eficácia dos testes e qual a melhor abordagem. Simplesmente aplicar os casos de testes apresentados de maneira ad hoc pode resultar na situação desejada.

A adoção de padrões para composição de Web Services é uma alternativa para melhorar a interoperabilidade de sistemas Web. Padrões Transacionais são úteis na construção de processos baseados em tais composições. Existe grande dificuldade em estabelecer critérios que permitam avaliar se o padrão é ou não seguido, principalmente quando a avaliação é para composições de $W e b$ Services, visto que muitas vezes não se tem acesso a detalhes de como foram combinados os serviços ou qual a ordem de execução das chamadas de cada um.

O presente estudo utiliza como orientação a aplicação de padrões transacionais que permitem combinar Web Services com características específicas, tais como possuir capacidade de re-executar, possuir condições de compensação, entre outros. Além disso, são tomadas como fundamento o conjunto de técnicas de mutação e perturbação de dados de testes, aplicáveis a Web Services. Com base nas características transacionais e também no conjunto de casos de testes gerados a partir das técnicas de mutação e perturbação, o presente trabalho busca identificar condições determinadas que permitam identificar de forma eficaz problemas na composição dos serviços, validar a condição de uso e como o fluxo de informação pode afetar o comportamento do serviço como um todo.

A partir da análise de cada uma das técnicas, bem como da análise das condições dos padrões, obtém-se a cobertura de técnicas para cada situação identificada na aplicação dos padrões transacionais. Tal cobertura pode ser verificada através da aplicação em um estudo de caso, cujo o objetivo é buscar compreender e atestar a forma de aplicar e como é possível identificar problemas na composição de Web Services para a elaboração de um processo.

\subsection{Trabalhos Futuros}

Existe ainda uma gama enorme de assuntos e questões a serem abordadas, todas relacionadas ao tema discutido neste trabalho. O escopo da análise foi específico para padrões transacionais, além de abordar a forma como testes baseados em mudação e perturbação de dados podem contribuir para a confiabilidade de composição de Web Services. Para os aspectos que não são cobertos pelas técnicas de perturbação, há espaço para pesquisa, de forma a explorar as condições nas quais a confiabilidade possa ser avaliada. Adicionado a isso, existem ainda outros padrões, que podem ser avaliados, por exemplo de Segurança, de tratamento excepcional, entre outros.

De maneira análoga, podem-se avaliar outras técnicas de testes que orientem como a confiabilidade deve ser obtida. Todas essas análises contribuem para a definição clara de critérios, não apenas para testes de Web Services, mas também para a própria composição deles.

A definição da comunicação entre os Web Services é outro item passível de aprofundamento. Neste trabalho foi considerada a troca de mensagens como alvo de análise. É possível identificar outros meios que permitam extrair condições de testes, refinando assim a sistemática de validação da composição de serviços.

Outra linha de próximos passos compreende a extensão da GenAutoWS de modo que a especialize, gerando assim testes para padrões. Assim como neste trabalho foi utilizado como modelo implementações em BPEL, pode-se também utilizar essas características e tornar a ferramenta muito mais poderosa, no sentido de disponibilidade de recursos e leque de opções de atuação. 


\section{Referências Bibliográficas}

[1] J. A. Abinader and R. D. Lins. Web Services em Java. Brasport, Tijuca, RJ, Brasil, 2006. $11,17,30$

[2] C. Allmann, C. Denger, and T. Olsson. Analysis of requirements-based test case creation techniques. Kaiserslautern, 2005, VIII, 2005. 30

[3] G. Alonso, F. Casati, H. Kuno, and V. Machiraju. Web Services - Concepts, Architectures and Applications. Springer, 1 edition, October 2003. 1

[4] J. M. Alston, D. A. Hess, and R. Ruggiero. Universal description, discovery and integration (uddi), 2002. Disponível em http://uddi.xml.org/. Acessado em julho de 2010. 17

[5] A. A. Andrews, J. Offutt, and R. T. Alexander. Testing web applications by modeling with fsms. Software and Systems Modeling, 4:326-345, 2005. 27

[6] E. R. Arjan de Mes. Web services credentials. Technical Report 3, IBM, 2003. 2, 7

[7] A. Avizienis, J.-C. Laprie, B. Randell, and C. Landwehr. Basic concepts and taxonomy of dependable and secure computing. IEEE Trans. Dependable Secur. Comput., 1:11-33, January 2004. 37

[8] S. Balasubramaniam, G. A. Lewis, E. Morris, S. Simanta, and D. B. Smith. Challenges for assuring quality of service in a service-oriented environment. In PESOS '09: Proceedings of the 2009 ICSE Workshop on Principles of Engineering Service Oriented Systems, pages 103-106, Washington, DC, USA, 2009. IEEE Computer Society. 11, 35

[9] A. Barbir, C. Hobbs, E. Bertino, F. Hirsch, and L. Martino. Challenges of testing web services and security in soa implementations. In Test and Analysis of Web Services, pages 395-440. Springer, 2007. 37

[10] L. Baresi and E. D. Nitto. Test and Analysis of Web Services. Springer-Verlag New York, Inc., Secaucus, NJ, USA, 2007. 11, 18, 58

[11] C. Bartolini, A. Bertolino, S. Elbaum, and E. Marchetti. Whitening soa testing. In ESEC/FSE '09: Proceedings of the the 7th joint meeting of the European software engineering conference and the ACM SIGSOFT symposium on The foundations of software engineering, pages 161170, New York, NY, USA, 2009. ACM. 2

[12] B. Beizer. Software testing techniques (2nd ed.). Van Nostrand Reinhold Co., New York, NY, USA, 1990. 28, 37

[13] A. Bertolino and A. Polini. The audition framework for testingweb services interoperability. In EUROMICRO '05: Proceedings of the 31st EUROMICRO Conference on Software Engineering and Advanced Applications, pages 134-142, Washington, DC, USA, 2005. IEEE Computer Society. 9, 18 
[14] S. Bhiri, C. Godart, and O. Perrin. Transactional patterns for reliable web services compositions. In ICWE '06: Proceedings of the 6th international conference on Web engineering, pages 137-144, New York, NY, USA, 2006. ACM. 1, 6, 8, 10, 43, 46, 50

[15] S. Bhiri, O. Perrin, and C. Godart. Ensuring required failure atomicity of composite web services. In $W W W$ '05: Proceedings of the 14th international conference on World Wide Web, pages 138-147, New York, NY, USA, 2005. ACM. 44, 46

[16] R. Blanco, J. García-Fanjul, and J. Tuya. A first approach to test case generation for bpel compositions of web services using scatter search. In ICSTW '09: Proceedings of the IEEE International Conference on Software Testing, Verification, and Validation Workshops, pages 131-140, Washington, DC, USA, 2009. IEEE Computer Society. 37

[17] J. Bloomberg. Testing web services today and tomorrow. The Rational Edge E-zine for the Rational Community, 2002. Disponível em http://www.p2080.co.il/go/p2080h/files/4989377677. pdf, acessado em janeiro de 2010. 27, 37

[18] G. Canfora and M. Di Penta. Testing services and service-centric systems: Challenges and opportunities. IT Professional, 8(2):10-17, 2006. 37

[19] G. Canfora and M. Penta. Service-oriented architectures testing: A survey. Software Engineering: International Summer Schools, ISSSE 2006-2008, Salerno, Italy, Revised Tutorial Lectures, pages 78-105, 2009. 6, 8, 37

[20] E. Cerami and S. St.Laurent. Web Services Essentials. O'Reilly \& Associates, Inc., Sebastopol, CA, USA, 2002. 17

[21] E. Chang, F. Hussain, and T. Dillon. Trust and Reputation for Service-Oriented Environments: Technologies For Building Business Intelligence And Consumer Confidence. Wiley, 1 edition, July 2006. 1, 17, 18

[22] S. Chatterjee and J. Webber. Developing enterprise web services: an architect's guide. Prentice Hall Press, Upper Saddle River, NJ, USA, 2003. 13, 22, 31

[23] A. S. Chaudhary, M. A. Saleem, and H. Z. Bukhari. Web services in distributed applications: Advantages and problems, 2003. 11

[24] L. Chen, Z. Wang, L. Xu, H. Lu, and B. Xu. Test case prioritization for web service regression testing. In SOSE '10: Proceedings of the 2010 Fifth IEEE International Symposium on Service Oriented System Engineering, pages 173-178, Washington, DC, USA, 2010. IEEE Computer Society. 9

[25] M.-H. Chen and H. M. Kao. Testing object-oriented programs an integrated approach. In ISSRE '99: Proceedings of the 10th International Symposium on Software Reliability Engineering, page 73, Washington, DC, USA, 1999. IEEE Computer Society. 34

[26] Y. Chen and A. Romanovsky. Improving the dependability of web services integration. IT Professional, 10(3):29-35, 2008. 1

[27] L. Copeland. A Practitioner's Guide to Software Test Design. Artech House, Inc., Norwood, MA, USA, 2003. 28, 31, 32, 33, 34

[28] F. Curbera, W. A. Nagy, and S. Weerawarana. Web services: Why and how. In In OOPSLA 2001 Workshop on Object-Oriented Web Services. ACM, 2001. 17

[29] N. J. Davies, D. Fensel, and M. Richardson. The future of web services. BT Technology Journal, 22(1):118-130, 2004. 11 
[30] L. F. J. de Almeida and S. R. Vergilio. Exploring perturbation based testing for web services. In Proceedings of the IEEE International Conference on Web Services, pages 717-726, Washington, DC, USA, 2006. IEEE Computer Society. 37

[31] A. C. de Melo and P. Silveira. Improving data perturbation testing techniques for web services. Information Sciences, 181(3):600 - 619, 2011. 37, 51, 58, 63, 77

[32] S. Devadas, A. Ghosh, and K. Keutzer. An observability-based code coverage metric for functional simulation. In ICCAD '96: Proceedings of the 1996 IEEE/ACM international conference on Computer-aided design, pages 418-425, Washington, DC, USA, 1996. IEEE Computer Society. 34

[33] G. A. Di Lucca and A. R. Fasolino. Testing web-based applications: The state of the art and future trends. Inf. Softw. Technol., 48(12):1172-1186, 2006. 2

[34] G. Dobson. Using ws-bpel to implement software fault tolerance for web services. In $E U$ ROMICRO '06: Proceedings of the 32nd EUROMICRO Conference on Software Engineering and Advanced Applications, pages 126-133, Washington, DC, USA, 2006. IEEE Computer Society. 1, 2

[35] S. Dustdar and W. Schreiner. A survey on web services composition. Int. J. Web Grid Serv., $1(1): 1-30,2005.8,11$

[36] A. Erradi, P. Maheshwari, and V. Tosic. Recovery policies for enhancing web services reliability. In ICWS '06: Proceedings of the IEEE International Conference on Web Services, pages 189-196, Washington, DC, USA, 2006. IEEE Computer Society. 1, 7, 37

[37] C. Ferris and J. Farrell. What are web services? Commun. ACM, 46(6):31, 2003. 1

[38] R. T. Fielding and R. N. Taylor. Principled design of the modern web architecture. In ICSE '00: Proceedings of the 22nd international conference on Software engineering, pages 407-416, New York, NY, USA, 2000. ACM. 16

[39] M. A. Friedman and J. M. Voas. Software Assessment: Reliability, Safety, Testability. John Wiley \& Sons, Inc., New York, NY, USA, 1995. 3, 4, 6, 8

[40] a. Garcia, Diego Zuquim Guimar and M. B. F. de Toledo. Semantics-enriched qos policies for web service interactions. In WebMedia '06: Proceedings of the 12th Brazilian symposium on Multimedia and the web, pages 35-44, New York, NY, USA, 2006. ACM. 8

[41] S. Graham, D. Davis, S. Simeonov, T. Boubez, R. Neyama, and Y. Nakamura. Building Web Services with Java: Making Sense of Xml, Soap, Wsdl, and Uddi. Sams, Indianapolis, IN, USA, 2001. 19

[42] H.-G. Gross. Component-based Software Testing With Uml. SpringerVerlag, 2004. 1

[43] R. Heckel and M. Lohmann. Towards contract-based testing of web services. Electron. Notes Theor. Comput. Sci., 116:145-156, 2005. 9

[44] H. Huang, W.-T. Tsai, R. Paul, and Y. Chen. Automated model checking and testing for composite web services. In ISORC '05: Proceedings of the Eighth IEEE International Symposium on Object-Oriented Real-Time Distributed Computing, pages 300-307, Washington, DC, USA, 2005. IEEE Computer Society. 27, 37

[45] IBM. Web services reliable messaging protocol. Technical report, IBM, 2005. Disponível em http://www.ibm.com/developerworks/library/specification/ws-rm/, acessado em fevereiro de 2010. 7 
[46] IEEE. IEEE standard for software test documentation. Technical report, IEEE Std 829-1998, 1998. 29

[47] IEEE. Ieee glossary, 2010. Disponível em http://www.ieee.org/education_careers/education/ standards/standards_glossary.html, acessado em maio de 2010. 18

[48] Jxweb. Jxweb project, 2010. Disponível em http://sourceforge.net/projects/jxweb/, acessado em abril de 2010. 38

[49] J.-C. Laprie. From dependability to resilience. In Supplemental Proceedings of the International Conference on Dependable Systems 83 Networks, pages 8-9, Anchorage, Alaska, USA, 2008. DSN. 1

[50] N. Laranjeiro, S. Canelas, and M. Vieira. wsrbench: An on-line tool for robustness benchmarking. In SCC '08: Proceedings of the 2008 IEEE International Conference on Services Computing, pages 187-194, Washington, DC, USA, 2008. IEEE Computer Society. 9, 39

[51] Z. J. Li, J. Zhu, L.-J. Zhang, and N. Mitsumori. Towards a practical and effective method for web services test case generation. In Automation of Software Test, 2009. AST '09. ICSE Workshop on, pages $106-114,18-19$ 2009. 8, 39

[52] D. Lübke. Unit testing bpel compositions. In Test and Analysis of Web Services, pages 149-171. Springer, 2007. 8, 38

[53] M. R. Lyu, editor. Handbook of software reliability engineering. McGraw-Hill, Inc., Hightstown, NJ, USA, 1996. 4

[54] K. Mahbub and G. Spanoudakis. Monitoring s-agreements: An event calculus-based approach. In Test and Analysis of Web Services, pages 265-306. Springer, 2007. 6

[55] E. Martin, S. Basu, and T. Xie. Websob: A tool for robustness testing of web services. In ICSE COMPANION '07: Companion to the proceedings of the 29th International Conference on Software Engineering, pages 65-66, Washington, DC, USA, 2007. IEEE Computer Society. 38

[56] J. McGovern, S. Tyagi, M. Stevens, and S. Mathew. Java Web Services Architecture. Morgan Kaufmann, San Francisco, CA, USA, 2003. 22

[57] S. Mehrotra, R. Rastogi, H. F. Korth, and A. Silberschatz. A transaction model for multidatabase systems. Technical report, University of Texas at Austin, Austin, TX, USA, 1992. 43

[58] L. Mei, W. Chan, and T. Tse. Data flow testing of service-oriented workflow applications. In ICSE '08: Proceedings of the 30th international conference on Software engineering, pages 371-380, New York, NY, USA, 2008. ACM. 37

[59] D. A. Menascé. Qos issues in web services. IEEE Internet Computing, 6(6):72-75, 2002. 1

[60] J. Mendling, B. F. van Dongen, and W. M. P. van der Aalst. Getting rid of the or-join in business process models. In EDOC, pages 3-14. IEEE Computer Society, 2007. 50

[61] J.-J. D. Michael P. Papazoglou. A surveyof web services technologies. Technical report, University of Trento, Trento, Italy, 2004. 4, 18

[62] T. Mikalsen, S. Tai, and I. Rouvellou. Estudio de interoperabilidad .net/j2ee, 2001. 17

[63] M. H. Mustafa Bozkurt and Y. Hassoun. Testing web services: A survey. Technical Report TR-10-01, Department of Computer Science, King's College London, January 2010. 6, 8, 25, $30,31,37$ 
[64] G. J. Myers and C. Sandler. The Art of Software Testing. John Wiley \& Sons, 2004. 28, 32, 34

[65] V. P. Nelson. Fault-tolerant computing: Fundamental concepts. Computer, 23(7):19-25, 1990. 4

[66] E. Newcomer. Understanding Web Services: XML, WSDL, SOAP, and UDDI. AddisonWesley Longman Publishing Co., Inc., Boston, MA, USA, 2002. 21

[67] E. Newcomer and G. Lomow. Understanding SOA with Web Services (Independent Technology Guides). Addison-Wesley Professional, 2004. 1

[68] H. Q. Nguyen, B. Johnson, and M. Hackett. Testing Applications on the Web: Test Planning for Mobile and Internet-Based Systems (2nd ed.). Wiley Publishing, Inc., Indianapolis, Indiana, USA, 2003. 27, 33

[69] Oasis. Web services reliable messaging protocol tc ws-reliability. Technical report, Organization for the Advancement of Structured Information Standards, 2003. Disponível em http://xml.coverpages.org/ws-reliablemessaging20030313.pdf, acessado em fevereiro de 2010. 7

[70] Oasis. Universal description, discovery and integration, 2004. Disponível em http://uddi.org/ pubs/uddi_v3.htm, acessado em julho de 2010. 3, 12

[71] Oasis. Web services security (wss) tc. Technical report, Organization for the Advancement of Structured Information Standards, 2006. 7

[72] Oasis. Web services business process execution language, 2007. Disponível em http://docs. oasis-open.org/wsbpel/2.0/OS/wsbpel-v2.0-OS.html, acessado em julho de 2010. 2, 13, 16

[73] J. Offutt and W. Xu. Generating test cases for web services using data perturbation. SIGSOFT Softw. Eng. Notes, 29(5):1-10, 2004. 8, 13, 25, 37, 40

[74] W. S. I. Organization. Web services interoperability organization, 2010. Disponível em http: //www.ws-i.org/, acessado em maio de 2010. 18

[75] S. Pallickara, G. Fox, and S. L. Pallickara. An analysis of reliable delivery specifications for web services. In ITCC '05: Proceedings of the International Conference on Information Technology: Coding and Computing (ITCC'05) - Volume I, pages 360-365, Washington, DC, USA, 2005. IEEE Computer Society. 7

[76] M. P. Papazoglou. Service -oriented computing: Concepts, characteristics and directions. In WISE '03: Proceedings of the Fourth International Conference on Web Information Systems Engineering, page 3, Washington, DC, USA, 2003. IEEE Computer Society. 2, 3

[77] A. M. Paradkar, A. Sinha, C. Williams, R. D. Johnson, S. Outterson, C. Shriver, and C. Liang. Automated functional conformance test generation for semantic web services. Web Services, IEEE International Conference on, 0:110-117, 2007. 9

[78] M. D. Penta, M. Bruno, G. Esposito, V. Mazza, and G. Canfora. Web Services Regression Test. Springer, 2007. 27, 35

[79] G. Pentafronimos, S. Papastergiou, and N. Polemi. Interoperability testing for e-government web services. In ICEGOV '08: Proceedings of the 2nd International Conference on Theory and Practice of Electronic Governance, pages 316-321, New York, NY, USA, 2008. ACM. 9, 18

[80] R. Pressman. Software Engineering: A Practitioner's Approach. McGraw-Hill, Inc., New York, NY, USA, 2010. 7, 27, 28, 30, 32, 33, 34 
[81] V. Pretre, F. Bouquet, and C. Lang. Using common criteria to assess quality of web services. In ICSTW '09: Proceedings of the IEEE International Conference on Software Testing, Verification, and Validation Workshops, pages 295-302, Washington, DC, USA, 2009. IEEE Computer Society. 37

[82] P. Ramsokul and A. Sowmya. A sniffer based approach to ws protocols conformance checking. In ISPDC '06: Proceedings of the Proceedings of The Fifth International Symposium on Parallel and Distributed Computing, pages 58-65, Washington, DC, USA, 2006. IEEE Computer Society. 9

[83] A. R. S. S. A. Correa. Técnicas para construção de testes funcionais automáticos. In 5a Conferência para a Qualidade nas Tecnologias da Informação e Comunicações. Instituto Português de Qualidade, 2004. 33

[84] G. K. Saha. Transient software fault tolerance using single-version algorithm. Ubiquity, 2005(August):1-1, 2005. 6, 7

[85] G. K. Saha. Fault tolerance in web services. Ubiquity, 2006(March):1, 2006. 3, 6

[86] T. Saneer. Patterns and strategies for building document-based web services. Technical report, Sun Microsystems, 2004. 20

[87] S. M. Serra da Cruz, M. L. M. Campos, P. F. Pires, and L. M. Campos. Monitoring ebusiness web services usage through a log based architecture. In ICWS '04: Proceedings of the IEEE International Conference on Web Services, page 61, Washington, DC, USA, 2004. IEEE Computer Society. 11

[88] M. L. Shooman. Reliability of Computer Systems and Networks: Fault Tolerance, Analysis, and Design. John Wiley \& Sons, Inc., New York, NY, USA, 2002. 1, 4, 37

[89] P. Silveira. Geração automática de casos de testes para web services. Master's thesis, Universidade De São Paulo, 2008. 2, 10, 37, 39, 51, 77

[90] J. Snell, D. Tidwell, and P. Kulchenko. Programming Web services with SOAP. O'Reilly \& Associates, Inc., Sebastopol, CA, USA, 2002. 19

[91] SoapUI. eviware soapui, 2010. Disponível em http://www.soapui.org/, acessado em abril de 2010. 38,39

[92] H.-H. Sthamer. The Automatic Generation of Software Test Data Using Genetic Algorithms. $\mathrm{PhD}$ thesis, University of Glamorgan, Nov. 1995. 33

[93] W. Tsai, R. Paul, L. Yu, A. Saimi, and Z. Cao. Scenario-based web services testing with distributed agents. IEICE transactions on information and systems, 86(10):2130-2144, 2003. 27,37

[94] W. T. Tsai, R. Paul, Y. Wang, C. Fan, and D. Wang. Extending wsdl to facilitate web services testing. In HASE '02: Proceedings of the 7th IEEE International Symposium on High Assurance Systems Engineering, page 171, Washington, DC, USA, 2002. IEEE Computer Society. 9

[95] W. van der Aalst and K. van Hee. Workflow Management: Models, Methods, and Systems. MIT Press, Cambridge, MA, USA, 2004. 50

[96] W3C. W3c soap version 1.2 part 0. Technical report, W3C, 2007. 3, 21

[97] W3C. W3c web services description language (wsdl) 1.1. Technical report, W3C, 2007. 3 
[98] W3C. The world wide web consortium (w3c), 2010. Disponível em http://www.w3.org/, acessado em fevereiro de 2010. 1, 16, 17

[99] P. J. Walsh. A measure of test case completeness (software, engineering). PhD thesis, State University of New York at Binghamton, Binghamton, NY, USA, 1985. 33

[100] S.-T. Wen, Q. Li, L. Yue, and A. Liu. An approach to validating transactional properties of ws-bpel composition. In Fifth International Conference on Semantics, Knowledge and Grid, 2009., volume 2009, pages 216 -223, oct. 2009. 8, 43

[101] J. Williams. The web services debate: J2ee vs. .net. Commun. ACM, 46(6):58-63, 2003. 35

[102] A. Wombacher, P. Fankhauser, and E. Neuhold. Transforming bpel into annotated deterministic finite state automata for service discovery. In In Intl. Conference on Web Services (ICWS, pages 316-323. IEEE Computer Society, 2004. 9

[103] M. R. Woodward and M. A. Hennell. On the relationship between two control-flow coverage criteria: all jj-paths and mcdc. Information 83 Software Technology, 48(7):433-440, 2006. 34

[104] WSUnit. Wsunit project, 2010. Disponível em https://wsunit.dev.java.net/, acessado em abril de 2010. 38

[105] Y. Yang, Q. Tan, and Y. Xiao. Verifying web services composition based on hierarchical colored petri nets. In IHIS '05: Proceedings of the first international workshop on Interoperability of heterogeneous information systems, pages 47-54, New York, NY, USA, 2005. ACM. 2 